University of San Diego

Digital USD

\title{
The Relationship between Nurse Manager Leadership Attributes and Nurse Clinical Autonomy: Magnet Versus Non-Magnet Hospitals
}

Catherine A. Verkaaik PhD

University of San Diego

Follow this and additional works at: https://digital.sandiego.edu/dissertations

Part of the Nursing Commons

\section{Digital USD Citation}

Verkaaik, Catherine A. PhD, "The Relationship between Nurse Manager Leadership Attributes and Nurse Clinical Autonomy: Magnet Versus Non-Magnet Hospitals" (2007). Dissertations. 357.

https://digital.sandiego.edu/dissertations/357

This Dissertation: Open Access is brought to you for free and open access by the Theses and Dissertations at Digital USD. It has been accepted for inclusion in Dissertations by an authorized administrator of Digital USD. For more information, please contact digital@sandiego.edu. 
UNIVERSITY OF SAN DIEGO

Hahn School of Nursing and Health Science

DOCTOR OF PHILOSOPHY IN NURSING

THE RELATIONSHIP BETWEEN NURSE MANAGER LEADERSHIP ATTRIBUTES AND NURSE CLINICAL AUTONOMY: MAGNET VERSUS NON-MAGNET HOSPITALS

By

Catherine A. Verkaaik

A dissertation presented to the

FACULTY OF THE HAHN SCHOOL OF NURSING AND HEALTH SCIENCE

UNIVERSITY OF SAN DIEGO

In partial fulfillment of the

Requirements for the degree

DOCTOR OF PHILOSOPHY IN NURSING

2007 
(C) Copyright by Catherine A. Verkaaik, 2007

All Rights Reserved 


\begin{abstract}
An Evaluation of the Relationship Between Nurse Manager Leadership Attributes and Nurse Clinical Autonomy: Magnet versus Non-magnet Hospitals

Purpose: This research evaluated relationships among hospital types (Magnet versus non-Magnet), nurse manger leadership attributes, and staff registered nurse autonomy. Hypothesis: Magnet hospital status would be related to positive nurse manager leadership attributes which would be related to greater clinical nurse autonomy and nurse manager leadership would mediate relationships between hospital status and clinical nurse autonomy.
\end{abstract}

Conceptual Basis and Background: Structural Contingency Theory modified in the Nursing Systems Outcomes Research model was the research model for conceptualizing the structure-environment-effectiveness relationship. Critical Social Theory (CST) provided the conceptual/motivational basis for this study, a lens through which to frame the question. Clinical nurse autonomy is characteristic of hospitals noted for good patient outcomes and excellent nursing care. Research demonstrates that leadership attributes of nurse managers are related to increased nurse autonomy and positive patient outcomes. Magnet hospitals have been found to have superior nurse executive attributes, greater nurse autonomy, and high-quality nursing care and to generate better patient care outcomes than non-Magnet hospitals.

Design and Methods: This study employed a pre-experimental, cross-sectional correlational design. Two groups (nursing managers and staff registered nurses) represented Magnet and non-Magnet hospitals. These two types of hospitals were matched on 12 criteria for a total of 388 hospitals. Statistical power analyses demonstrated sufficient power for detecting down to between medium effects and large 
effects for the 104 units included. Chief Nursing Officers, nursing managers and staff registered nurses were contacted via email addresses or phone numbers. Measurements were demographic questions, and assessments for leadership actions (Nurse Managers' Actions Scale, Mrayyan, 2004) and clinical autonomy (Autonomy Scale developed by Blegen, Goode, Johnson, Maas, Chen \& Moorhead, 1993).

Results: There were no mean differences between hospital types. There was a relationship between manager leadership attributes and nurse clinical autonomy and this relationship was dependent on Magnet status.

Implication: This type of research will help identify leadership traits and attributes that empower nurse autonomy, which is related to better nurse recruitment, nurse job satisfaction, nurse retention, and patient outcomes, and it will evaluate the role of Magnet hospital status in these relationships. It may also enable developing alternative praxisbased approaches. 


\section{Dedication}

For my husband Wolfgang (Wolfie) Douglas Verkaaik for his endless faith in me and for all those fabulous dinners in and out.

For our son who knows the ways of the sea, therefore acknowledging and recognizing the ebbs and flows of the days we live......He is everything to me.

To my parents who have long since passed, but who are a part of who I am and achieved....you'd love this!

Thank-you family 


\section{Preface}

"Good leadership consists of motivating people to their highest levels by offering them opportunities, not obligations."

Lao Tzu, $4^{\text {th }}$ Century B.C.

\section{Acknowledgements}

No doctoral student can manage, let alone survive, the dissertation process without committee members that make it possible. I am grateful to my committee members: Jane M.

Georges, Ph.D., RN, Sharon A. McGuire, Ph.D., RN, and Marty J. Shively, Ph.D., RN.

To all my friends who have supported me over the years with nothing but kindness, patience and understanding, I too missed those innocent lazy days at the beach.

My deepest gratitude and dedication to an amazing man, Tom Smith, Ph.D., who was there every step of the way and who now has become a dear friend.......this research would have never reached fruition without you.

The best lesson learned from my teacher, Tom Smith, during this research process, is "to live well"... he has made this possible. 


\section{TABLE OF CONTENTS}

\begin{tabular}{|c|c|c|c|c|c|c|c|c|}
\hline LIST OF TABLES • & • & - & • & • & $\cdot$ & - & - & - \\
\hline LIST OF FIGURES . & $\cdot$ & . & • & • & • & • & $\cdot$ & . \\
\hline LIST OF APPENDICES . & • & . & . & - & • & . & . & . \\
\hline
\end{tabular}

CHAPTER

I. INTRODUCTION • .

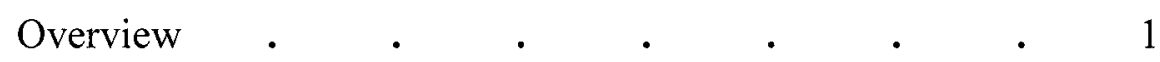

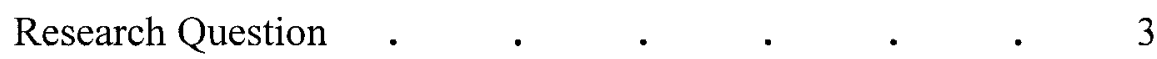

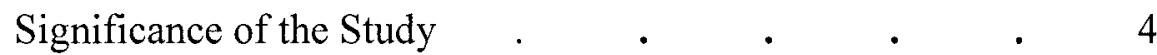

Conceptual Framework and Research Lens . $\quad$ • $\quad$ • 4

Structural Contingency Theory as Framework $\quad$ - 4

Critical Social Theory as Lens. $\quad$ - $\quad$ - 5

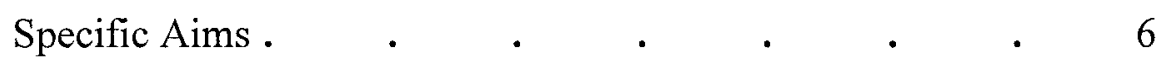

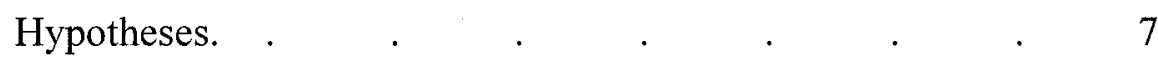

II . BACKGROUND AND SIGNIFICANCE $\quad$ - $\quad$ - $\quad$ • $\quad$ - 9

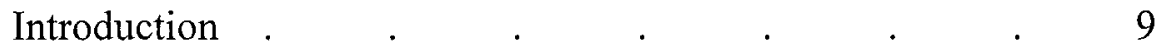

Conceptual Framework and Research Lens . $\quad$ • $\quad$ • 9

Structural Contingency Theory $\quad$ - $\quad$ • $\quad 9$

Critical Social Theory as Critical Lens $\quad$ - $\quad$ - 13

History of Magnet Hospitals • $\quad$ • $\quad$ • $\quad$ • $\quad$ • 13

Nursing Leadership and Magnet Hospitals • • $\quad$ • 16

Autonomy of Nurses and Magnet Hospitals • $\quad$ • $\quad$ - 22

Hospital Type Comparisons • $\quad$ • $\quad$ • 23 
Comparison of Unit Types $\quad$ • $\quad$ • $\quad$ • $\quad$ • 27

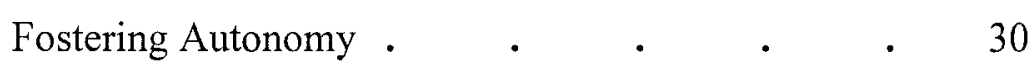

Critical Social Theory as Critical Lens $\quad$ • $\quad$ • 36

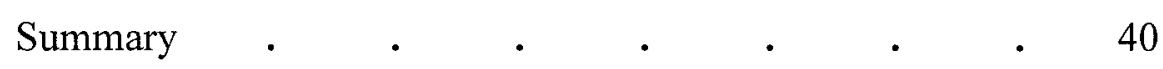

Themes in Research Literature $\quad$. $\quad$. 40

Leadership and Autonomy $\quad$ - . $\quad$. $\quad$ - 41

Instruments and Procedures $\quad$ • $\quad$ - $\quad$ - 42

Gaps in the Literature . $\quad$ • . 43

Implications and Importance of Proposed Study $\quad$ - $\quad 43$

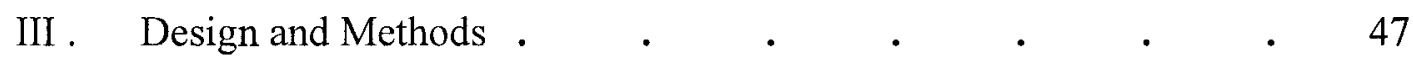

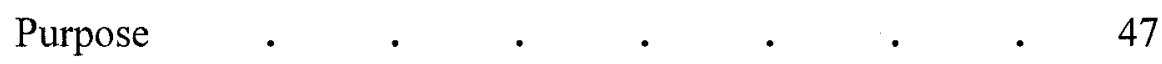

Research Design Description . $\quad$. $\quad$ • 47

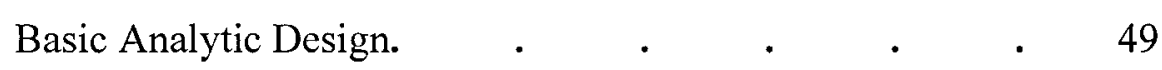

Power Analyses and Sample Size Calculations. $\quad$ • $\quad 49$

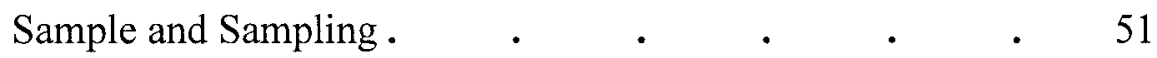

Hospital Sample Selection Completed $\quad$ • $\quad 52$

Determining the Matched Hospitals . $\quad$ - 55

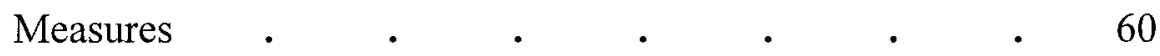

Data Collection Procedures . $\quad$ • $\quad$ • $\quad$ - 62

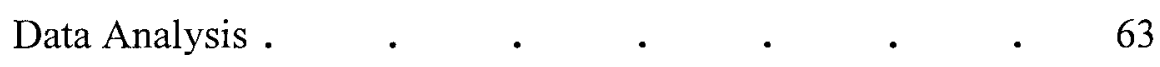

Human Subjects Research $\quad . \quad$. $\quad$. $\quad$. 65

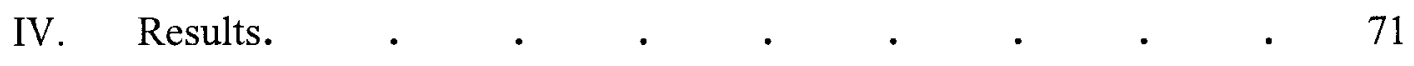

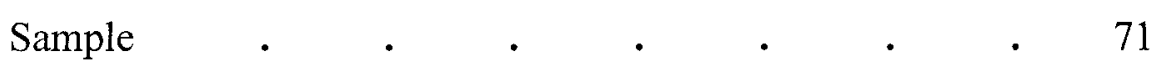


Comparing Characteristics of the Magnet and

Non-Magnet Hospitals.

Manager's and Staff Registered Nurses'

Demographics Compared Between Magnet and

Non-Magnet Hospitals.

Evaluating Distributional Properties of the Six Dependent

Variables

Testing of the Seven Formal Hypotheses . . . 77

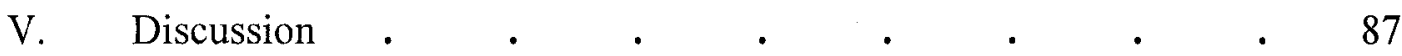

Overview and Purpose of the Study . $\quad . \quad$. 87

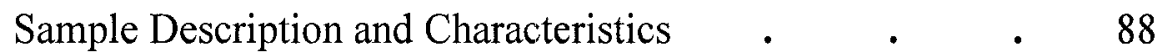

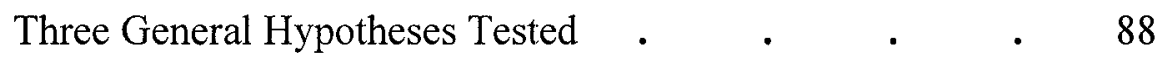

Consistency of Results and Existing Literature. $\quad$ • $\quad 90$

Implications for the Nursing Profession . $\quad$ - $\quad$ - 93

Implications for Future Research • • • • $\quad$ • 95

Limitations of the Current Study $\quad$ - $\quad$. $\quad$. $\quad$ • 97

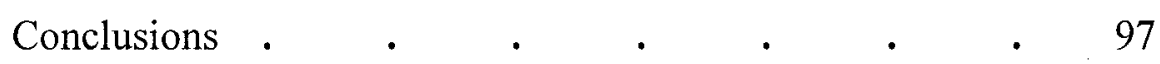

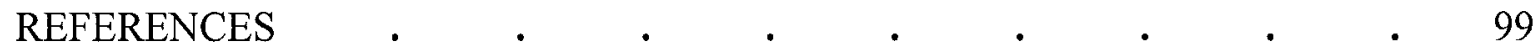




\section{LIST OF TABLES}

TABLE

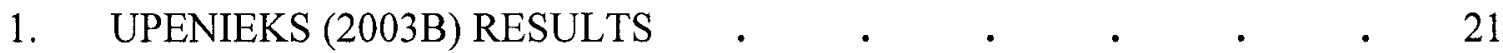

2. THE SOURCE OF THE THREE PRIMARY DEPENDENT VARIABLES. 48

3. BASIC ANOVA DESIGN OF STUDY $\quad$ • $\quad$ • $\quad$ • $\quad$ • $\quad$ • 49

4. FORMAL POWER ANALYSES FOR DETERMINING ACCEPTABLE

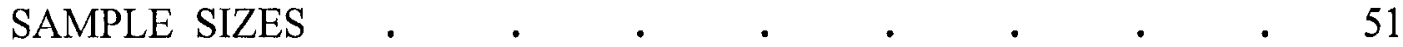

5. CHARACTERISTICS FOR MATCHING MAGNET AND

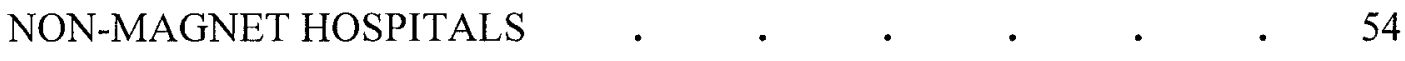

6. TESTING OF MAGNET VERSUS NON-MAGNET HOSPITAL MATCHING 58

7. HOSPITAL SUBSET CHARACTERISTICS COMPARED FOR MAGNET AND

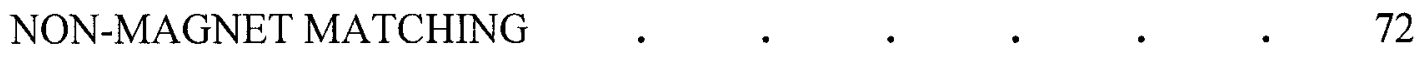

8. MANAGER DEMOGRPAHIC VARIABLES AND COMPARISON OF MAGNET

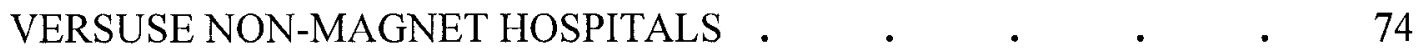

9. STAFF REGISTERED NURSE DEMOGRPAHIC VARIABLES AND COMPARISON OF MAGNET VERSUSE NON-MAGNET HOSPITALS 75

10. EVALUATIONS OF PARAMETRIC ASSUMPTIONS OF NORMALITY (SKEWNESS AND KURTOSIS) AND EQUALITY OF VARIANCES FOR THE SIX DEPENDENT VARIABLES AND PRESENTING THEIR MEANS AND

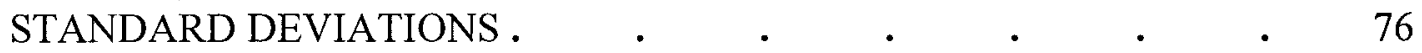

11. MEANS AND STANDARD DEVIATIONS OF THE NURSE MANAGER'S ACTION SCALE (NMAS) WITHIN THE 2 (HOSPITAL TYPE) BY 2 (NURSE

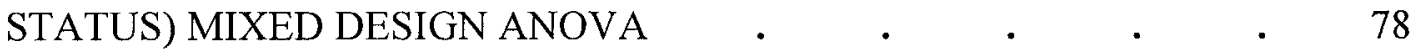


12. MEANS AND STANDARD DEVIATIONS OF THE AUTONOMY SCALEPATIENT WITHIN THE 2 (HOSPITAL TYPE) BY 2 (NURSE STATUS) MIXED DESIGN ANOVA •

13. MEANS AND STANDARD DEVIATIONS OF THE AUTONOMY SCALEUNIT WITHIN THE 2 (HOSPITAL TYPE) BY 2 (NURSE STATUS)

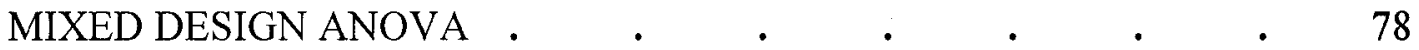

14. CORRELATION MATRIX OF MANAGER AND STAFF REGISTERED NURSE RATINGS OF MANAGER ATTRIBUTES AND NURSE

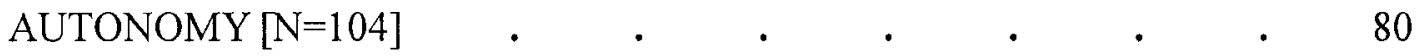

15. CORRELATION MATRIX OF MANAGER AND STAFF REGISTERED NURSE RATINGS OF MANAGER ATTRIBUTES AND NURSE AUTONOMY AMONG MAGNET HOSPITALS ONLY [N = 30] • • $\quad 82$

16. CORRELATION MATRIX OF MANAGER AND STAFF REGISTERED NURSE RATINGS OF MANAGER ATTRIBUTES AND NURSE AUTONOMY AMONG NON-MAGNET HOSPITALS ONLY $[\mathrm{N}=74] \quad . \quad 82$

17. CORRELATIONS BETWEEN HOSPITAL TYPE (MAGNET VERSUS NON-MAGNET) AND THE DEPENDENT VARIABLES . $\quad$ • $\quad$. 86 


\section{LIST OF FIGURES}

FIGURE

1. NSOR MODIFIED SCT MODEL FOR THE CONCEPTUAL RESEARCH

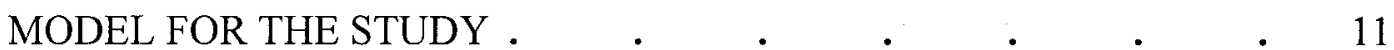

2. CRITICAL SOCIAL THEORY SHOWING RELATIONSHIPS AMONG

INEQUALITY, POWER IMABLANCE, AND HUMAN SUFFERING AS

WELL AS REPRESENTING EDUCATION EMPOWERING AND

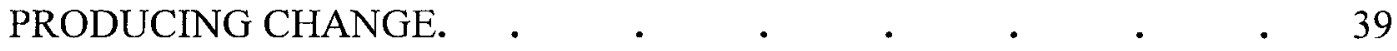

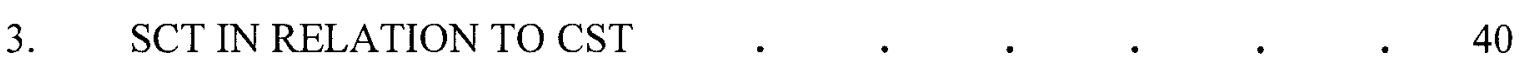

4. TWO MODELS OF RELATIONSHIP: COMMON CAUSE (A) VERSUS

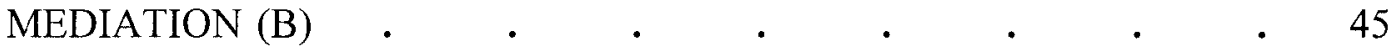




\section{LIST OF APPENDICES}

APPENDICES

A. BACKGROUND INFORMATION FOR NURSING MANAGERS .

B. BACKGROUND INFORMATION FOR STAFF REGISTERED

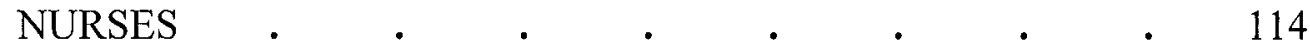

C. NMAS FOR NURSE MANAGERS . . . . . 117

D. NMAS FOR STAFF REGISTERED NURSES . $\quad$ • 120

E. AUTONOMY SCALE FOR NURSE MANAGERS AND STAFF

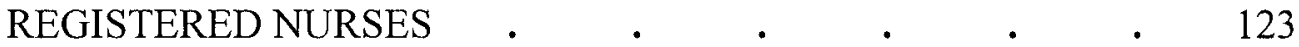

F. INTRODUCTION LETTER TO NURSE MANAGERS . $\quad 128$

G. INTRODUCTION LETTER TO STAFF REGISTERED NURSES . 131

H. INFORMED CONSENT FORM $\quad$ - • $\quad$ • $\quad$ • 133

I. EXPERIMENTAL SUBJECTS' BILL OF RIGHTS. $\quad$ • 136

J. UNIVERSITY OF SAN DIEGO IRB APPROVAL • . $\quad$ • 138

K. UNIVERSITY OF CALIFORNIA, SAN DIEGO IRB APRROVAL . $\quad 140$

L. VA SAN DIEGO HEALTHCARE SYSTEM DOCUMENTS I $\quad 143$

M. EAST CAROLINA UNIVERSITY AND MEDICAL CENTER IRB • 147

N. PERMISSION TO USE INSTRUMENTS • . $\quad$ • $\quad 149$ 
Chapter I. Introduction

Overview

Good patient care is reflected in patient satisfaction and decreased mortality rates. Research has determined that such patient satisfaction and decreased mortality result from both characteristics of individual health care professionals and attributes of the hospital organization. Magnet hospitals have been found to have outstanding nursing care and to generate better patient care outcomes than non-Magnet hospitals (Aiken, Smith, \& Lake, 1994). Some general questions in this research literature include what are the relationships among hospital type (Magnet versus non-Magnet), organizational dimensions, nurse manager leadership characteristics, staff nursing attributes, nurse autonomy, nursing job satisfaction, and patient outcomes? However, for at least leadership characteristics and nurse autonomy, the literature does not include an empirical assessment of this central relationship. This study did such an empirical evaluation of this relationship between leadership and nurse autonomy.

Magnet hospitals demonstrate organizational attributes that provide nurses with the organizational support needed to fully realize and provide high-quality patient care when compared to non-Magnet hospitals (McClure, Poulin, Sovie \& Wandelt, 1983). Magnet hospital status serves as an example of excellence, quality patient outcomes, and best practices so diligently sought in today's competitive healthcare environment. Hence, hospital type can be used as one way of understanding how nurse manager leadership traits and nurse clinical autonomy function.

Studies assessing the attributes of Magnet hospitals have demonstrated that a vital organizational characteristic was the quality of nursing leadership and that Magnet 
hospitals fostered nurse autonomy, greater nurse job satisfaction, higher rates of nurse retention, and better patient outcomes (Lewis \& Matthews, 1998; Upenieks, 2003a; Aiken, Smith, \& Lake, 1994; Davidson, Flocarell, Crawford, Dupart, \& Clifford, 1997). Nursing leadership establishes the working climate for nurses within a hospital. In turn, perceived leadership characteristics are related to nurse autonomy (Mrayyan, 2004), while nurse autonomy is related to job satisfaction, nurse retention, and patient outcomes (Aiken, Smith, \& Lake, 1994; Upenieks, 2002). However, although Mrayyan (2004) did research empirically the relationship between leadership attributes and nurse autonomy, both of these constructs were assessed through reports from only the nursing staff. Nurse leaders were not involved. Hence, the relationship between leadership attributes and nurse autonomy in this study was only the relationship between leadership attributes as reported (perceived) by the nursing staff and autonomy as self-reported by that same nursing staff.

The concept of autonomy has risen to a level of great importance over the past twenty years and has become synonymous with human rights and dignity (Beauchamp \& Childress, 2001). Autonomy has assumed a prominent role in many areas of moral systems and practical ethics: in medical ethics through informed consent; in social policy by setting standards of general well being and welfare; and even in debates of animal rights. Nursing research has linked autonomy and nursing practice to improved job satisfaction, professionalism, and patient outcomes. Recent literature has examined the relationship of the autonomy of nurses and successful achievements of health care agencies, in particular the achievement of Magnet hospital status (Gleason-Scott, Sochalski \& Aiken, 1999). 
Clinical autonomy was an important attribute evident in Magnet hospitals, espousing a nursing service that fostered participative management and support for professional development (Upenieks, 2002). Autonomy set the stage for nurses to practice the skills of their profession and provided the opportunity for nurses to decide how and when work was orchestrated. When these characteristics were present, especially clinical autonomy, the connection between the professional nurses' extraordinary level of responsibility and their power base created the environment that fostered nursing's expression of clinical judgment, effective communication, collaborative partnerships and improved patient outcomes (Havens \& Aiken, 1999; Gleason-Scott, Sochalski, \& Aiken, 1999; Weisman \& Nanthanson, 1985). Research Question

Although the literature has shown that Magnet hospitals compared with nonMagnet hospitals have more positive leadership characteristics and higher levels of nurse autonomy and discusses how leadership fosters autonomy, this relationship between leadership and autonomy appears to be inferred. There has not been reported research where both leaders and nursing staff are appropriately assessed regarding leadership characteristics and nurse autonomy. This is the case even within Magnet hospitals. Hence, research is needed to directly assess this important relationship and address this knowledge gap in the literature.

The basic research question in this study was whether leadership characteristics are actually related to nurse autonomy. Both of these constructs were reported by nurse leaders as well as by nursing staff. Magnet hospital status was also used to understand this important relationship between leadership and autonomy. 
Significance of the Study

The alleviation or amelioration of patient suffering is one of the goals of nursing. Patient outcomes are directly impacted by the competence and decisions of nurses. There is a strong relationship between nurse autonomy and patient outcomes (Kramer, Schmalenberg, Lund, King, Poduska, Goode, \& Rapp, 2005). Hence, understanding clinical nurse autonomy and its sources can be understood as centrally important to the nursing mission.

There is empirical support in the literature for Magnet hospitals evidencing higher levels of both positive leadership attributes and nurse autonomy compared to non-Magnet hospitals. However, there is very little empirical support for an implicit assumption found in this same literature, namely that leadership attributes foster nurse autonomy. In order to further improve patient outcomes, it is important to evaluate this assumption. Hence, this study investigated the direct relationship between leadership and autonomy and how this relationship varies as a function of Magnet hospital status.

\section{Conceptual Framework and Research Lens}

Structural Contingency Theory as Framework. The conceptual framework for this study was that of Structural Contingency Theory (SCT) as modified in the nursingspecific SCT, the Nursing Systems Outcomes Research (NSOR) model. SCT (Donaldson, 1999) provided an organizational content model for conceptualizing the structure-environment-effectiveness relationship for organizations and maintains that organizations are more effective when their structures account for the nature of their organizations task environment. It is the match or fit between the context of an organization and its structure that produces good outcomes. For nursing within hospitals, 
context includes hospital characteristics from number of beds to technological complexity of services offered. Within SCT, organizational structure would be the nature of the hospitals' professional nursing practice. Professional nursing practice is defined in the literature as nurse autonomy, which is the nurses' active participation in decision-making, the acceptance of nurses' practicing independently and working within collaborative relationships with physicians (Mark, Salyer, \& Wan, 2003).

Critical Social Theory as Lens. As mentioned above, autonomy has become synonymous with human rights and dignity (Beauchamp \& Childress, 2001) and since the construct of autonomy addresses the issue of power relationships, it may even be seen as central to the philosophical stance of Critical Social Theory (CST). Hence, CST served as the lens through which this research project was viewed.

CST is a philosophical approach to conceptualizing humanity's efforts to define and clarify human struggles with the goal of freedom and empowerment of people (Lutz, Jones, \& Kendall, 1997; Ray, 1992; Stevens, 1989). This approach maintains that simply describing and understanding a phenomenon is insufficient. One must also choose action to ameliorate human suffering. Using this lens, it is understood that inequality produces power imbalance and power imbalance generates human suffering. Education is to be used to promote action to produce change to relieve human suffering.

Hence, CST lens provides the basic view of human relationships, be they personal, political, economic, institutional, or organizational, while the conceptual framework of SCT/NSOR provides the specific organizational content model that through research can establish empirical relationships and suggest directions for eliciting change within organizations. 
This SCT/NSOR frame functioned as a research model, supplying content and pointing to mechanisms by which the goals of CST can be achieved.

Specific Aims

This research focused primarily on three sets of variables: Hospital type (the 97 Magnet hospitals in the United States each matched with three non-Magnet hospitals), nurse manager leadership traits and staff registered nurse clinical autonomy. The overreaching goal for this proposed study was to understand the relationships among these three variables in order to potentially increase the efficiency of hospitals and, hence, improve patient outcomes by reducing patient suffering. The primary research question was whether leadership attributes were related to nurse autonomy. The two subsamples of participants were (1) nurse managers who directly supervise the nursing staff of a unit and (2) staff registered nurses including nurses with associate degree, bachelor degrees, and masters degrees who provide the direct patient care services. To address the primary research question, the following were the specific aims:

[1] Evaluate the differences in means of dependent variables between Magnet and non-Magnet hospitals on nurse manager leadership attributes and nurse clinical autonomy.

[2] Evaluate the differences between nurse manager leadership attributes and nurse clinical autonomy as reported by nurse managers versus staff registered nurses.

[3] Evaluate the relationship between nurse manager leadership attributes and nurse clinical autonomy for all research participants. 
[4] Evaluate the difference in the relationship between nurse manager leadership attributes and nurse clinical autonomy within Magnet versus non-Magnet hospitals.

[5] Evaluate two general models of relationship (mediation versus common cause) among hospital type (Magnet, non-Magnet), nurse manager leadership attributes, and nurse clinical autonomy. The common cause model assumes that hospital type generates both leadership attributes and nurse autonomy while the mediation model assumes that hospital type generates leadership attributes that, in turn, generate nurse autonomy.

\section{Hypotheses}

The three general hypotheses for this research were as follows: [1] there are differences between hospital type with Magnet hospitals being higher than Non-Magnet hospitals on nurse manager leadership attributes and clinical nurse autonomy, [2] there are positive relationships between nurse manager leadership attributes and clinical nurse autonomy, and [3] these relationships would vary as a function of hospital type.

There are seven specific hypotheses that were formally evaluated:

[1] Magnet hospitals would have more positive nurse manager leadership traits than nonMagnet hospitals (aim 1).

[2] Magnet hospitals would be higher on the nurse clinical autonomy scales than nonMagnet hospitals (aim 1).

[3] Positive nurse manager leadership traits as self-report versus such traits as reported by staff registered nurses would be less different within Magnet hospitals than within nonMagnet hospitals (aim 2). 
[4] Nurse clinical autonomy as self-report versus such autonomy as reported by nursing managers would be less different within Magnet hospitals than within non-Magnet hospitals (aim 2).

[5] Positive nurse manager leadership traits and nurse clinical autonomy would be positively correlated (aim 3).

[6] Compared to Magnet hospitals, non-Magnet hospitals' positive nurse manager leadership traits and nurse clinical autonomy would have lower correlations (aim 4). [7] The mediation model would better fit the data than the common cause model. That is, a model where hospital type causes positive nurse manager leadership traits that, in turn, cause higher nurse clinical autonomy would better fit the data than a model where nurse manager leadership traits and nurse clinical autonomy are related to each other because both are caused by hospital type (aim 5). 


\section{Chapter II. Background and Significance}

\section{Introduction}

This research project evaluated the relationships among hospital types (Magnet and non-Magnet), leadership characteristics, and clinical nurse autonomy. Structural Contingency Theory (SCT) was used as the research model, specifically a version that was the modification for the field of nursing known as the Nursing Systems Outcomes Research (NSOR) model. Critical Social Theory (CST) provided the basic lens through which to view this research, as discussed later. SCT conceptualizes the match between the context of an organization and its structure as being a primary determinant of organizational functional efficacy. To use the SCT framework and to understand the issues involved in the relationships among hospital types, leadership characteristics, and clinical nurse autonomy, the following sections will review the history of Magnet hospitals, the literature on nursing leadership and Magnet hospitals, and the literature on autonomy of clinical nurses and Magnet hospitals. The area of nurse autonomy will in turn cover hospital type, comparison across types of hospital units, and the general issue of fostering autonomy within hospitals.

\section{Conceptual Framework and Research Lens}

Structural Contingency Theory. The general conceptual model for this study was SCT, which provided a model for conceptualizing the structure-environmenteffectiveness relationship and maintains that organizations are more effective when structures reflect organizational functions. It is the match between the context of an organization and its structure that produces good outcomes, i.e., patient satisfaction. Nursing within the hospital context would include hospital characteristics from number 
of beds to technological complexity of services offered as well as leadership style of managers. Within SCT, organizational structure would be the nature of the hospitals' professional nursing practice and van Offenbeck and Knip (2004) have delineated nurse practitioner roles within this structure. Professional nursing practice is defined in the literature as the nurses' active participation in decision-making, the acceptance of nurses' practicing independently and working within collaborative relationships with physicians (Mark, Salyer, \& Wan, 2003).

Indeed, Mark, Salyer, \& Smith (1996) present a nursing-specific SCT, the Nursing Systems Outcomes Research (NSOR) model. The NSOR model uses concepts supported by nursing systems research that includes Magnet hospital literature (Scott, Sochalski, \& Aiken, 1999). As stated above, SCT predicts that organizational effectiveness (such as patient outcomes) is a result of having the appropriate structure given the context. Within NSOR, context of care is the organizational task environment and its technological complexity while structure of care is the administrative mechanisms that enable organizational task achievement. Importantly, in the NSOR model, context of care impacts structure of care, which, in turn, impacts organizational effectiveness, e.g., patient outcomes.

Figure 1 presents the general NSOR model that functioned as the conceptual model in this study. This is the NSOR model as modified by Larrabee, Ostrow, Withrow, Janney, Hobbs, and Burant (2004) through the addition of 'process of care,' incorporating nurse job satisfaction. This proposed study evaluated the relationship between context of care and structure of care (operationalized as leadership attributes and autonomy 
respectively) and how this relationship depends on the Magnet or non-Magnet status of hospitals.

In the NSOR model, there are three components to context of care. These components are nurse manager leadership style, staffing, and unit turbulence. Barker (1992) defines nurse manager leadership style as the manager's behavioral approach to control and decision-making.

Figure 1. Nursing Systems Outcomes Research modified SCT model for the conceptual research model for the study

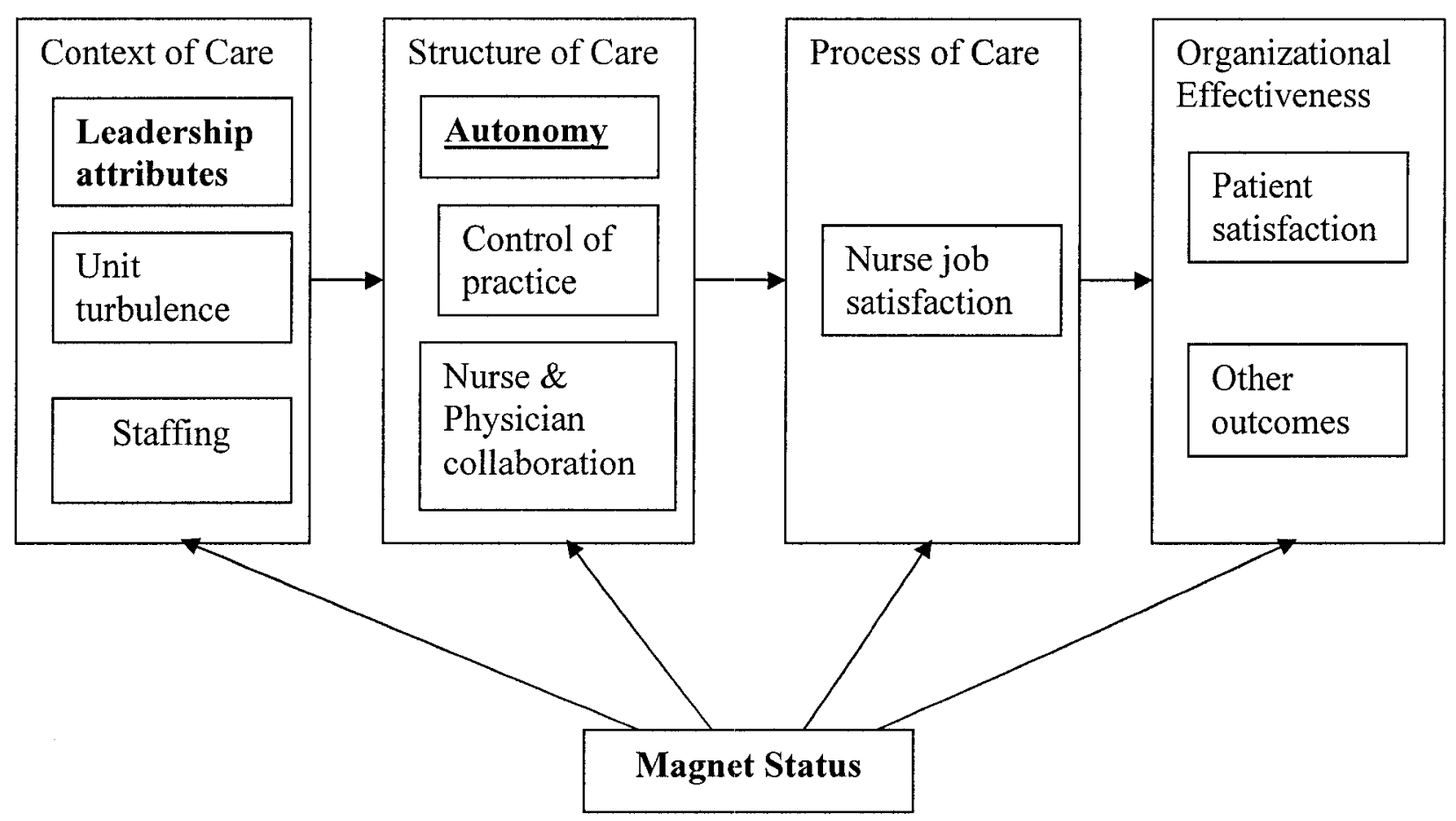

The American Nurses Association (ANA, 1996) defines staffing as the nursing personnel available for providing patient care. And Salyer (1995) defines unit turbulence as the level of random change and instability in the internal environment in response to external environmental conditions. Structure of care within the NSOR model consists of autonomy, control of practice, and the nurse-physician collaboration. Finally, NSOR 
defines organizational effectiveness as the outcome variable of patient satisfaction. For the NSOR model, the relationships among these general elements are hypothesized to be that context of care affects structure of care, which, in turn, affects organizational effectiveness.

Mark, Salyer, \& Wan (2003) empirically evaluated these causal relationships within the nursing-specific SCT model, NSOR model, in their Outcomes Research in Nursing Administration Project (ORNA). This empirical study involved 1682 registered nurses and 1326 patients from 124 general medical-surgical nursing units within 64 general short-term acute care hospitals in the southeast. These researchers operationalized the constructs of context, structure, and outcome (effectiveness). For context, they used hospital characteristics (e.g., technological complexity, hospital teaching status, and hospital size) and nursing unit characteristics (e.g., years of experience, education, skill mix, and unit size). For structure as professional practice, they used such variables as decentralization and autonomy. For organizational outcome, they used such assessments as nurses' work satisfaction and nursing turnover. Finally, among the variables used for patient outcome were patient satisfaction and reported patient falls. The results of their multilevel structural equation modeling program, testing all causal relationships at once, supported the validity of this model in predicting both organizational and patient outcomes. For example, professional nursing practice was consistently related to nurses' work satisfaction and skill mix predicted patient satisfaction. In general, the three SCT/NSOR constructs of context, structure, and outcome were related as hypothesized. 
Within the context of this proposed research, it would be expected that Magnet hospitals would be more likely than non-Magnet hospitals to generate better contexts of care, leading to better structure of care, leading to better organizational effectiveness. In this proposed research, leadership attributes would be context of care while nurse autonomy would be structure of care.

Critical Social Theory as Critical Lens. Critical Social Theory provides a broad-based conceptual philosophy that can be used as a lens through which nursing can address issues related to communication, power, leadership, autonomy, collaboration, empowerment and other emancipatory concerns (Boutain, 1999; Braten, 1991; Held, 1980; Allen, Benner, \& Diekel, 1986; Berman, Ford-Gilboe, \& Campbell, 1998; Duffy \& Scott, 1998; Held, 1980; Holter, 1992; Kim \& Holter, 1995; Mclain, 1988; Popkewitz, 1990; Wells, 1995; Wilson, 1992). Critical theory is a philosophical approach to understanding society's attempts to define and clarify human struggles with the goal of emancipation and empowerment of people (Lutz, Jones \& Kendall, 1997; Ray 1992; Stevens, 1989). Additional presentation of CST as critical lens is presented below. History of Magnet Hospitals

Because the early eighties was a period of severe nursing shortages, the American Academy of Nursing, McClure, Poulin, Sovie \& Wandelt, in their seminal 1983 study, attempted to identify how to make nursing a more appealing career choice. Initially, the American Academy of Nursing Fellows listed 165 hospitals with reputations for successfully attracting and training nurses while also delivering high-quality nursing care. McClure et al. (1983) investigated the attributes of autonomy, control, and collaborative relationships (within the NSOR model, the structure of care; see Figure 1) regarding how 
these might be related to hospitals being attractive to nurses and to good nursing care. A qualitative analysis of interviews from staff and nurse administrators from the 165 hospitals highlighted the significance of autonomy and control over practice as vital characteristics of professional nursing practice. The primary initiative was to identify hospitals whose flat organizational framework, investments in education, and influential nurse executives supported unit-based decision-making processes by nurses (GleasonScott, Sochalski \& Aiken, 1999; Aiken, Havens \& Sloane, 2000). Eventually, 41 of these hospitals were identified as having high nurse satisfaction, low job turnover, and low nurse vacancy rates. Because of their success in attracting and keeping nurses, these hospitals were designated as Magnet hospitals. Importantly, in their empirical study, Mark, Salyer, \& Wan (2003) supported the causal relationship between enhanced levels of professional nursing practice and lower levels of nursing turnover.

Although not a study of Magnet hospitals, Aiken, Clarke, Sloane, Sochalski, and Silber (2002) demonstrated the importance of such a hospital attribute as nurse/patient ratios to nurse job satisfaction and patient outcomes. They surveyed 168 nonfederal adult general hospitals in Pennsylvania involving 10,184 staff nurses surveyed, and 232,342 general orthopedic and vascular surgery patients discharged between April 1, 1998, and November 30, 1999. The authors found that after adjusting for patient and hospital characteristics, there was a related $23 \%$ increase in the odds of nurse burnout and a $15 \%$ increase in the odds of job dissatisfaction for each additional patient per nurse. Not only was there a relationship between nurse/patient ratios and nurse response, but there was also a relationship between nurse/patient ratios and patient outcomes. Again after adjusting for patient and hospital characteristics, for each additional patient per 
nurse, there was a $7 \%$ increase in likelihood of dying within 30 days of admission and a $7 \%$ increase in the odds of failure-to-rescue for each additional patient per nurse.

In 1990 the American Nurses Association (ANA) authorized the American Nurses Credentialing Center (ANCC) to establish a formal program to acknowledge excellence in nursing services. The Magnet Nursing Services Recognition Program is a voluntary form of external professional nurse peer review and on-site evaluation by nurse experts, similar to the Joint Commission on Accreditation of Healthcare Organizations (JCAHO). Magnet review is available to all hospital and nursing care home facilities based on the hospital's ability to meet 14 standards of nursing care.

The label Magnet Hospital originally was given to a group of U.S. hospitals that were able to attract and retain professional registered nurses during a national nursing shortage in the 1980s. The primary initiative was to identify hospitals whose flat organizational framework, investments in education, and influential nurse executives supported unit-based decision-making processes by nurses (Gleason-Scott, Sochalski \& Aiken, 1999; Aiken, Havens \& Sloane, 2000).

Havens \& Aiken (1999) described how originally designated Magnet hospitals throughout the 1980s and into the early 1990 s consistently demonstrated three distinct core features of a professional practice model. These core features were professional autonomy over practice (the nursing profession defines own guidelines and standards of practice), nursing control over the practice environment (within the practice setting, the nurse makes autonomous decisions), and effective communication between nurses, physicians and administrators. Magnet hospitals demonstrated organizational attributes that provided nurses with the organizational support needed to fully realize and provide 
high-quality patient care when compared to non-Magnet hospitals. This overview contended that the professional practice model demonstrated in Magnet hospitals is an empirically based framework that is critical in redesigning nursing practice in hospitals. With this emphasis, Magnet hospital status could serve as an example of excellence, quality patient outcomes, and best practices so diligently sought in today's competitive healthcare environment.

Nursing Leadership and Magnet Hospitals

Empowerment leads to autonomy and the significance of this concept cannot be underestimated. Leaders make a difference in the way organizational behaviors are developed and transmitted to staff, which in turn sets the culture for the institution. Studies assessing the attributes of Magnet hospitals demonstrated that the most vital organizational characteristic was the context of care, which in this study is defined as the quality of nursing leadership (Lewis \& Matthews, 1998; Upenieks, 2003a, 2003b) (see Figure 1). Nurse leaders have identified leadership attributes that they feel were crucial in achieving organizational success and improved job satisfaction among nurses. The characteristics identified were being supportive and knowledgeable, maintaining high standards and living up to the expectations of staff, remaining highly visible to clinical nurses and responsive to their needs, upholding open lines of communication, valuing education and professional development, preserving a position of power and status within the hospital, and keeping actively involved in state and national professional organizations (Gleason-Scott, Sochalski \& Aiken, 1999). Evaluating themes in nursing literature in the UK, USA, and Australia between 1992 and 1997, Cook (1999) identified similar themes and characteristics. 
Indeed the characteristics of leadership (context of care) are identified in the literature as crucial to the functioning of the nursing staff (structure of care), the general climate in the organization, and patient outcomes (organizational effectiveness), all three important constructs in SCT/NSOR (see Figure 1) with the improving of the experience of nurses and better patient outcomes being the goals. In a review of literature of the relationships of nursing practice models and job satisfaction outcomes, Upenieks (2000) concluded, “ . . implementation of nursing practice models is highly dependent on manager skill in leading and maintaining the change process" (page 330). She also noted that regardless of the exact type of nursing practice model that was being implemented, the models all continue to identify self-governance, effective relations, support, and interdependence as the crucial elements for professional nurse practice.

Hastings and Waltz (1995) conducted a multi-component intervention study targeting role transitions, nursing care delivery system strengthening, unit-level governance, and career advancement support for staff nurses. Findings over a one and a half year follow-up included improved job satisfaction, organizational commitment, control, responsibility, praise, and recognition, with the primary effects taking place at the level of the unit. Importantly, Hastings and Waltz emphasized the key role of management skills. Although there was no comparison group, Westrope, Vaugh, Bott \& Taunton (1995) in their own three-year shared governance intervention study also highlighted the central importance of the role of the nursing manager in facilitating and supporting the change process. The staff nurses were more satisfied with the quality of care and had a higher level of commitment to the organization because of the positive influence of the nurse manager.

As mentioned earlier, comparing Magnet and non-Magnet hospitals may be one way to evaluate what makes a difference in hospital functioning where it is expected that 
hospital type affects context of care (e.g., leadership) which affects structure of care (e.g., nurse autonomy) which affects organizational effectiveness (e.g., patient outcomes). Upenieks (2002) examined whether there were differences in the levels of job satisfaction among clinical nurses employed in diverse hospital settings (two Magnet and two comparable non-Magnet hospitals) and whether these differences were linked to leadership provided by the nurse executive. There was a $44 \%$ return rate generating a sample of 305 medical-surgical registered nurses with usable questionnaires from the distribution of 700 questionnaires. These nurses filled out the Revised Nursing Work Index (NWI-R) that had three subscales, autonomy, nurse control over the practice setting, and relations between nurses and physicians. For this study, three additional scales were developed to assess three dimensions of hospital structures: self-governance, organizational structure, and educational opportunities. In addition, besides the quantitative scales filled out by the staff nurses, interviews were conducted with 16 nurse leaders with three to five nurses from each of the hospitals. Within each hospital, one nurse leader at the executive level was recruited and two to three at the director or manager level. These qualitative data were evaluated by the Downe-Wamboldt (1992) content analysis method and then compared with the quantitative data via a triangulation matrix. This use of triangulation meets a major criterion for good qualitative research, that of employing multiple methods of data gathering as a recursive check on validity (Ambert, Adler, Adler, \& Detzner, 1995; Denzin \& Lincoln, 2000).

The NWI-R is a revision of the Nursing Work Index (Kramer and Hafner, 1989) and consists of 49 items rated on a 4-point Likert-type scale assessing staff nurse perceptions of specific organizational traits in their work setting (for example, "This 
factor is present in my current job situation"). Upenieks (2002) reports that the three subscales of the NWI-R and the three newly developed scales all had good internal reliability with Cronbach alphas ranging from .82 to .92 for Magnet hospitals and from .86 to .89 for non-Magnet hospitals.

Upenieks (2002), in examining whether Magnet hospitals continued to provide higher levels of job satisfaction and empowerment among nurses when compared with non-Magnet hospitals, found that the characteristics of nurse leaders were positively related to nurse autonomy and their making decisions. These characteristics included support of nursing (defined as seeing clinical nurses as the most essential component), leadership style (being passionate about nursing and being respected), central beliefs (leading to serve and providing nurses with right tools and resources), adequate staffing, autonomous climate, participatory management, collaborative teamwork, and compensation (adequate pay). Staff nurses in Magnet hospitals also identified crucial elements to greater access to work empowerment structures such as opportunity, information and resources, and more important, greater accessibility of Magnet nurse leaders and better support of clinical autonomous decision making by Magnet nurse leaders.

In a follow up study, Upenieks (2003b) evaluated the same 16 interviews from her 2002 study to assess in more detail what constitutes effective nursing leadership and comparing Magnet versus non-Magnet hospitals. In this exploratory descriptive design, inductive and deductive content analysis was employed to learn about perceptions of successful nursing leadership attributes in the acute healthcare setting. The six deductive categories derived from the 2002 study were supportive organizational climate, 
collaborative nurse-physician relationships, autonomous climate, clinical ladders/continuing education, participatory management, and adequate staffing. Upenieks asked the leaders three qualitative questions: [1] What do you consider to be your most effective leadership traits? [2] What are the most important elements of a successful organization that supports professional nursing practice? [3] How is a successful organization created?

Results from this Upenieks (2003b) study can be seen in Table 1. She did not formally test for differences in percentages of Magnet versus non-Magnet hospital leaders referring to basic organizational elements, perhaps due to the small sample sizes of seven Magnet and nine non-Magnet hospital leaders. Still, an examination of Table 1 shows that apparent differences between Magnet and non-Magnet hospital leaders can be separated into three groupings. The greatest percentage discrepancies were between those who mentioned climate ladders/continuing education (55\% difference) and adequate staffing ( $35 \%$ difference). The least discrepancies were for adequate compensation (6\%) and flexible schedules $(10 \%)$. All other discrepancies between these two groups varied in magnitude (from $19 \%$ to $16 \%$ ).

Upenieks also noted there were differences between the context of care for Magnet and non-Magnet leaders related to their principal value system, compassion and identity with the bedside nurse, and hospital administrative goals. The Magnet nurse leaders possessed traits that were categorized as "empowering" and "people-oriented" skills. In addition, Magnet hospitals attract leaders with strong people attributes, who are amiable, visible, and able to create a supportive environment that encompasses trust, autonomy and open communication (Upenieks, 2003b). 
Table 1. Upenieks (2003b) results for differences between Magnet and non-Magnet hospitals on nine organizational elements

\begin{tabular}{|l|c|c|}
\hline \multirow{2}{*}{ Organizational Elements } & \multicolumn{2}{|c|}{$\begin{array}{c}\text { Nurse Leaders Who Referred to } \\
\text { Element as Present in Their Organization }\end{array}$} \\
\cline { 2 - 3 } & Magnet $\mathrm{n}=7$ & non-Magnet $\mathrm{n}=9$ \\
\hline Supportive organizational climate & 86 & 67 \\
\hline Collaborative nurse-physician relationships & 72 & 56 \\
\hline Autonomous climate & 86 & 67 \\
\hline Climate ladders/continuing education & 100 & 45 \\
\hline Participatory management & 72 & 55 \\
\hline Adequate staffing & 57 & 22 \\
\hline Adequate compensation & 28 & 22 \\
\hline Flexible schedules & 43 & 33 \\
\hline Daycare services & 0 & 0 \\
\hline
\end{tabular}

In Mrayyan's research (2004), an examination of the role of perceived nurse managers' actions in enhancing staff nurses' autonomy was assessed. This was an empirical study using quantitative assessments for both nurse manager characteristics and staff nurse autonomy. Findings demonstrated a significant positive correlation $(r=.58, p$ $<.01$ ) between staff nurse reported perceptions of nurse managers' actions and nurses' self-reported ratings of autonomy with significant positive correlations for self-reported ratings of the two autonomy subscales (patient care $r=.34, p<.01$; unit operations $r=$ $.62, \mathrm{p}<.01)$. A limitation of this research is that Mrayyan did not have nurse managers respond to the Nurse Managers' Action Scale (NMAS), but rather had staff registered nurses report their perception of the nurse managers by filling out the NMAS. The Nurse Managers' Action Scale (NMAS) developed for this study was based on the literature (Hersey \& Blanchard, 1988; Taunton, Krampitz \& Woods 1989a 1989b, 1997; Weaver, Byrnes, Dibella \& Hughes 1991). Items asked how often the nurse manager performed certain actions, such as 'supports nurses to resolve conflicts with physicians'. A fivepoint Likert scaled was designed: 1 "does not do" to 5 "always does." Reliability and 
validity for the Nurse Managers' Action Scale were described as satisfactory. Mrayyan used the Autonomy Scale (Blegen, 2001) to measure nurses' autonomy. This scale consisted of a 42-item self-report questionnaire and has two 21 -item subscales assessing decisions about patient care and decisions about unit operations. The Autonomy Scale demonstrated content validity through an expert panel and was found to also be satisfactory. Additional descriptive and psychometric information on the Autonomy Scale is presented in the next section.

Leadership characteristics literature is broad-based and includes qualities of Magnet nurse leaders and what types of traits support a favorable nursing environment, as well as the relationship between such traits and autonomy. Nonetheless, Upenieks (2003b) noted the need for additional comparative research on leadership style differences between Magnet and non-Magnet hospitals. Additionally, there is a need for more quantitative research evaluating the relationship between leadership attributes and nurse autonomy. Autonomy of Nurses and Magnet Hospitals

Noting that there has been a recently created demand for a professional response regarding development of advanced roles for nurses and that such roles require the exercise of autonomy, Keenan (1999) presented a concept analysis of autonomy. She identified the following as the defining attributes of autonomy: independence, capacity for decision-making, judgment, knowledge, and self-determination. Ballou's (1998) concept analysis of autonomy also identified similar attributes. Empirical evidence from Magnet hospitals supports the finding that nurses in these agencies exhibit these 
characteristics reflecting structure of care (McKay, 1983; Slavitt, 1979). Hence, both Keenan (1999) and Ballou (1998) identify autonomy as being of central importance. Hospital Type Comparisons. From 1983 to 1991, several studies were conducted to identify specific attributes that were embedded in the Magnet hospital environment. Slavitt (1979) began measuring nurses' job satisfaction and the relationship between autonomy and decreased job satisfaction with the Job Diagnostic Survey tool developed by Hackman and Oldham (1975). This instrument had been used in earlier studies to assess nurses' attitudes toward their jobs (Munson \& Heda, 1976; Weisman, Alexander, \& Chase, 1980). Professional autonomy was defined as the degree to which the job provided substantial freedom, independence and the discretion of the employee to arrange his/her own work schedule. This definition of autonomy was used to further develop and refine the Job Diagnostic Survey. However, in a literature review and summary of the area of professional autonomy, McKay (1983) recommended the expansion of the definition of autonomy to include technology expertise, knowledge and skill expertise commensurate with patient acuity and ability to develop joint-practice models.

In their seminal work, McClure, Poulin, Sovie \& Wandelt (1983) investigated the attributes of autonomy, control, and collaborative relationships. A qualitative analysis of staff and nurse administrators' interviews highlighted the significance of autonomy and control over practice as vital characteristics of professional nursing practice. The study identified these attributes as the framework for recruitment and retention of professional nurses within the sample of hospitals designated as Magnet hospitals.

Using this designation of Magnet hospitals in a descriptive study of job satisfaction, Kramer and Schmalenberg (1987) interviewed over 1,000 nurses in 16 
Magnet hospitals. Although particularly interested in the impact of Diagnostic Related Groups (DRGs), the authors did evaluate job satisfaction, job insecurity, and autonomy and decision-making finding that job satisfaction and autonomy were generally characteristic of nurses in the Magnet hospitals. However, little information was presented regarding the interview and any rating or scaling procedures that were used. Although this was essentially qualitative research, such approaches do have their own criteria for research evaluation (Cobb \& Hagemaster, 1987; Ambert et al., 1995; Morse, 2003). These evaluative criteria include at least describing what the researcher did, intercoder reliability information, and multiple methods of data gathering as a recursive check on validity. Kramer and Schmalenberg (1987) do not offer information about their interviews, about intercoder reliability, and, apparently, used only the interview as a single source of information for most of the research content. They did use a few rating scales such as 10-point scale for job insecurity, but they do not provide any reliability or validity information for this scale. It is also not clear whether the interview also asked about job insecurity so that the rating scale could then be cited as a use of multiple methods of data gathering.

Kramer and Schmalenberg (1987) also did not specify or measure elements that were then evaluated regarding their relationships to job satisfaction, making it difficult to determine why nurses at Magnet hospitals demonstrated job satisfaction. Finally, there was no comparison of Magnet hospital characteristics and nurses with non-Magnet hospitals. However, the study did provide a beginning survey of prevalence of job satisfaction in Magnet hospitals and, in a follow-up study, these same two authors along 
with a third investigator did present formal information about procedures and did compare Magnet with non-Magnet hospitals.

In this follow-up study, Kramer, Schmalenberg \& Hafner (1989) investigated 16 Magnet hospitals and 8 comparison hospitals to assess the relationship between variables in hospital organization, productivity and job satisfaction. The Nurses Work Index (NWI) was used to measure nursing work values related to job satisfaction and perceived productivity. Kramer and Hafner (1989) reported good internal consistency reliability (Cronbach alpha) of the NWI subscales as noted above). A discussion of the direct relationship between autonomy and job satisfaction was included with autonomy identified as a significant positive variable in relation to job satisfaction and productivity. Although the study emphasized the importance of autonomy, it lacked a direct measure of autonomy, a considerable flaw in the design.

In a qualitative study using the same 16 Magnet hospitals in her previous publications (Kramer \& Schmalenberg, 1987; Kramer, Schmalenberg \& Hafner, 1989), Kramer (1990) followed up with interviews of the nurse executives at 14 of the original 16 Magnet hospitals. These interviews were not face-to-face, but were conducted via telephone during a statistical/demographic survey in 1989. As in her 1987 study, (Kramer \& Schmalenberg, 1987), Kramer does not present information about the interview used. So, again, it is difficult to evaluate validity and reliability of assessments. Although, as in the earlier study, there was no comparison of Magnet hospital characteristics and nurses with non-Magnet hospitals, the results of this study focused on how the Magnet hospitals were faring over the few years since the first study. Also, between the first qualitative study and this one, Kramer, Schmalenberg \& Hafner (1989) 
did publish a quantitative study with well-described procedures and instruments (see above). In this 1990 study, Kramer notes that, again, the importance of autonomy surfaced. She noted the affirmative effect of staff autonomy and its positive relationship to the clinical competence of the nurses.

It may be that patient outcomes, one form of organizational effectiveness, are also related to the nurse autonomy dimension of structure of care. From the above studies, Magnet hospitals have been shown to foster nurse autonomy. If Magnet hospitals are also different in patient outcomes, perhaps nurse autonomy is related to patient outcomes. In a study of mortality rates, Aiken, Smith, and Lake (1994) demonstrated significant differences in mortality rates between Magnet hospitals known for good nursing care and non-Magnet hospitals. Aiken et al. identified Magnet and non-Magnet hospitals in the Health Care Financing Administration Medicare hospital mortality rate file that was linked to the 1988 American Hospital Association annual survey of hospitals. Each of the identified 39 Magnet hospitals was statistically matched through a discriminate function analysis using 12 hospital characteristics with five control hospitals (for a total of 195 such hospitals) to control for organizational variation between hospitals and patient composition. These hospital characteristics overlapped with those used by Mark, Salyer, and Wan (2203) as their operationalization of the SCT/NSOR construct of context of care. Magnet hospitals demonstrated a $4.6 \%$ lower mortality rate than the matched controls ( $p=0.026, \mathrm{CI}$ of 0.9 to 9.4 fewer deaths). Magnet hospitals, so designated because of the autonomy of their nurses and the nature of their organization, had better patient outcomes and significantly lower mortality rates. 
However, in this particular study, the authors conceptually described autonomy as exercise of professional judgment, but they neither operationally defined autonomy nor used autonomy as part of the research question. They discussed autonomy only in terms of stating that Magnet hospitals are more likely to provide greater nurse autonomy than non-Magnet hospitals. Still, in their review of the literature, they do report two studies (Kramer \& Hafner, 1989; Aiken \& Smith, 1993) that directly compare Magnet and nonMagnet hospitals on operationally defined attributes of nurse autonomy derived from the Nursing Work Index. (The Nursing Work Index, its sub-scales, and their operational definition of autonomy are discussed above.) The authors argue that because these hospital types are different on nurse autonomy, then the differences of patient mortality between these hospitals may be attributable to the presence of nurse autonomy. Yet, they do not directly evaluate the relationship between nurse autonomy and patient outcomes in this study.

Nonetheless, these findings suggested that perhaps implementation of the organizational attributes of professional nursing practice models found in Magnet hospitals enabled nurses to exercise their professional knowledge, judgment, and skill to intervene in situations that could otherwise result in negative outcomes for the patient. This would certainly support the general SCT model and the nursing-specific NSOR model where context of care (leadership style within a hospital or unit) would impact structure of care (nurse autonomy) that would then impact on organizational effectiveness (patient outcomes).

Comparisons of Unit Types. Comparing hospitals with different organizational structure (Magnet versus non-Magnet hospitals) on differences in nurse autonomy and 
other characteristics is one way to study these relationships. Another similar approach to evaluating these relationships is to compare different organizational structures at the unit level. In 1997, Aiken, Sloane, and Lake examined patient satisfaction with nursing care within two models of organizing care for acquired immunodeficiency syndrome (AIDS) patients that developed as hospitals responded to the AIDS epidemic. These two models are specialized AIDS units devoted solely to the care of patients with AIDS and scatterbed arrangements where AIDS patients are incorporated onto multi-diagnosis medical units.

Important for the purposes of this literature review and the research on nurse autonomy, dedicated AIDS units had characteristics that were not typical of general medical units. These characteristics were those that would be expected to be attractive to nurses and patients as well as possibly affect the quality of care (Fox, Aiken, \& Messikomer, 1990; McGuirk \& Miles, 1987). On dedicated AIDS units, nurses were likely to have unusually high levels of professional autonomy with the professional relationships tending to be egalitarian. The authors also noted that they had demonstrated in another publication (Aiken \& Sloan, 1997) that nurses practicing on dedicated AIDS units had lower job-related burnout rates that could be attributed mostly to the organizational attributes of the specialized units. Hence, with different levels of nurse autonomy and burnout rates, the question was whether there were also differences in patient satisfaction between AIDS dedicated units and scatter-bed medical units.

Patient interview data were gathered from over 600 consecutive AIDS admissions in 40 patient care units in 20 hospitals from 11 high AIDS incidence cities. Ten hospitals with dedicated AIDS units were matched with comparable hospitals with scattered-bed 
AIDS units. Patient satisfaction was assessed using the both a multi-item patient satisfaction scale and a single-item overall patient satisfaction rating. The 21 -item scale was based on the LaMonica/Oberst Patient Satisfaction Scale and researcher-developed items pertinent to AIDS care (LaMonica, Oberst, Madea, \& Walf, 1986). Internal consistency was very good with a Cronbach alpha of .93. Also, the average interitem correlation for the 21 items was .38 .

Although the average correlation of .38 may seem low, it is important to note that the averaged underlying correlations are for single items. Single item assessment generally has low reliability. That is why multi-item assessment is usually employed. In the case of this scale, the average correlation of .38 among individual items yielded an overall estimation of reliability of .93 . Of course, the usually lower reliability of single items is an issue for the single interview question used in this study. This question was "On a scale of 0 to 10 , where 0 indicates complete disregard for you as a patient and 10 indicates the best care you can imagine, how would you rate your nursing care in this unit?" Even given the likely lower reliability of this single interview question, it did correlate highly with the 21 -item scale $(\underline{r}=.62, \underline{p}<.001)$ even with the differences in the assessments.

The findings in this study demonstrated that after controlling for the Magnet hospital effects, measurements of patient satisfaction remained significantly higher on the specialized units than in the general medical-surgical units. The authors suggested that the organizational differences and differences in the practice of nursing between the unit types regarding nurse autonomy and professional egalitarianism might have been responsible in part for the results of the study. 
These initial descriptive studies provided the groundwork for further examinations of Magnet hospital nurses and, in one case, dedicated AIDS units nurses, including attributes related to characteristics of structure of care (increased autonomy, control over practice, and physician collaboration). Although these attributes have been related to greater job satisfaction, the real value in this collection of early multi-site nursing research projects was the link made between processes of nursing practice (structure of care reflected in nurse autonomy) and patient outcomes (organizational effectiveness) even though such a relationship was generally not specifically tested. The question becomes given that organizational characteristics are important and may be related to nursing autonomy: What is it that fosters such autonomy?

Fostering Autonomy. In a study of nurse autonomy, Schutzenhofer and Musser (1994) surveyed 542 registered nurses from four states. They were attempting to identify how certain variables affected staff registered nurse autonomy. However, like Johnson (1988), Schutzenhofer and Musser noted that many studies on nurse autonomy are either flawed or lack comprehensiveness in identifying the professional autonomy characteristics. Among the weakness of these studies are nonrandom samples, small samples, and the use of inappropriate measures of nursing autonomy such as the Pankratz and Pankratz (1974) autonomy scale (Perry, 1986; Pinch, 1985; and Wood, Tiefje, \& Abraham, 1986). Such methodological weaknesses resulted in inconsistent findings.

To address methodological weaknesses, Schutzenhofer and Musser's (1994) study used two general instruments, Schutzenhofer's 1987 Nursing Activity Scale (NAS) and Spence, Helmrich, and Stapp (1974) Personal Attributes Questionnaire (PAQ). The NAS is a 30-item scale with five items not scored and used for assessments of internal 
consistency. Items on this scale described clinical situations applicable to a variety of clinical specialties in which the nurse must exercise some degree of professional nursing autonomy. Cronbach alphas for this scale ranged from .81 to .92 (Schutzenhofer, 1987; Dent, 1990, Martin et al., 1991); while in this study the Cronbach alpha was .81. Hence, reliability as assessed via internal consistency appears adequate. The PAQ, a 24-item scale that evaluates gender-stereotyped expressive and instrumental personal characteristics (Spence \& Helmreich, 1978; Spence \& Helmreich, 1980), has an average subscale reliability coefficient of .82 with construct validity attained on all the items. In this study significant relationships were noted between autonomy and the following: nursing education, practice setting, clinical specialty, functional role, membership in professional organizations and gender stereotyped personality traits with personality traits associated with men related to an increase in the sense of autonomy for the nurse. Interestingly, Sweet \& Norman (1995) point out that until the historical roles of women are defined once and for all and that the work of further emancipation begins, nursing will remain frozen in time. There were no relationships between autonomy and age or years of nursing experience. There was also an absence of a significant relationship between autonomy and the type of hospital, challenging the notion that universityaffiliated teaching hospitals supported autonomy more effectively.

In another study, Kovner, Hendrickson, Knickman, \& Finkler (1994) examined the impact of several variables on nurse satisfaction in 37 New Jersey hospitals using the Stamps and Piedmont Nurse Satisfaction Measurement Tool (Stamps \& Piedmonte, 1986). This tool was based on the need-fulfillment theory influenced by Social Reference Group Theory that was represented by including questions comparing peer groups' 
attitudes. The six dimensions of work satisfaction included pay, autonomy, task requirements, organizational requirements, interactions and professional status. Each of the six dimensions is represented by a short description. The participant is presented with all possible pairs of the six dimensions and asked to identify which of the pair is more important to job satisfaction or morale. These rankings allow the ranking the six dimensions in order of importance. The instrument also contains 44 items that assess level of satisfaction within each of the six dimensions. The reliability of the instrument's dimensions was assessed by Cronbach alphas, which in this study ranged from .71 to .84 except for professional status, which was at .44 . These generally agree with the reliabilities previously reported by Stamp and Piedmonte (1986) where the range was from .52 to .81 . Also, in this study, validity of the six dimensions was supported by a factor analysis.

The results of this study showed that nurses ranked autonomy second only to pay as most important to job satisfaction and morale. Importantly, this study also involved pre-post assessments where different innovations were introduced into the environment. The innovations included case management, shared governance, various reorganization of delivery of care, and education. These innovations were not developed or controlled by the authors in regard to their introduction to the settings. Innovations produced expected changes in ratings, including those of autonomy. Changes were indeed found in ratings of autonomy from pre to post introduction of innovations.

Looking at organizational differences and nurse autonomy, Aiken, Havens \& Sloane (2000) compared two groups of Magnet hospitals: seven currently nominated Magnet hospitals were compared to 13 original Magnet designated hospitals. The basic 
question here is whether American Nurses Credentialing Center's (ANCC) applicationbased process for designating Magnet hospitals identifies hospitals evaluated by nurses as favorably as the hospitals that were originally selected by the American Academy of Nursing (AAN) for Magnet designation. In this study, nurses were asked to respond to a 15-page self-administered survey that included the NWI-R to evaluate their practice in the areas of autonomy, control over practice, and nurses' relations with physicians. The NWI-R is a revision of the Nursing Work Index (Kramer and Hafner, 1989) and consists of 49 items rated on a 4-point Likert-type scale assessing staff nurse perceptions of specific organizational traits in their work setting (for example, "This factor is present in my current job situation"). The authors report that three of NWI-R subscales have consistently demonstrated acceptable internal consistency via Cronbach alphas (autonomy subscale: .78, control subscale: .79, and nurse-physician relations subscale: .73). Although there were several differences noted between the hospitals with over a decade apart in Magnet recognition, the data demonstrated a level of nurse practice environments comparable to those in the original Magnet hospitals. The data presented strong evidence for consumers and nurses to use ANCC Magnet recognition to identify hospitals with good nursing care (Aiken, Havens, \& Sloane, 2000). The methods section of this study noted several limitations. Groups of hospitals were not matched in size. Current Magnet hospitals were teaching hospitals and all were current members of the Council of Teaching Hospitals compared with $31 \%$ of the original hospitals. In a closer examination of the hospital size and scope of services, original Magnet hospitals reported an average of 398 beds, while current Magnet hospitals averaged 457 beds. Although not 
significant, number of beds was identified as a potential variable in the study and was statistically controlled.

Autonomy and job satisfaction were also found to be related to Magnet hospital designation in another study assessing differences in job satisfaction of nurses in Magnet and non-Magnet hospitals (Upenieks, 2002). Although this study was presented above in the leadership section, it is presented here because of its relevance to autonomy and outcomes. Upenieks chose a convenience sample of 2 Magnet hospitals and 2 comparable non-Magnet hospitals from an exhaustive list of Magnet and non-Magnet hospitals. Using both quantitative and qualitative data, triangulation was used. Medicalsurgical nurses were invited to complete a questionnaire, the Revised Nursing Work Index (NWI-R). The NWI-R was used to assess autonomy, nurse control over the practice setting, and the relations between nurses and physicians. The tool was selected on the basis of an extensive literature review, which showed the tool to be reliable and valid in assessing job satisfaction. A 2-tailed t-test was applied to compare differences in NWI-R mean scores. In addition, a qualitative analysis completed by the nurse executives was matrixed with the NWI-R survey tool. The matrix system facilitated the comparison of transcribed responses to interview questions and survey results, and a more precise explanation of the possible differences in job satisfaction scores between Magnet and non-Magnet nurses.

Seven hundred questionnaires were distributed with a return rate of $44 \%$. This was identified as a low response rate and was explained by the fact that nurses lacked time and energy due to prohibitive schedules and patient assignments. The authors did not note whether there were differential response rates across the two hospital types. 
Nurses at Magnet hospitals were newer to the profession, compared to nurses at nonMagnet hospitals. This may have contributed to higher scores overall, as apprentices in any field tend to be more excited about their profession. The use of both qualitative and quantitative research methodologies enhanced the study results, because Magnet leaders' rich qualitative responses stressed the importance of providing clinical nurses with education opportunities, information sharing, and flatter organizational structures equaling an increased level of autonomy that fosters job satisfaction.

The results were consistent with other studies suggesting that registered nurses at Magnet hospitals had more autonomy and control over their practice setting when compared to non-Magnet nurses. Hence, these hospital types were different on structure of care. The differences were related to greater visibility and receptivity by Magnet nurse executives, including a professional nursing milieu, and a more than adequate nurse-topatient ratio. The link between the level of nurse's job satisfaction and leadership provided by the nurse executive was overwhelming. Importantly, the Mrayyan (2004) study that evaluated the relationship between perceived management characteristics and nurse autonomy would certainly support this as well.

As described earlier in the Nursing Leadership and Magnet Hospital sub-section, Mrayyan (2004) conducted an examination of the role of perceived nurse manager leadership in enhancing staff nurses' autonomy and found a strong correlation $(\underline{r}=.88, \underline{p}$ $<.001$ ) between nurse managers' actions assessed by the NMAS and nurses' autonomy assessed by the Autonomy Scale. This is one of the few studies that tested directly the relationship between perceived leadership attributes and nurse self-reported autonomy using psychometrically sound tools. More research using sound instruments to directly 
evaluate the empirical relationship between leadership attributes and registered staff nurse autonomy needs to be done. In particular, research needs to be conducted wherein leadership attributes are assessed by having nurse managers respond to assessments rather than having staff nurses give their perception of nurse managers as Mrayyan did in her 2004 study. Gaps in the literature are addressed in the summary section below.

\section{Critical Social Theory as Critical Lens}

As discussed above, CST provides a broad-based conceptual philosophy. This

philosophy can be used as a lens for understanding how nursing can address issues related to communication, power, leadership, autonomy, collaboration, empowerment and other emancipatory concerns (Boutain, 1999; Braten, 1991; Held, 1980; Allen, Benner, \& Diekel, 1986; Berman, Ford-Gilboe, \& Campbell, 1998; Duffy \& Scott, 1998; Held, 1980; Holter, 1992; Kim \& Holter, 1995; Mclain, 1988; Popkewitz, 1990; Wells, 1995; Wilson, 1992). The goal of CST is the emancipation and empowerment of people (Lutz, Jones \& Kendall, 1997; Ray 1992; Stevens, 1989).

The political dimensions of power and interpretation of those power imbalances and ideologies are the underlying assumptions that attempt to demystify social oppressive meanings, leading to freedom. The idea that not all people are heard or that tradition has meanings that serve the interests of only a few are principles held by Critical Theorists, feminism, participatory inquiry and neo-Marxism (Guba, 1990). One of the best exemplars of the operationalization and application of critical theory is the work of Pablo Freire $(1972,1995)$ and the development of the phenomenon of praxis, understood as reflective practice used as a method of overcoming oppression. 
The term praxis is a process involving being informed, reflective, dialogical; to create change that liberates an individual or group from oppression (Freire, 1972). Freire was particularly concerned with providing a liberating education to people that would promote action to ameliorate the conditions of the oppressed. Praxis in sociological and anthropological arenas has been integrated as a format society and people can use to overcome powerlessness (Freire, 1995). Praxis as a process of reflective practice, a dialectic between reflection and action, and an approach to understanding and changing power relationships in nursing is less well conceptualized, although it serves as a foundation to adult learning theory, a teaching/learning process critical to meet the learning needs of many of today's nursing students (Thorne \& Hayes, 1997). This is a paradigm shift from educational and practice passivity to assertiveness and self-directed action and learning (Lutz et al., 1997). Praxis, as an active approach to change, is also well demonstrated in Georges' 2002 article where she critiqued Morse's 2001 article on the praxis theory of suffering. In this article, Georges explains that the suffering of the patient must be understood from within the patient's and not the care provider's experience. It might be pointed out here that such praxis, such understanding of and individualized response to the patient's suffering can only genuinely take place if the nurse can function autonomously in that setting. There is certainly an emergent awareness of the issues of autonomy in nursing and of the power relationships within hospital settings among administration, physicians, nurses, and patients. This awareness also involves the relationship between nurse autonomy and both the recruitment and retention of nurses as well as the amelioration of the suffering by patients. This developing awareness is even reflected in work at such institutions as Massey University 
(http://cohss.massey.ac.nz/papers/outlines/168/168142_WEL_I_12.shtml) and new web sites with such offerings as Nursing Praxis and the Reflexive Practitioner Collected Papers 1993-1999 by Gary Rolfe (http://www.nursingpraxis.com/gary.htm). Such web sites and collections of papers are an attempt to enable change in the world and are congruent with critical ethnography, which has as its central tenet that science itself and, hence, conventional ethnography, with its description of conditions is insufficient without aims of changing the conditions that it describes (Thomas, 1992; Brown, 2004). Adopting praxis will lead to greater nursing autonomy and the development of better healthcare standards and health outcomes (Ballou, 1998; Boyle, Bott, Hansen, Woods \& Taunton 1999; Davidson, Flocarell, Crawford, Dupart, \& Clifford, 1997; Mrayyan, 2004). Praxis and its subsequent autonomy is a defining characteristic of Magnet hospitals (Scott, Sochalski \& Aiken, 1999).

Critical theory can be important to the transformation of nursing. Critical theory is aligned towards emancipatory methods and actions, like consciousness awareness that solidifies the melding of theory and practice. Critical theorists search for hidden sources of power and domination within the processes of dialogue. These sources are then challenged and new emancipated modes of human action are revealed. Transformation of existing social institutions is then possible. Critical theory embraces language as a focus of social control and domination, empowering communities to take action against oppressive structures (Thompson, 1987). See Figure 2 for a graphic illustration of the relationships among education, inequality, power imbalance, and human suffering.

How then can critical theory be used within nursing to influence nursing autonomy, effective communication, collaboration (mutual collegiality) across 
disciplines, and empowered clients and families? An advantage of critical theory for nursing is the opportunity for nurses to shatter the ideological status quo and to formulate an alternative plan for healthcare change. Applying this view means that one looks for

Figure 2. Critical Social Theory showing relationships among inequality, power imbalance, and human suffering as well as representing education empowering and producing change.

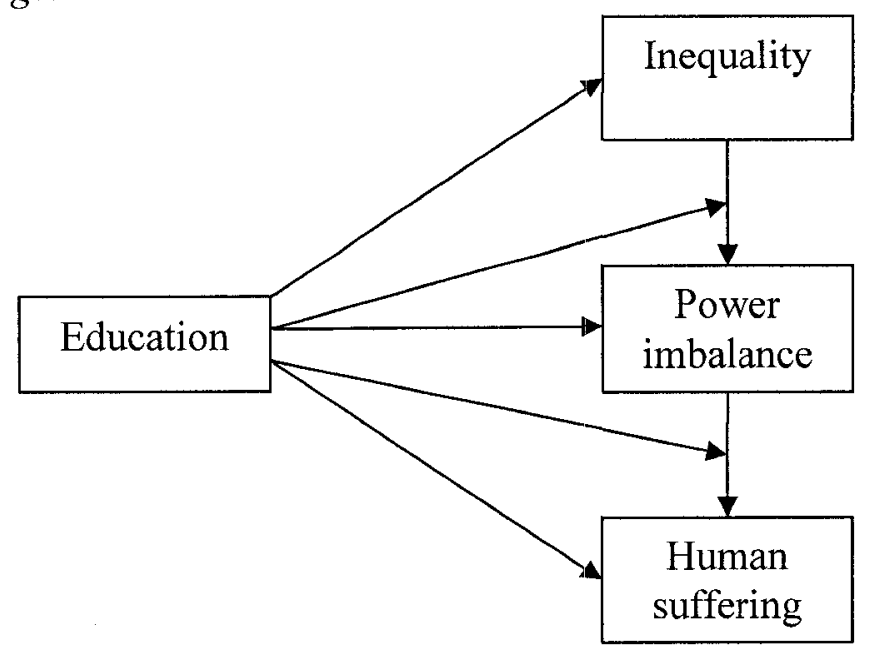

contradictions in a situation as a guide to what is going on and what is likely going to happen. Assessing the position of the individuals within the patient-provider or the nurse-physician relationship can assist in achieving greater insight into the power issues that link the patient, physician and nurse and establish an environment of coerced communication (Duffy \& Scott, 1998). From this philosophical perspective, another phenomenon that can be explored is empowerment or powerlessness of either patient or nurse and the actions necessary to bring about emancipatory change, balance, and progress (Allen, 1985; Henderson, 1995). Georges (2002) also clearly delineates research implications of praxis for nursing investigations, both quantitative and qualitative.

Structural Contingency Theory, discussed above in detail can be understood in relation to CST. Here, SCT provides the mechanisms through which action can produce 
education and change (see Figure 3 for the relationship of SCT/NSOR with the elements of CST). As discussed above, the nursing specific SCT, NSOR, was used in this study.

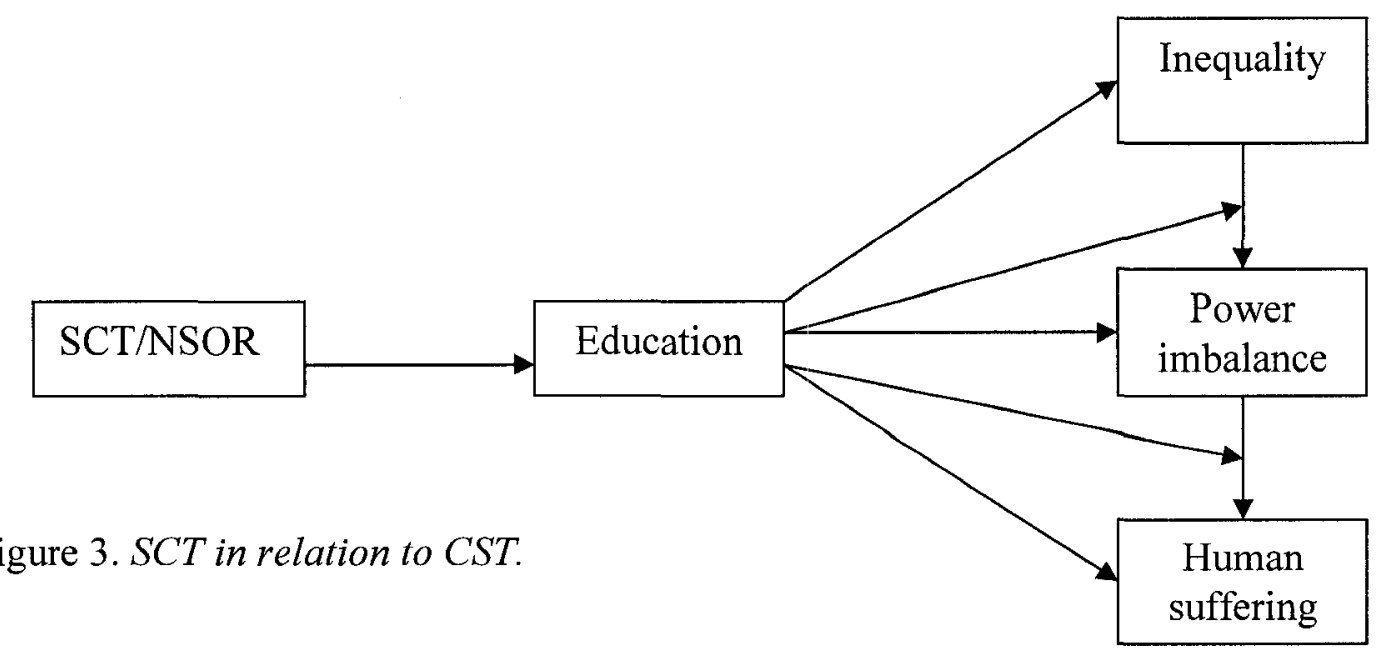

Summary

There are four areas of summary included here. These areas are themes, leadership and autonomy, instruments and procedures, and gaps in the literature.

Themes in Research Literature. Many themes consistent with SCT and NSOR have emerged from this literature review of the concept of registered nurses' clinical autonomy in relationship to Magnet and non-Magnet hospital status. These themes include: (a) professional nursing practice in Magnet hospitals allow for increased autonomy in clinical decision-making, control of the practice environment, and good communications with physicians; (b) three other strong attributes that were associated with professional practice are responsibility, authority and accountability; (c) autonomy in clinical decision-making occurred whenever a nurse made an independent judgment about the presence of a clinical issue and provides the resolution through nursing care; (d) autonomy gave identity, independence and authority to nursing practice and added power 
as well; (e) autonomy was not a fixed variable but was measured in degrees, as there were few fully autonomous groups; (f) clinical autonomy related to the scope of practice for which staff nurses were accountable; $(\mathrm{g})$ organizational autonomy was a characteristic of environments in which staff nurses are supported in participating in the decisionmaking that guides the organization; (h) executive nursing leadership in the form of receptivity and visibility were perceived by staff nurses as important leadership characteristics; (i) the importance of executive nursing leadership as part of the hospital's leadership team where nurse executives in Magnet facilities were perceived as having more power by the staff, and more supportive of the staff nurses in their autonomous personal decision-making. These themes are generally consistent with SCT and the nursing specific NSOR model; they support the necessity to evaluate the fit between organizational environment and organizational tasks, dialogue, change, autonomy, and clinical action to benefit patients. Additionally, there appears to be expected relationships among hospital type, context of care, structure of care, and organizational effectiveness.

Leadership and Autonomy. The research studies cited leadership and autonomy as they varied between Magnet and non-Magnet hospitals with Magnet hospitals having better leadership and greater nurse autonomy. Additionally, job satisfaction was higher in Magnet than in non-Magnet hospitals and higher job satisfaction was related to greater nurse autonomy. Finally, autonomy and job satisfaction related strongly to more successful recruitment and better retention. Early Magnet research defined recruitment and retention as the framework in hiring and holding nurses who provided excellent patient care. However, these relationships were not usually directly evaluated. The 
major exception to this was the research of Mrayyan (2004), which used operationalized definitions of both perceived leadership attributes (managers' actions) and nurse autonomy. This allowed her to directly assess the empirical relationship between perceived leadership and autonomy. However, a limitation of Mrayyan's study is that the leadership attributes assessed were those perceived by staff nurses, not those reported by the leaders themselves. Hence, her study could more properly have been titled, 'Nurses' autonomy: influence of perceived nurse managers' actions."

Instruments and Procedures. The most frequently utilized instrument was the Nursing Work Index (NWI) along with the Revised Nursing Work Index (NWI-R), generally using the three subscales that measure the constructs of nurse autonomy, nurse control over the practice setting, and nurses' relations with physicians. Psychometrically sound instruments need to be used in future research. Several newer studies incorporated a qualitative component. Content analysis was defined in only one of the three studies (Upenieks, 2002) and that analysis method was defined by the Downe-Wambolt approach. The other studies (McClure, Poulin, Sovie \& Wandelt, 1983; Kramer, 1990) attempted to match interview question answers to components drawn from quantitative results and subscale mean scores. Upenieks (2002) developed a more sophisticated method of matching these items utilizing a "matrix" system that was developed specifically for this triangulation method. Upenieks's method appeared to better facilitate the comparison of transcribed responses to interview questions and survey results, resulting in a more precise explanation of the differences in job satisfaction scores between Magnet and non-Magnet hospitals. 
Gaps in the Literature. One of the gaps in the literature consisted of use of instruments with methodological flaws perhaps resulting in inconsistent findings. Another gap is the need for comprehensive studies as well as studies focused on specific relationships among field elements such as that between leadership traits and nursing autonomy, the focus of the current proposed research. The one study that directly assessed leadership traits and nursing autonomy was Mrayyan's (2004). However, this study did not assess leadership traits by having leaders respond to questionnaires. Rather, Mrayyan actually measured leadership traits as those perceived and reported by the same staff nurses who also reported their own autonomy levels. This would probably account for the very high correlation of .88 .

A major gap in the research to date appears to be in the continuous process of demonstrating the relationship between autonomous, evidenced based nursing practice and measurable patient outcomes. This is an essential factor in further identifying nurses' significant and varied contributions to healthcare systems.

Evidenced-based research has been applied to nursing practice models and has proven to improve patient and staff well-being. The research completed on Magnet and non-Magnet nursing practice models have repeatedly demonstrated that the Magnet model is the current practice model of choice. Leaders redesigning the delivery of patient care are urged to look at these hallmark studies that highlight Magnet hospitals and to use what is already known to work.

Implications and Importance of Proposed Study

Implications for nursing research in the area of autonomy and the positive relationship in Magnet hospital staff would benefit from studies utilizing both 
quantitative and qualitative approaches. Based on past research, the Magnet nursing practice model could be instituted within the hospital framework and still remain flexible enough to ensure stability of the model while balancing healthcare costs. Magnet practice models are rich in registered nursing staff but may not be feasible or easy to implement in many regions of the United States. However, when compared to nursing turnover statistics, this model may again provide an alternative to costly nursing orientations and preceptorships. Pay is also a factor to be considered when evaluating job satisfaction, although within in the literature reviewed it may not be as big as a problem as once noted. Importantly, the healthcare consumer would also benefit from the development of such research and practice. Such consumers could themselves evaluate hospitals and care in light of such information and make their own healthcare decisions regarding which hospitals they would find of interest and value. Such consumer evaluation empowers the consumer.

It should be noted that the research supports the importance of the structure of care element of nurse autonomy in the healthcare industry and that the benefits of this accrue not only to nurses but also to patients. Indeed, all participants in the healthcare system become beneficiaries when such systems foster egalitarian professional relationships, shared responsibilities, and individual autonomy. Hospitals become more efficient organizations, administrators are confronted by fewer disgruntled supervisees, nurses have greater job satisfaction and lower turnover rates, and patients report increased satisfaction and greater perceived nurse caring, as well as have better health outcomes. 
The current proposed research evaluated the relationship among hospital type (Magnet versus non-Magnet hospitals), leadership characteristics, and clinical nurse autonomy, in order to more fully understand the relationship between leadership and autonomy. The implicit model used in the research literature was that of mediation where hospital type affects leadership quality and leadership quality, in turn, affects nurse autonomy. The proposed research explicitly differentiated between two general models of these relationships, the common cause model and the mediation model (see Figure 4).

Figure 4. Two Models of Relationship: Common Cause (A) versus Mediation (B)

A.

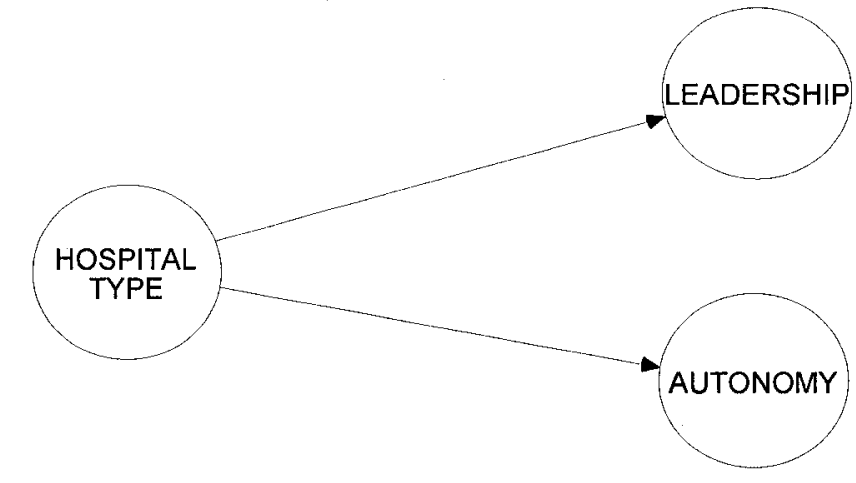

B.

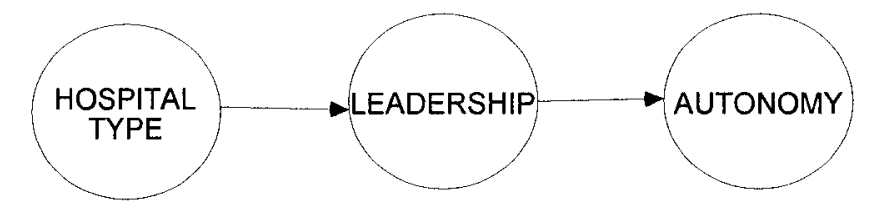

The question was does hospital type directly affect both leadership and autonomy (common cause) or does hospital type directly affect only leadership and then leadership directly affects autonomy with hospital type affecting autonomy indirectly through its affect on leadership (mediation)? It was hypothesized that the mediation model is the correct one. The two concepts of leadership attributes and nurse autonomy were operationalized using psychometrically sound assessments and were both given to the same individuals. Hence, this study extended results of earlier research and directly 
tested the relationship between leadership and autonomy. This direct test specifically extended the research of Mrayyan (2004) to using nurse managers' reports of their own responses rather than having staff nurses reporting their perception of nurse manager actions as well as comparing responses between Magnet and non-Magnet hospitals. 
Chapter 3. Design and Methods

\section{Purpose}

The purpose of this research was to evaluate the relationships among hospital types (Magnet versus non-Magnet), nurse manger leadership attributes, and staff registered nurse autonomy, in order to address the basic research question: What is the relationship between leadership attributes and nurse autonomy.

\section{Research Design Description}

This study employed a pre-experimental static-group comparison design (Campbell \& Stanley, 1963, p. 12-13; Leedy \& Ormrod, 2005) with a matching procedure to help ensure equivalence between the two groups on salient characteristics of hospitals. A pre-experimental design is one where the independent variable is not manipulated and the two groups are not the result of random assignment of subjects; hence, there is no formal experimental control group. Additionally, although there are causal assumptions underlying the hypotheses, these assumptions were not formally tested since there was no longitudinal component in the design.

In this study, there were two primary independent variables, the grouping variable of hospital status (Magnet versus non-Magnet) and the repeated measures variable of nurse status (nurse manager versus registered staff nurse). The nurse status independent variable is a repeated measure because each of the dependent variables (leadership and autonomy) were assessed for both nurse managers and registered staff nurse. Given that part of the question here involved Magnet versus non-Magnet hospitals and nurse manager versus registered staff nurse status, it was not feasible to use a true experimental design since such status cannot be randomly assigned. 
This design used three dependent variables as presented in Table 2. The basic assessments consisted of measuring leadership traits using the Nurse Manager's Action Scale (Mrayyan, 2004) and nurse clinical autonomy using the Autonomy Scale (Blegen et al., 2001) with its two sub-scales of patient care and unit operation decisions. Each nurse manager self-reported using the NMAS and reported perceived clinical autonomy of the registered staff nurses using the Autonomy Scale. Each registered staff nurse selfreported using the Autonomy Scale and reported perceived leadership traits of the nurse manager using the NMAS. Within the SCT/NSOR model, leadership attributes represented the context of care and nurse autonomy represented the structure of care.

Table 2. The sources of the three primary dependent variables

\begin{tabular}{|c|c|c|}
\cline { 2 - 3 } \multicolumn{1}{c|}{} & \multicolumn{2}{|c|}{ Source of data } \\
\hline $\begin{array}{c}\text { Primary Dependent } \\
\text { Variables }\end{array}$ & Nurse Managers & Registered Staff Nurses \\
\hline $\begin{array}{c}\text { Leadership attributes from } \\
\text { the NMAS total score }\end{array}$ & Self-reported & Perceived \\
\hline $\begin{array}{c}\text { Nurse Autonomy Scale: } \\
\text { operations }\end{array}$ & Perceived & Self-reported \\
\hline $\begin{array}{c}\text { Nurse Autonomy Scale: } \\
\text { patients }\end{array}$ & Perceived & Self-reported \\
\hline
\end{tabular}

Major advantages for this type of design included not using manipulated independent variables; using relatively simple, but psychometrically sound questionnaires; and research being conducted in the real world of nursing, thus providing external validity. Major disadvantages included lack of the benefits of manipulating independent variables, such as explicit control over the levels of the independent variables, and random assignment of subjects to conditions. Another major disadvantage of this design was the lack of longitudinal assessment. The lack of an experimental design with the absence of both the manipulation of independent variables and 
assessment over time made it much more difficult to make inferences regarding causal relationships.

Basic Analytic Design

Although this study used four different statistics (ANOVA, correlation, the difference between correlations, and multiple linear regression), Table 3 presents the basic overall design of the study. This basic design was a 2 (Nurse Status, nurse managers versus registered staff nurses) by 2 (Hospital Type, Magnet versus nonMagnet) ANOVA mixed design with nurse status as a repeated measure. This design allowed testing for differences on one dependent variable at a time (e.g., leadership or autonomy) between all manager nurses and registered staff nurses and between all Magnet hospitals and non-Magnet hospitals. Additionally, this design also allowed the testing of the interaction of nurse status by hospital type and the evaluation of simple effects (e.g., nurse status differences within Magnet hospitals.)

Table 3. Basic ANOVA design: 2 Nurse Status (manager vs. staff nurse) by 2 Hospital Type (Magnet vs. non-Magnet) repeated measures ANOVA with Nurse Status as the repeated measure (three dependent variables used were Nurse Managers' Action Scale and the two sub-scales of The Autonomy Scale)

\begin{tabular}{lc|c|c|c} 
& & \multicolumn{2}{|c|}{ Hospital Type } & \\
& & Magnet & Non-Magnet & \\
\cline { 2 - 4 } \multirow{2}{*}{$\begin{array}{c}\text { Nurse } \\
\text { Status }\end{array}$} & $\begin{array}{c}\text { Dependent } \\
\text { variable }\end{array}$ & $\begin{array}{c}\text { Dependent } \\
\text { variable }\end{array}$ & Manager mean \\
\cline { 2 - 5 } & $\begin{array}{c}\text { Staff } \\
\text { Nurse }\end{array}$ & $\begin{array}{c}\text { Dependent } \\
\text { variable }\end{array}$ & $\begin{array}{c}\text { Dependent } \\
\text { variable }\end{array}$ & Staff Nurse mean \\
\hline & Magnet mean & Non-Magnet mean &
\end{tabular}

\section{Power Analyses and Sample Size Calculations}

Statistical power is the likelihood of detecting an effect when, in fact, there is such an effect present. This is the same as saying that it is the probability that a statistical 
test will yield statistically significant results (Cohen, 1988). It is important for a study to have sufficient statistical power so that in the case of non-significant results, the researcher can state that there is no effect present with some assurance of not committing a Type II error. A Type II error is one where a researcher concludes that there is no effect when an effect is truly present. One condition under which such an error can be made is when the study lacks sufficient power to detect effects of particular sizes. Statistical power is a function of specified alpha level, sample size, and effect size or the magnitude of the effect.

The convention for acceptable statistical power is a minimum of .80 . Another convention in this area is that effect sizes are defined as small, medium, and large. Different statistical tests have different scales of effect size. For ANOVA effect sizes, Cohen's $(1988,1992) f$ (the standard deviation of the group means divided by the common within-group standard deviation) can be used to define an effect size of small as $f=.10$, medium as $f=.25$, and large as $f=.40$.

For the power analyses here procedures and tables from Cohen $(1988 ; 1992)$ and the SOLO Power Analysis computer program (Hintze, 1991) were used to evaluate power for the main effects and interaction effect for the 2 (Nursing Status) $\times 2$ (Hospital Type) mixed design ANOVA with nursing status as the repeated measure. Table 4 shows that setting alpha at .05 and assuming a sample of 130 hospital units, there was sufficient power (.80) for both main effects and the interaction to detect down to medium sizes $(f=.25)$. If the total sample size had turned out to be 80 , there would be sufficient power $(.80)$ to detect down to between a medium and large ANOVA effects of $f=.32$. Even if the sample size had been as small as 52, there would be sufficient power (.80) to 
detect large effects. Since the proposal for this study was to acquire a total sample of between 80 and 130 units, the sampling procedures used in this study yielded sufficient power for the proposed ANOVA design to detect down to between large and medium effects. Even if a sample size of only 80 subjects had resulted from the procedures, there would still have been power to detect down to between a medium and large effect.

Table 4. Formal power analyses for determining acceptable sample sizes

\begin{tabular}{|c|c|c|}
\hline Total Sample Size & Effect Size (Cohen's $f$ ) & Statistical Power \\
\hline 130 & .25 & .80 \\
\hline 80 & .32 & .80 \\
\hline 52 & .40 & .80 \\
\hline
\end{tabular}

For the tests of the differences in correlations of nurse managers with staff registered nurses measurements between Magnet and non-Magnet hospitals, again power analyses showed that there was more than sufficient power with the sample sizes in Table 4. For such differences between correlations, the definitions of magnitude of effect sizes use a measurement called ' $\mathrm{q}$ '. This $\mathrm{q}$ is the difference between the Fisher $\mathrm{Z}$ transformations of the two correlations (Cohen, 1988, 1992) with small defined as $q=$ .10 , medium as $\mathrm{q}=.30$, and large as $\mathrm{q}=.50$. For sufficient power $(.80)$ to detect large effects here, $\mathrm{q}=.50$, with alpha set at .05 , a sample size of about 130 was required. Hence, the upper limit projected sample size for this study yielded sufficient power to detect at least large effects in differences between correlations.

\section{Sample and Sampling}

The populations were nursing managers and staff registered nurses in Magnet and non-Magnet hospitals. The two sub-samples of participants were (1) nurse managers who directly supervise the nursing staff of a unit and (2) staff registered nurses including 
nurses with associate bachelor, and master degrees who provide the direct patient care services representing Magnet and non-Magnet hospitals. A major advantage of this sampling approach was that different geographic areas and different types of hospitals were represented. Another major advantage was that the two types of hospitals were matched on a basic set of 11 criteria (see Table 5). This matching procedure helped assure that any Magnet versus non-Magnet hospital differences found were most likely not be due to differences on these 11 characteristics. A major disadvantage of this approach was that not all nursing managers and staff registered nurses responded and, thus, the sample was composed of volunteers who were effectively self-selected. Additionally, given the research design as described above, there was no random assignment to condition of even these self-selected participants. Also, although the selection of the staff registered nurses within each hospital was done by the nursing managers, there was a criterion for such selection. This criterion was that the staff registered nurses were selected in alphabetical order of last name. There was also the issue of using self-report. Self-report is always a concern regarding response bias as well as whether the research participant is answering truthfully.

Hospital Sample Selection Completed. As of April 5, 2004, approximately 100 hospitals had been designated as Magnet hospitals. The entire population of available Magnet hospitals found on in the AHA hospital data base were included in the study. There were 97 Magnet hospitals in this AHA database. In order to compare Magnet and non-Magnet hospitals and control for organizational differences, the matching strategy used by Aiken, Smith and Lake, (1994) was replicated as closely as possible. Aiken et al. (1994), from a possible list of 5,053, "matched" five non-Magnet hospitals to each of the 
39 available Magnet hospitals using specific organizational characteristics like average daily census, number of beds and financial status. The entire list of organizational characteristics used by Aiken, Lake and Smith are delineated below. For this study, the proposed potential sample consisted of the 97 available Magnet hospitals, which represented the entire population of Magnet hospitals in April, 2004 and three matched non-Magnet hospitals from those 4,702 available from the AHA database for each Magnet hospital resulting in a sample of 388 hospitals. Why there were three matches here versus five matches for Aiken et al. (1994) is discussed below. The target sample of 388 hospitals represented approximately $6.5 \%$ of hospitals in America.

Construction of the matched control sample using multivariate matching was achieved by utilizing data available through the American Hospital Directory. The American Hospital Directory is an online data source for American hospitals. The database of information is built from Medicare claims data, cost reports, and other public use files obtained from the federal Centers for Medicare and Medicaid Services. The data also includes the American Hospital Association (AHA) Annual Survey Data. To replicate Aiken, Smith and Lake's study (1994), the AHA Annual Survey Data were used. The AHA Annual Survey Data contains hospital characteristics that are derived from hospital surveys and other proprietary sources. The survey has been collected annually since 1946 and is widely regarded as the most authoritative and comprehensive source of individual hospital data available.

Data regarding the 97 Magnet hospitals were entered into a database created within the Statistical Package for the Social Sciences (SPSS version 10). Next, data specific to all non-Magnet hospitals were loaded into another SPSS database. As noted 
above, there were 4,702 non-Magnet hospitals available. All but one of the 11 specific hospital characteristics used in the Aiken, Lake and Smith study (1994) were used to sort and cluster. These characteristics ultimately allowed for non-Magnet and Magnet hospitals with other like characteristics to be "matched." The one Aiken et al. (1994) hospital characteristic not used was item number 8 on the Aiken et al. list, proportion of physicians that are board certified. This characteristic was not available in the current AHA database. The specific characteristics that were used in order to match non-Magnet to Magnet facilities are presented in Table 5. These same hospital characteristics were also used as the operationalization of the SCT/NSOR construct of context of care in the Mark, Salyer, and Wan (2003) empirical study that evaluated the general causal model implicit in SCT and NSOR.

Table 5. Characteristics for Matching Magnet and non-Magnet Hospitals

\begin{tabular}{|l|l|}
\hline Criterion & Criterion Content \\
\hline 1. Ownership & Percent Public, private for profit, private not-for-profit \\
\hline 2. Membership & $\begin{array}{l}\text { Member of Council of Teaching Hospitals (ordinal: } \\
\text { yes/no) }\end{array}$ \\
\hline 3. Size & Average Daily Census (ADC) \\
\hline 4. Beds & Number of Hospital beds \\
\hline 5. Discharges & Number of Medicare discharges \\
\hline 6. Financial Status & Payroll (millions of dollars) \\
\hline 7. Occupancy Rate & Percent of beds used \\
\hline $\begin{array}{l}\text { 8. Physician } \\
\text { Certification* }\end{array}$ & Board Certified physicians/ all physicians (\%) \\
\hline 9. Payroll expense & Expense per hospital bed (1,000 dollars) \\
\hline \multicolumn{2}{|l|}{ 10. High Technology } \\
$\begin{array}{l}\text { High technology index score (scored 0-5 based on the } \\
\text { presence or absence of: cardiac-cath lab, extracorporeal } \\
\text { lithotripter, MRI, open heart surgery capability and organ } \\
\text { transplant capability }\end{array}$ \\
\hline 11. Emergency Visits & Number of emergency visits/ADC (ratio) \\
\hline 12. Catchments & Metropolitan statistical area size \\
\hline
\end{tabular}


As can be seen in Table 6, the Magnet hospitals were significantly different from non-Magnet hospitals on all 11 of these hospital characteristics. This is why a matching procedure needed to be carried out. It was necessary to ensure that the two types of hospitals in this study were not different on these characteristics in order to be able to evaluate the relationships specified in the hypotheses without concern for any relationships found being actually determined by differences in this potentially confounding characteristics.

Determining the Matched Hospitals. A propensity score, which represents the probability of a particular hospital being designated a Magnet hospital, was obtained by assigning "Magnet designation" and "non-Magnet designation" as the dependent, dichotomous variable for all 4,799 hospitals (4702 non-Magnet and 97 Magnet). The scoring was zero (0) if the hospital is a Magnet hospital and one (1), if the hospital was not a Magnet hospital. After Magnet designation or non-Magnet designation was determined for each hospital, a logistic regression was run for the 11 organizational characteristics as described above. The resultant discriminant function was used to determine a predicted logit, which is the propensity score.

After a propensity score was calculated for all hospitals, each Magnet hospital was sequentially matched with the non-Magnet hospitals that have the most similar propensity scores. To ensure that no non-Magnet hospital serves as a match for more than one Magnet hospital, after a hospital was selected as a match, it was removed from the database. This process was repeated until statistically significant differences began to emerge for the 11 characteristics between the set of Magnet hospital and the set of the 
"matched" non-Magnet hospitals. Such differences emerged on the fourth set of random matches (see Table 6).

In their matching using five non-Magnet hospitals for each Magnet, Aiken et al. (1994) had one significant Magnet versus non-Magnet hospital difference on their 12 characteristics. This difference was for the payroll expense per hospital bed characteristic and took place on the first randomizing matching procedure [Magnet mean $=109$ versus non-Magnet mean $=95, \mathrm{p}<.05]$.

In the randomization matching process for this study, no such significant differences emerged until the fourth randomization. In the fourth randomization, four such differences were present. These were for average daily census, number of hospital beds, financial status payroll, and payroll expense for hospital bed (see Table 6). The ability of the data to support as many randomizations as Aiken et al. used was limited by the differences in the AHA database number of Magnet hospitals, the number of nonMagnet hospitals, and the ratio of number of Magnet to non-Magnet hospitals. Aiken et al. (1994) had only 39 available Magnet hospitals, but 5,053 available non-Magnet hospitals. This is a ratio of Magnet to non-Magnet hospitals of .008 $(0.8 \%)$. In the current study, there were 97 available Magnet hospitals, but only 4,702 available non-Magnet hospitals. This is a ratio of Magnet to non-Magnet hospitals of $.02(2.0 \%)$. The difficulty in producing more than three sets of randomized matches for the Magnet hospitals was the result of this large increase in the proportion of available Magnet to non-Magnet hospitals. Hence, only the first three sets of randomized matches were used. As can been seen in Table 6, there were no differences between the Magnet hospitals and 
non-Magnet hospitals on any of the 11 characteristics from the first to the third matching cycle.

As an additional check on the matching cycles, the average propensity scores are also presented in Table 6. First, overall the 97 Magnet and the 4,702 non-Magnet hospitals are clearly different on propensity scores (means of 2.4 versus $5.4, \mathrm{p}<.001$ ). Second, and importantly, when the 97 Magnet hospitals are compared to each of the three sets of 97 matched non-Magnet hospitals, there were no significant differences on the propensity scores and any of the three matching cycles. Indeed, these propensity scores (linear combinations of the 11 control variables in the discriminate function) are the same for Magnet hospitals and each of the three 3 sets of matched non-Magnet hospitals $($ means $=2.4,2.4,2.5,2.5)$.

The maximum sample size for the study itself was estimated at 388 with a sample size of 130 providing enough statistical power to detect down to at least medium effects and a sample size of 80 being able to detect between medium and large effects. These numbers were identified through formal power analyses as described below. Advantages of this sampling procedure included there being a large subject pool available and a wide range of subject characteristics [e.g., age, sex, education, experience, and ethnicity]. 
Table 6. Testing of Magnet versus non-Magnet Hospital Matching

\begin{tabular}{|c|c|c|}
\hline Characteristic & $\begin{array}{l}\text { Magnet } \\
\mathrm{n}=97\end{array}$ & $\begin{array}{l}\text { Potential } \\
\text { controls } \\
n=4702\end{array}$ \\
\hline $\begin{array}{l}\text { Ownership \% } \\
\text { Public } \\
\text { Private for-profit } \\
\text { Private not-for-profit }\end{array}$ & $\begin{array}{l}14.4 \\
1.0 \\
84.5\end{array}$ & $\begin{array}{l}27.2^{*} \\
16.0^{* *} \\
56.8^{* *}\end{array}$ \\
\hline $\begin{array}{l}\text { Member - Council of } \\
\text { Teaching Hospitals \% }\end{array}$ & 47.4 & $5.7^{* *}$ \\
\hline $\begin{array}{l}\text { Hospital size } \\
\text { Average daily Census } \\
\text { (ADC) }\end{array}$ & $\begin{array}{l}335.6 \\
(195.11)\end{array}$ & $\begin{array}{l}107.4 \\
(134.05)^{* *}\end{array}$ \\
\hline Hospital beds & $\begin{array}{l}443.7 \\
(236.74)\end{array}$ & $\begin{array}{l}160.0 \\
(171.41)^{* *}\end{array}$ \\
\hline Medicare discharges & $\begin{array}{l}8367.7 \\
(5581.46) \\
\end{array}$ & $\begin{array}{l}2501.0 \\
(3138.33)^{* *}\end{array}$ \\
\hline $\begin{array}{l}\text { Financial Status } \\
\text { Payroll (million } \\
\text { dollars) }\end{array}$ & $\begin{array}{l}155.1 \\
(129.65)\end{array}$ & $\begin{array}{l}32.6 \\
(49.41)^{* *}\end{array}$ \\
\hline Occupancy rate & $0.75(0.13)$ & $0.59(0.22)^{* *}$ \\
\hline $\begin{array}{l}\text { Payroll } \\
\text { expense/hospital bed } \\
\text { ratio }(1,000 \text { dollars })\end{array}$ & $\begin{array}{l}346.8 \\
(179.67)\end{array}$ & $\begin{array}{l}179.5 \\
(121.81)^{* *}\end{array}$ \\
\hline $\begin{array}{l}\text { High-technology index } \\
\text { score }^{\mathrm{a}}\end{array}$ & $3.5(1.34)$ & $1.3(1.45)^{* *}$ \\
\hline $\begin{array}{l}\text { \# emergency } \\
\text { visits/ADC ratio }\end{array}$ & $\begin{array}{l}185.8 \\
(123.90)\end{array}$ & $\begin{array}{l}322.5 \\
(460.40)^{*}\end{array}$ \\
\hline $\begin{array}{l}\text { Metropolitan statistical } \\
\text { area size }^{b}\end{array}$ & $4.3(1.61)$ & $2.4(2.38)^{* *}$ \\
\hline Propensity score & $2.4(1.39)$ & $5.4(1.69)^{* *}$ \\
\hline
\end{tabular}

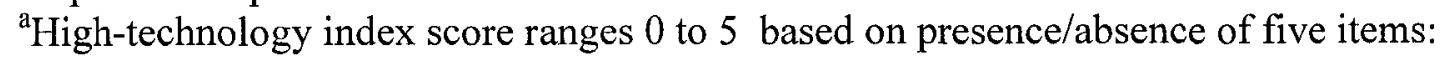
cardiac-catheterization lab, extracorporeal lithotripter, magnetic resonance imaging facility, open-heart surgery facility, organ transplantation capability ${ }^{b}$ Metropolitan statistical area size is an ordinal variable whose values range from 0 to 6 using Census Bureau MSA population size categories of 0 (non-metropolitan, no city $50,000+$ nor more than total population 100,000+), 1 (under 100,000), $2(100,000$ to $250,000), 3$ (250,000 to 500,000$), 4(500,000$ to $1,000,000), 5(1,000,000$ to $2,500,000), 6$ $(2,500,000+)$. 
Table 6 Continued. Testing of Magnet versus non-Magnet Hospital Matching

\begin{tabular}{|c|c|c|c|c|}
\hline & \multicolumn{4}{|c|}{ Matched Control Non-Magnet Hospitals } \\
\hline Characteristic & $\begin{array}{c}1 \\
n=97\end{array}$ & $\begin{array}{c}2 \\
\mathrm{n}=97\end{array}$ & $\begin{array}{c}3 \\
n=97\end{array}$ & $\begin{array}{c}4 \\
n=97 \\
\end{array}$ \\
\hline $\begin{array}{l}\text { Ownership \% } \\
\text { Public } \\
\text { Private for-profit } \\
\text { Private not-for-profit }\end{array}$ & \begin{tabular}{|l|}
12.4 \\
0.0 \\
87.6
\end{tabular} & $\begin{array}{l}17.5 \\
0.0 \\
82.5\end{array}$ & $\begin{array}{l}13.4 \\
0.0 \\
86.6\end{array}$ & $\begin{array}{l}14.4 \\
0.0 \\
85.6\end{array}$ \\
\hline $\begin{array}{l}\text { Member - Council of } \\
\text { Teaching Hospitals \% }\end{array}$ & 46.4 & 44.3 & 45.4 & 42.3 \\
\hline $\begin{array}{l}\text { Hospital size } \\
\text { Average daily Census } \\
\text { (ADC) }\end{array}$ & $\begin{array}{l}322.4 \\
(237.80)\end{array}$ & $\begin{array}{l}288.1 \\
(188.88)\end{array}$ & $\begin{array}{l}330.7 \\
(240.87)\end{array}$ & $\begin{array}{l}270.73 \\
(151.32)^{*}\end{array}$ \\
\hline Hospital beds & \begin{tabular}{|l|}
435.7 \\
$(319.38)$ \\
\end{tabular} & $\begin{array}{l}388.1 \\
(261.36) \\
\end{array}$ & $\begin{array}{l}440.6 \\
(305.77) \\
\end{array}$ & $\begin{array}{l}360.9 \\
(187.04)^{*}\end{array}$ \\
\hline Medicare discharges & \begin{tabular}{|l|}
8246.6 \\
$(6466.72)$ \\
\end{tabular} & $\begin{array}{l}7177.6 \\
(4596.86) \\
\end{array}$ & $\begin{array}{l}8308.5 \\
(5031.27)\end{array}$ & $\begin{array}{l}7018.0 \\
(4343.57)\end{array}$ \\
\hline $\begin{array}{l}\text { Financial Status } \\
\text { Payroll (million } \\
\text { dollars) }\end{array}$ & $\begin{array}{l}137.4 \\
(112.09)\end{array}$ & $\begin{array}{l}121.3 \\
(87.82)\end{array}$ & $\begin{array}{l}138.4 \\
(117.31)\end{array}$ & $\begin{array}{l}104.6 \\
(69.53)^{* *}\end{array}$ \\
\hline Occupancy rate & \begin{tabular}{|l|}
0.74 \\
$(0.17)$ \\
\end{tabular} & $\begin{array}{l}0.75 \\
(0.27)\end{array}$ & $\begin{array}{l}0.74 \\
(0.11) \\
\end{array}$ & $\begin{array}{l}0.74 \\
(0.13)\end{array}$ \\
\hline $\begin{array}{l}\text { Payroll } \\
\text { expense/hospital bed } \\
\text { ratio (1,000 dollars) }\end{array}$ & $\begin{array}{l}334.9 \\
(237.34)\end{array}$ & $\begin{array}{l}323.7 \\
(156.97)\end{array}$ & $\begin{array}{l}307.4 \\
(110.52)\end{array}$ & \begin{tabular}{|l}
291.78 \\
$(104.75)^{*}$
\end{tabular} \\
\hline $\begin{array}{l}\text { High-technology index } \\
\text { score }^{\mathrm{a}}\end{array}$ & $3.5(1.31)$ & $3.6(1.35)$ & $3.5(1.28)$ & $3.5(1.1)$ \\
\hline $\begin{array}{l}\text { \# emergency } \\
\text { visits/ADC ratio }\end{array}$ & $\begin{array}{l}196.2 \\
(126.47)\end{array}$ & $\begin{array}{l}181.2 \\
(103.92)\end{array}$ & $\begin{array}{l}198.1 \\
(110.56)\end{array}$ & $\begin{array}{l}188.6 \\
(92.35)\end{array}$ \\
\hline $\begin{array}{l}\text { Metropolitan statistical } \\
\text { area size }^{\mathrm{b}}\end{array}$ & $4.4(1.62)$ & $4.4(1.66)$ & $4.3(1.70)$ & $4.4(1.57)$ \\
\hline Propensity score & $2.4(1.37)$ & $2.5(1.23)$ & $2.5(1.15)$ & $2.7(1.00)$ \\
\hline
\end{tabular}

* $\mathrm{p}<.01{ }^{* *} \mathrm{p}<.001$

${ }^{a}$ High-technology index score ranges 0 to 5 based on presence/absence of five items: cardiac-catheterization lab, extracorporeal lithotripter, magnetic resonance imaging facility, open-heart surgery facility, organ transplantation capability

${ }^{b}$ Metropolitan statistical area size is an ordinal variable whose values range from 0 to 6 using Census Bureau MSA population size categories of 0 (non-metropolitan, no city $50,000+$ nor more than total population 100,000+), 1 (under 100,000), 2 (100,000 to $250,000), 3$ ( 250,000 to 500,000$), 4$ ( 500,000 to $1,000,000), 5$ (1,000,000 to $2,500,000), 6$ $(2,500,000+)$. 
To generate a sample of between 80 and 130 records (one record per unit consisting of a nurse manager and up to five staff registered nurses), the initial contacting and mailing involved 232 units from 58 hospitals (15 Magnet hospitals and 43 nonMagnet hospitals) with an average of three units from each hospital. The expectation is that these initially contacted units would yield between 80 and 130 units from at least six Magnet and 18 non-Magnet hospitals. The number of Magnet and non-Magnet hospitals in this study, exceeded this expectation.

The final sample for this dissertation consisted of nine Magnet and 23 nonMagnet hospitals. There were a total of 104 completed units and 416 subjects (104 nurse managers and 312 staff registered nurses).

\section{Measures}

There were two primary independent variables in this study. One was nurse status, which is whether a respondent is a unit nurse manager or a unit registered staff nurse. The other independent variable was hospital status with Magnet hospital versus non-Magnet hospital designations deriving from the ANCC classifications.

The measurement package consisted of three self-administered surveys consisting of demographic questions, and standardized assessments for leadership actions and clinical autonomy. The time to complete a package was about 10 minutes.

Demographic questions included information on sex, age, marital status, ethnicity, level of education, years of nursing experience, income, and, for nursing managers, years in management position (see Appendices A and B).

The nursing managers' actions (leadership) construct was assessed using the Nurse Managers' Actions Scale (NMAS) (Mrayyan, 2004) with nursing managers 
reporting their own actions rather than having others [staff nurses] report them as Mrayyan did in her research. This 11-item scale was developed based on literature covering such areas as organizational management (Hersey \& Blanchard, 1988), impact of management on employee retention (Taunton, Krampitz, Woods, 1989a, 1989b; Taunton, Boyle, Woods, Hanson, \& Bott, 1997), and the role of nurse executives (McGillis and Donner, 1997). Each of the 11 items uses a 5-point Likert rating scale regarding frequency of action ranging from 1 "does not do" to 5 "always." The 11 items cover such actions as communicating openly with all team members, supporting nurses in resolving conflicts, allowing self-scheduling, and involving nurses in capital expenditure planning. Scoring is achieved by simply adding up the 11 Likert responses for a total score. A version appropriate to their role was administered to the nursing managers and staff registered nurses (see Appendices C \& D).

Mrayyan (2004) reported on both validity and reliability of the NMAS. Content validity of the NMAS was assessed via a 10-person nurse manager group used as an expert panel. Following the deletion of an item that was not working well and the adding of three items to capture panel recommended areas of nurse action, a final scale of 11 items was developed. The internal consistency of the 11-item scale was acceptable (Cronbach alpha $=.88)$ using the .70 criterion set by Thorndike (1982).

The nursing clinical autonomy construct was assessed using the Autonomy Scale (AS) developed by Blegen, Goode, Johnson, Maas, Chen, \& Moorhead (1993). This 42item scale assesses two areas of autonomy: patient care and unit operations. It was given to both nurse managers and staff registered nurses. Blegen et al. used an expert panel and grouped the patient care items into four groups: defining patient care provision, 
enhancing staff collaboration, handling patient and physician complaints, and resolving diagnosis and discharge-related issues. The panel also grouped the unit operations items into four groups: organizing their own work, planning to deliver high quality care, developing and revising patient care procedures, and managing unit resources. This $42-$ item scale uses a 5-point response choice ranging from 1 "nurses have no authority and accountability" to 5 "nurses have full independent authority and accountability" (see Appendix E). Scoring for this instrument was achieved by summing the 21 items for patient care decisions and the 21 items for the unit operation decisions separately. These 2 sub-scale scores were used in this study. Adding these two sub-scales together would generate a total score. Content validity was evaluated as satisfactory by the expert panel. Reliability was acceptable for both the AS patient care subscale (Cronbach alpha $=.78$ ) and the AS unit operations subscale (Cronbach alpha = .92).

\section{Data Collection Procedures}

As was done in Sales' (2004) VA hospital research, each Chief Nursing Officer was contacted through email and/or phone and this officer was requested to provide a list of nursing units in the facility with the nurse managers of each unit identified. Chief Nursing Officers were initially contacted via email addresses obtained from marketing services (e.g., http://www.Salesuniverse.com) and existing web sites (e.g., http://nursingworld.org/ancc/Magnet/facilites.html\#PA, which contains emails of CNOs for all Magnet hospitals). Such use of email has become more common in this type of research (Sheehan \& Hoy, 1999). Previous research has demonstrated that having identified contacts within a hospital and, by extension, within a hospital unit, increases 
the likelihood of good response rates. For example, Mark, Sayler, and Wan (2003) had an identified 'study coordinator' for each hospital.

After the contact with the CNO and the nurse managers, a package of up to six coded, stamped, addressed, return envelopes containing an introductory statement, a request to participate and a consent form was mailed to each nurse manager. See Appendix for these communications and instruments. Each nurse manager was asked to call the researcher upon receipt of the package. In case of lost packages, a substitute package was sent. Codes on the envelopes allowed identification of which hospital and which unit.

The nurse manager was instructed to contact up to five staff registered nurses on the unit. The choice of staff registered nurses was to be carried out by using an alphabetical order of last names. For any unit, at least a single staff registered nurse responding was required in order to have a useable unit data record. This was because each unit was represented as a single record of data including the nurse manager's responses to the manager-designated instruments and staff registered nurses' response to the staff nurse-designated instruments. When there was more than a single staff registered nurse responding from a unit, the data were averaged across the nurses from that unit.

The instruments that were included accessed each of the constructs needed to test the hypotheses in this research.

\section{Data Analysis}

First, Magnet versus non-Magnet hospitals were compared regarding the matching criteria to determine how well the matching worked. 
Second, testing was done comparing Magnet and non-Magnet hospitals for demographic differences of managers and of staff registered nurses.

Third, an evaluation of the distributional properties of each variable of interest was conducted. This included testing whether statistical assumptions for parametric statistics were met. This was accomplished through testing for normality of each continuous variable checking skewness and kurtosis as well as testing for differences in variance between groups on each variable. In order for deviations from normality to be a problem in statistical analyses, such deviations must be egregious, defined as a z-score value over 5 or 10 . Although a $z$-score is technically statistically significant at $1.96(\mathrm{p}<$ $.05)$, parametric statistics are very robust to violations of the assumption of normality. Hence, unless there is an extreme violation of this parametric assumption, violations may be ignored generally.

Fourth, the following specific hypotheses were evaluated:

[1] Magnet hospitals would have more positive nurse manager leadership traits than nonMagnet hospitals. This hypothesis was tested using the main effect for hospital type from the ANOVA.

[2] Magnet hospitals would be higher on nurse clinical autonomy than non-Magnet hospitals. This hypothesis was tested using the ANOVA main effect for hospital type. [3] Positive nurse manager leadership traits as self-report versus such traits as reported by staff registered nurses would be less different within Magnet hospitals than within nonMagnet hospitals. This hypothesis was tested using the nursing type by hospital type interaction effect from the ANOVA with the expectancy that there would be a significant interaction. 
[4] Nurse clinical autonomy as self-report versus such autonomy as reported by nursing managers would be less different within Magnet hospitals than within non-Magnet hospitals. This hypothesis was also tested using the nursing type by hospital type interaction effect from the ANOVA with the expectancy that there would be a significant interaction.

[5] Positive nurse manager leadership traits and nurse clinical autonomy would be positively correlated. This hypothesis was tested using the Pearson product moment correlation.

[6] Compared to Magnet hospitals, non-Magnet hospitals' positive nurse manager leadership traits and nurse clinical autonomy would have lower correlations. The difference between correlations procedure was used to test this hypothesis.

[7] The mediation model would better fit the data than the common cause model. That is, a model where hospital type causes positive nurse manager leadership traits that, in turn, cause higher nurse clinical autonomy would better fit the data than a model where nurse manager leadership traits and nurse clinical autonomy are related to each other because both are caused by hospital type. Although the intent was to use multiple linear regression to test this hypothesis, given the absence of a significant relationship between Magnet hospital status and the dependent variables, this test was not run.

For statistical significance testing, alpha was set at .05 .

\section{Human Subjects Research}

\section{An Overview of Subject Selection and Characteristics.}

The composition of the sample being studied was established by the requirements of subject selection per the purpose, aims, and hypotheses of the study. Subjects were 
recruited between September 2005 and February 2007. These volunteer subjects were professionals working in hospitals in the roles of register nurse managers and registered staff nurses. There were no age, sex, or ethnicity criteria for enrollment. It is also important to note that none of these subjects were selected because of any present mental illness, and there were no subpopulations chosen because of pregnancy, prisoner status, institutionalization, or for any specific characteristic other than their professional role in a hospital. Hence, this sample was not from a vulnerable population.

Inclusion of Women. Given the professional roles of the subjects recruited for this study, the majority were female. There were 2.7 million nurses in the United States in 2000. Only an estimated 146,902 , or 5.4 percent, were men, and males accounted for about 8 percent of students enrolled in four-year college nursing programs, according to a 2000 survey by the Division of Nursing of the U.S. Department of Health and Human Services (Daily Health News Headlines from Healthfinder.gov, 2003). The percent of males in this study sample was low, $10.6 \%$ managers and $8.3 \%$ staff registered nurses. Therefore, we believe that this investigation adequately gathered information representative of female and male RNs.

Inclusion of Minorities. Silver (2003) reports Geraldine Bednash, PhD., executive director of the American Association of Colleges of Nursing (AACN) in Washington, D.C. as stating that 13.4 percent of registered nurses are minorities while minorities constitute 30 percent of the population. Nonetheless, minorities were present in the current study population.

Inclusion of Children. Due to the nature of the research question, there were no children in the study's sample. 


\section{$\underline{\text { Sources of Research Material. }}$}

The research data gathered were generated from an internet based questionnaire site. There were three questionnaires: a demographic survey asking for basic descriptive information, a questionnaire assessing nurse manger leadership attributes, and a questionnaire measuring registered nurse autonomy. All materials were limited to specific research purposes that were outlined in the proposal.

\section{Potential Risks.}

No significant risks are known to be associated with the proposed protocol. As described in the proposal, the only request of subjects was to fill out a brief demographic questionnaire and two psychometrically sound instruments used in published research to assess leadership attributes and autonomy. Subjects were free not to participate and free to refuse any questions or testing they would like. No medications or similar materials were being administered to subjects, and no blood draws or invasive procedures were included in this protocol.

The risk for psychological harm through responding to these questionnaires and rating items on questionnaires regarding leadership attributes and nurse autonomy was minimal. These questionnaires have been used in previous research without reports of such harm. Still, it is possible that a subject might have experience minor anxiety while filling out the questionnaires, although none reported this. 


\section{Procedures for Protecting Subjects and Minimizing Risks.}

In this study, the protection of human subjects was an important consideration. All subjects were given a copy of the "Experimental Human Subject's Bill of Rights." Additionally, the following briefly describes the other steps taken.

Informed Consent. Each subject was provided a research package. This package included a consent form, an introductory statement and a request to participate letter, the questionnaires, and a stamped return envelope. Participants were given consent for being included in the research via their signing of the consent form. They then filled out the questionnaires and, once completing them, mailed the stamped return envelope. This consent process, the use of mailed and return mailed questionnaires, as well as the protocols for managing the data were evaluated by three IRBs: University of San Diego, the University of California San Diego/VA San Diego Healthcare System, and the Eastern Connecticut University Medical Center.

Procedures to Protect Confidentiality. Careful procedures were instituted to protect confidentiality. These included the following: (1) the research package was under the control of the individual subject once she or he received it; (2) consent forms were stored separately from questionnaire forms; (3) any information that connects subjects' names with any specific data was kept in a locked file cabinet with access limited only to the research personnel working on this protocol; and (4) access to the computer storage of information was limited only to those individuals directly involved in this study.

Special considerations were taken regarding maintaining security of computerized data. These included: (1) using complex passwords for access; (2) avoiding any easily guessed password for any of the datasets; (3) working with computer experts; (4) storing 
and analyzing data on a computer system isolated from the internet; and (5) taking steps to build a wall against Trojan-horse-like programs.

All Personnel Are Well Trained and Are Monitored Regarding Maintenance of Confidentiality and Other Human Subjects Protection Issues.

All research staff were trained regarding confidentiality procedures. All consent forms were in accordance with HIPAA regulations and the IRBs. All project staff working on the study complied with HIPAA regulations by taking online training, including: (1) Research Aspects of HIPAA Tutorial, (2) Basic Principles of Human Research Subjects Protection, and (3) Basic HIPAA 1021: Workforce Training. Anyone working on the study also complied with HIPAA regulations by signing a Healthcare Confidentiality Agreement. Part of this training and ongoing supervision involved reminders regarding the need to never put identifying information inappropriately into the computer or onto any of the research instruments. Once a questionnaire set had been received, no identifying information was kept in the same database as the completed questionnaires. Identifying data were kept in a locked file cabinet with access limited to the doctoral student and the specific research assistants for whom such information was essential. Furthermore, a series of safety measures were developed, and there was limited access to information stored in password-protected computers.

Potential Benefits of the Proposed Research and the Safety Ratio.

Through the evaluation of relationships among hospital type, leadership characteristics, and level of nurse autonomy, this research will help identify leadership traits and attributes that empower nurse autonomy, which is related to better nurse recruitment, nurse job satisfaction, nurse retention, and patient outcomes. This research 
also emphasizes the importance of doing quantitative research to demonstrate assumed relationships among important nursing constructs. The results allow an evaluation of the relevance of structural contingency theory and underscore the importance of training nurse managers so that their leadership attributes serve the goals of the hospital organization.

When one considers the low level of risk involved in the type of information gathering that was proposed here, the careful steps to optimize confidentiality, and the potential benefits of the research, the ratio of risks to potential benefits appeared to be extremely low.

Finally, for participating in this research, each subject was entered in a drawing to receive $\$ 250.00$. 
Chapter 4. Results

\section{Sample}

The data analyzed here came from a final sample of 416 subjects (104 nurse managers and 312 staff registered nurses) representing 104 completed units for 9 Magnet and 23 non-Magnet hospitals. These data were collected between September 2005 and February 2007. The response rate for hospitals was 55\% (32 of 58 contacted hospitals) and for completed units the response rate was $60 \%$ (104 of 174). Of those that were completed, there was an average of 3.25 units per hospital and 3 nurses per unit. Comparing Characteristics of the Magnet and Non-Magnet Hospitals. Table 7 presents the comparisons of 9 Magnet and 23 non-Magnet hospitals on the 11 hospital characteristics that were used in the original matching of non-Magnet to Magnet hospitals. Also for information purposes, the propensity scores for Magnet versus nonMagnet hospitals are provided. These statistical analyses were run in order to evaluate whether the matching procedures were successful. There were no statistically significant differences between Magnet and non-Magnet hospitals for any variable in Table 7, including the propensity score. Hence, the matching was quite successful. 
Table 7. Hospital Subset Characteristics Compared for Magnet and Non-Magnet Matching*

\begin{tabular}{|l|c|c|}
\hline Characteristic & $\begin{array}{l}\text { Magnet } \\
\mathrm{N}=9\end{array}$ & $\begin{array}{l}\text { Non-Magnet } \\
\mathrm{n}=23\end{array}$ \\
\hline $\begin{array}{l}\text { Ownership public vs. private not-for-profit } \\
\mathrm{N}(\%) \text { private not-for-profit }\end{array}$ & $7(77.8)$ & $17(73.9)$ \\
\hline $\begin{array}{l}\text { Member - Council of Teaching Hospitals } \\
\mathrm{N}(\%)\end{array}$ & $2(22.2)$ & $12(52.2)$ \\
\hline $\begin{array}{l}\text { Hospital size Average daily Census (ADC) } \\
\text { mean (sd) }\end{array}$ & $328.7(144.18)$ & $271.4(132.87)$ \\
\hline Hospital beds mean (sd) & $422.0(180.61)$ & $372.7(197.30)$ \\
\hline Medicare discharges mean (sd) & $7481.1(6072.58)$ & $6155.3(5045.62)$ \\
\hline $\begin{array}{l}\text { Financial Status Payroll (million dollars) } \\
\text { mean (sd) }\end{array}$ & $127.0(58.75)$ & $112.3(58.17)$ \\
\hline Occupancy rate mean (sd) & $0.8(0.24)$ & $0.7(0.10)$ \\
\hline $\begin{array}{l}\text { Payroll expense/hospital bed ratio (1,000 } \\
\text { dollars) mean (sd) }\end{array}$ & $317.0(139.42)$ & $340.0(181.78)$ \\
\hline High-technology index score mean (sd) & $3.3(1.00)$ & $3.5(0.99)$ \\
\hline \# emergency visits/ADC ratio mean (sd) & $210.7(132.11)$ & $165.9(113.73)$ \\
\hline Metropolitan statistical area size ${ }^{\mathrm{b}}$ mean (sd) & $4.0(1.12)$ & $4.4(1.70)$ \\
\hline Propensity score mean (sd) & $2.8(1.00)$ & $2.5(0.90)$ \\
\hline
\end{tabular}

* No difference between Magnet and non-Magnet Hospitals was statistically significant. ${ }^{a} \mathrm{High}$-technology index score ranges 0 to 5 based on presence/absence of five items: cardiac-catheterization lab, extracorporeal lithotripter, magnetic resonance imaging facility, open-heart surgery facility, organ transplantation capability ${ }^{\mathrm{b}}$ Metropolitan statistical area size is an ordinal variable whose values range from 0 to 6 using Census Bureau MSA population size categories of 0 (non-metropolitan, no city $50,000+$ nor more than total population 100,000+), 1 (under 100,000), $2(100,000$ to $250,000), 3$ (250,000 to 500,000$), 4(500,000$ to $1,000,000), 5(1,000,000$ to $2,500,000), 6$ $(2,500,000+)$.

\section{Managers' and Staff Registered Nurses' Demographics Compared Between}

Magnet and Non-Magnet Hospitals. For demographic information, data are grouped according to nurse status as managers or staff registered nurses. See Table 8 for nurse manager demographics and Table 9 for staff registered nurse demographics. These tables also report tests of differences between Magnet and non-Magnet hospitals. For analyses, the few values that were missing were imputed via an SPSS Missing Values Analysis 
procedure. Unlike simple mean substation, this procedure maintains existing relationships among the variables and does not distort the standardized error terms.

For both managers and staff registered nurses, the average age was in the 40's, most were females, nonHispanic, Caucasian, and married. Regarding education levels, most managers $(87.5 \%)$ had at least a bachelor degree with $52.6 \%$ of staff registered nurses having a least a bachelor degree. For managers, average years as registered nurse $=22.0$, average years as a manager $=9.3$, average years in current position $=5.2$, average years with their $\mathrm{CNO}=6.9$, average hours/week $=48.9$, and average yearly salary $=$ $\$ 87,155$. Of these managers, $80 \%$ belonged to a professional nursing organization. For staff registered nurses, average years as registered nurse $=13.1$, average years on the unit $=7.4$, average years with their manager $=3.9$, average hours $/$ week $=36.8$, and average salary $=\$ 59,070$. Of these staff registered nurses, $55.8 \%$ belonged to a professional nursing organization.

Regarding demographic differences between Magnet and non-Magnet hospitals, for nurses there no significant differences other than a difference in percent of nonHispanic individuals (Magnet $=85.5 \%$, non-Magnet $=98.3 \%$ ). For managers, there were a number of significant differences between Magnet and non-Magnet hospitals. For managers, there was also a difference in non-Hispanic individuals (Magnet $=83.3 \%$, nonMagnet $=95.59 \%$ ) reflecting the difference found for staff registered nurses. Other significant manager differences between the 2 hospital types were for age (Magnet $=$ 42.4 , non-Magnet $=48.3$, years as registered nurse $($ Magnet $=17.8$, non-Magnet $=23.7)$ and years as manager $($ Magnet $=6.6$, non-Magnet $=10.3$ ). 
Table 8. Manager Demographic Variables and Comparison of Magnet versus NonMagnet Hospitals

\begin{tabular}{|c|c|c|c|c|}
\hline Variables & $\begin{array}{c}\text { All Managers } \\
\quad \mathrm{N}=104\end{array}$ & $\begin{array}{c}\text { Magnet } \\
\text { Managers } \\
\mathrm{N}=30\end{array}$ & $\begin{array}{c}\text { Non-Magnet } \\
\text { Managers } \\
N=74\end{array}$ & $\begin{array}{l}\text { Statistical } \\
\text { Test } \\
\text { t-test or } \chi^{2}\end{array}$ \\
\hline Female N (\%) & $93(89.4)$ & $25(83.3)$ & $68(91.9)$ & 1.65 \\
\hline Age mean (sd) & $46.6(8.21)$ & $42.4(7.31)$ & $48.3(8.01)$ & $3.45^{* *}$ \\
\hline $\begin{array}{l}\text { Marital Status N }(\%) \\
\text { Single } \\
\text { Married } \\
\text { Divorced } \\
\text { Widowed }\end{array}$ & $\begin{array}{l}13(12.5) \\
73(70.2) \\
17(16.3) \\
1(1.0)\end{array}$ & $\begin{array}{c}5(16.7) \\
22(73.3) \\
3(10.0) \\
0(0.0)\end{array}$ & $\begin{array}{c}8(10.8) \\
51(68.9) \\
14(18.9) \\
1(1.4)\end{array}$ & 2.09 \\
\hline $\begin{array}{l}\text { Ethnicity Non-Hispanic N } \\
(\%)\end{array}$ & $96(92.3)$ & $25(83.3)$ & $71(95.9)$ & $4.78 *$ \\
\hline $\begin{array}{l}\text { Race N (\%) } \\
\text { Caucasian } \\
\text { African-American } \\
\text { Asian }\end{array}$ & $\begin{array}{c}89(85.6) \\
9(8.7) \\
6(5.8)\end{array}$ & $\begin{array}{l}24(80.0) \\
3(10.0) \\
3(10.0)\end{array}$ & $\begin{array}{c}65(87.8) \\
6(8.1) \\
3(4.1)\end{array}$ & 1.55 \\
\hline $\begin{array}{l}\text { Education N (\%) } \\
\text { Diploma } \\
\text { Associate } \\
\text { Bachelor } \\
\text { Masters } \\
\text { Doctorate }\end{array}$ & $\begin{array}{c}4(3.8) \\
9(8.7) \\
47(45.2) \\
43(41.3) \\
1(1.0)\end{array}$ & $\begin{array}{c}1(3.3) \\
2(6.7) \\
14(46.7) \\
13(43.3) \\
0(0.0)\end{array}$ & $\begin{array}{c}3(4.1) \\
7(9.5) \\
33(44.6) \\
30(40.5) \\
1(1.4)\end{array}$ & 0.69 \\
\hline $\begin{array}{l}\text { Years Registered Nurse } \\
\text { mean (sd) }\end{array}$ & $22.0(8.59)$ & $17.8(6.74)$ & $23.7(8.71)$ & $3.32 *$ \\
\hline $\begin{array}{l}\text { Years as Manager mean } \\
\text { (sd) }\end{array}$ & $9.3(8.14)$ & $6.6(6.48)$ & $10.3(8.54)$ & $2.15^{*}$ \\
\hline $\begin{array}{l}\text { Years Current Position } \\
\text { mean (sd) }\end{array}$ & $5.2(5.20)$ & $5.3(5.01)$ & $5.1(5.30)$ & -0.20 \\
\hline $\begin{array}{l}\text { Years with CNO mean } \\
\text { (sd) }\end{array}$ & $6.9(6.26)$ & $7.3(5.31)$ & $6.7(6.63)$ & -0.46 \\
\hline Hours/Week mean (sd) & $48.9(10.72)$ & $47.4(11.63)$ & $49.4(10.36)$ & 0.87 \\
\hline $\begin{array}{l}\text { Nurse Organization } N \\
(\%)\end{array}$ & $80(76.9)$ & $21(70.0)$ & $59(79.7)$ & 1.14 \\
\hline Yearly Salary mean (sd) & $\begin{array}{c}87,155.03 \\
(18,050.86)\end{array}$ & $\begin{array}{c}85,409.86 \\
(11,123.33) \\
\end{array}$ & $\begin{array}{c}87,862.54 \\
(20,219.46)\end{array}$ & 0.63 \\
\hline
\end{tabular}

$*=\mathrm{p}<.05 \quad * *=\mathrm{p}<.001$ 
Table 9. Staff Registered Nurse Demographic Variables and Comparison of Magnet versus Non-Magnet Hospitals

\begin{tabular}{|c|c|c|c|c|}
\hline Variables & $\begin{array}{c}\text { All Nurses } \\
\mathrm{N}=312 \\
\end{array}$ & $\begin{array}{l}\text { Magnet } \\
\text { Nurses } \\
\mathrm{N}=83\end{array}$ & $\begin{array}{c}\text { Non-Magnet } \\
\text { Nurses } \\
\mathrm{N}=229 \\
\end{array}$ & $\begin{array}{l}\text { Statistical } \\
\text { Test } \\
\text { t-test or } \chi^{2} \\
\end{array}$ \\
\hline Female N $(\%)$ & $286(91.7)$ & $72(86.7)$ & $214(93.4)$ & 3.58 \\
\hline Age mean (sd) & $40.7(10.72)$ & $41.5(10.24)$ & $40.4(10.90)$ & -.078 \\
\hline $\begin{array}{l}\text { Marital Status N }(\%) \\
\text { Single } \\
\text { Married } \\
\text { Separated } \\
\text { Divorced } \\
\text { Widowed }\end{array}$ & $\begin{array}{c}65(20.8) \\
190(60.9) \\
5(1.6) \\
46(14.7) \\
6(1.9)\end{array}$ & $\begin{array}{c}15(18.1) \\
52(62.7) \\
2(2.4) \\
11(13.0) \\
3(3.6)\end{array}$ & $\begin{array}{c}50(21.8) \\
138(60.3) \\
3(1.3) \\
35(15.3) \\
3(1.3)\end{array}$ & 2.78 \\
\hline $\begin{array}{l}\text { Ethnicity Non- } \\
\text { Hispanic N (\%) }\end{array}$ & $296(94.9)$ & $71(85.5)$ & $225(98.3)$ & $20.23 * *$ \\
\hline $\begin{array}{l}\text { Race N (\%) } \\
\text { Caucasian } \\
\text { African-American } \\
\text { Asian }\end{array}$ & $\begin{array}{c}259(83.0) \\
18(5.8) \\
35(11.2) \\
\end{array}$ & $\begin{array}{c}70(84.3) \\
3(3.6) \\
10(12.0) \\
\end{array}$ & $\begin{array}{c}189(82.5) \\
15(6.6) \\
25(20.9) \\
\end{array}$ & 1.00 \\
\hline $\begin{array}{l}\text { Education N (\%) } \\
\text { Diploma } \\
\text { Associate } \\
\text { Bachelor } \\
\text { Masters }\end{array}$ & $\begin{array}{c}22(7.1) \\
124(39.7) \\
145(46.5) \\
19(6.1)\end{array}$ & $\begin{aligned} 7 & (8.4) \\
31 & (37.3) \\
41 & (49.4) \\
4 & (4.8)\end{aligned}$ & $\begin{array}{c}15(6.6) \\
93(40.6) \\
104(45.4) \\
15(6.6)\end{array}$ & 1.70 \\
\hline $\begin{array}{l}\text { Years Registered } \\
\text { Nurse mean (sd) } \\
\text { Yearc on Init }\end{array}$ & $\frac{13.1(10.08)}{74(718)}$ & $\frac{13.8(10.06)}{84(718)}$ & $\frac{12.9(10.10)}{70(716)}$ & $\frac{-0.75}{-150}$ \\
\hline $\begin{array}{l}\text { Years with Manager } \\
\text { mean (sd) }\end{array}$ & $3.9(3.96)$ & $4.2(3.60)$ & $3.8(4.08)$ & -.081 \\
\hline $\begin{array}{l}\text { Hours/Week } \\
\text { mean(sd) }\end{array}$ & $36.8(7.13)$ & $37.0(6.68)$ & $36.8(7.54)$ & -0.15 \\
\hline $\begin{array}{l}\text { Nurse Organization } \\
N(\%)\end{array}$ & $174(55.8)$ & $41(49.4)$ & $133(58.1)$ & 1.86 \\
\hline $\begin{array}{l}\text { Yearly Salary } \\
\text { mean(sd) }\end{array}$ & $\begin{array}{c}59,070.63 \\
(16,292.27)\end{array}$ & $\begin{array}{c}59,416.50 \\
(16,375.95)\end{array}$ & $\begin{array}{c}58,945.27 \\
(16,296.00)\end{array}$ & -0.22 \\
\hline
\end{tabular}

$*=\mathrm{p}<.05 \quad * *=\mathrm{p}<.001$

Evaluating Distributional Properties and Variances of the Six Dependent Variables

Testing for normality was carried out for the 6 dependent variables of interest.

Managers and staff registered nurses each filled out 3 scales: Nurse Manager's Action

Scale (NMAS) and two subscales of the nurse Autonomy Scale (AS) one subscale for the 
patient and one subscale for the unit. The evaluation of the assumption of normality for the 6 scales yielded no egregious violation for the 2 parameters representing normality, skewness and kurtosis. The z-scores for skewness and kurtosis for the 6 dependent variables are presented in Table 10. Four of the $12 \mathrm{z}$-scores were significant at $\mathrm{p}<.05$ and two were significant at $p<.001$. Nonetheless, only one of the $12 \mathrm{z}$-scores was greater than 5 and none were greater than 10 . Hence, no normality assumption violation would be defined as egregious and, therefore, no transformations were necessary.

Table 10. Evaluations of Parametric Assumptions of Normality (Skewness and Kurtosis) and Equality of Variances for the Six Dependent Variables and Presenting Their Means and Standard Deviations

\begin{tabular}{|l|c|c|c|c|c|c|}
\hline $\begin{array}{l}\text { Dependent } \\
\text { Variables }\end{array}$ & $\begin{array}{c}\text { Scale } \\
\text { mean } \\
(\mathrm{sd})\end{array}$ & Skewness & $\begin{array}{c}\text { Skewness } \\
\text { z-score }\end{array}$ & Kurtosis & $\begin{array}{c}\text { Kurtosis z- } \\
\text { score }\end{array}$ & $\begin{array}{c}\text { Levene's } \\
\text { Test via } \\
\text { F-test }\end{array}$ \\
\hline Managers & & & & & & \\
\hline NMAS & $4.1(0.46$ & -0.492 & $-2.08^{*}$ & 0.43 & 0.09 & 0.52 \\
\hline AS-patient & $4.0(0.48)$ & -0.473 & $-2.00^{*}$ & -0.173 & -0.37 & 0.60 \\
\hline AS-unit & $3.2(0.63)$ & 0.301 & 1.27 & -0.303 & -0.65 & 0.49 \\
\hline $\begin{array}{l}\text { Staff } \\
\text { Registered } \\
\text { Nurses }\end{array}$ & & & & & & \\
\hline NMAS & $3.8(0.55)$ & -0.292 & -1.23 & -0.57 & -1.22 & $5.88^{*}$ \\
\hline AS-patient & $4.2(0.32$ & -1.021 & $-4.31^{* *}$ & 3.21 & $6.84^{\mathrm{b}}$ & 0.50 \\
\hline AS-unit & $3.3(0.56)$ & -0.127 & -0.54 & 0.511 & 1.09 & 0.60 \\
\hline
\end{tabular}

Table 10 also presents evaluations of homogeneity of variance, an additional assumption of parametric statistics. These were conducted within the ANOVA runs reported below. Using the Levene's Test of Equality of Error Variances, 5 of the 6 dependent variables had F-tests less than 1 reflecting the absence of any effect. Hence for these 5 , the parametric assumption of homogeneity of variances was met. For the other dependent variable, staff registered nurse rated management leadership 
characteristics, the F-test was significant $(F(1,102)=5.88, p<.02)$. This means that the assumption of homogeneity of variance for this dependent variable was not met.

Violating such an assumption increases the likelihood of a Type I error, finding a significant result when the actual effect is not present. However, as reported below, the ANOVA for this dependent variable did not yield a significant effect. Hence, the violation of this assumption had no appreciable influence.

Testing of the Seven Formal Hypotheses

In order to test hypotheses numbers 1 through 4, a 2 (Hospital Type: Magnet vs. non-Magnet) by 2 (Nurse Status: Manager vs. Staff Registered Nurse) mixed design ANOVA with Nurse Status as the repeated measure was run for each of the 3 scales. Tables 11,12 , and 13 report the means and standard deviations for these analyses. Hypothesis 1: Magnet hospitals would have more positive nurse manager leadership traits than non-Magnet hospitals. This hypothesis was tested using the ANOVA main effect for hospital type. The main effect for hospital type was not significant $[F(1,102)=1.07, p=.31]$. This hypothesis was not supported. See Table 11 for means and standard deviations.

Hypothesis 2: Magnet hospitals would be higher on the nurse clinical autonomy than non-Magnet hospitals. This hypothesis was tested using the ANOVA main effect for hospital type. For the dependent variable Autonomy Scale for patient, the main effect for hospital type was not significant $[F(1,102)=2.40, p=.13]$. This hypothesis was not supported. See Table 12 for means and standard deviations. For the dependent variable Autonomy Scale for unit, the main effect for hospital type was not significant $[F(1,102)=$ 
2.13, $\mathrm{p}=.15]$. This hypothesis was not supported. See Table 13 for means and standard deviations.

Table 11. Means and Standard Deviations of the Nurse Manager's Action Scale (NMAS) within the 2 (Hospital Type) by 2 (Nurse Status) mixed design ANOVA

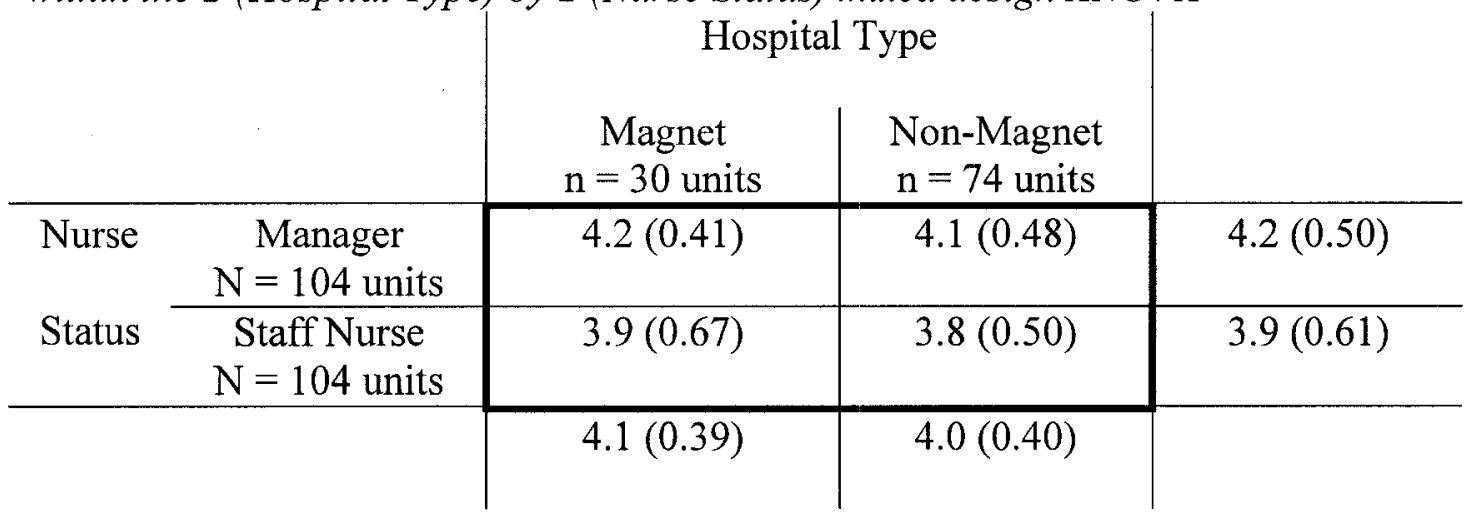

Table 12. Means and Standard Deviations of the Autonomy Scale-Patient within the 2 (Hospital Type) by 2 (Nurse Status) mixed design ANOVA

\begin{tabular}{|c|c|c|c|c|}
\hline \multirow{2}{*}{\multicolumn{2}{|c|}{ 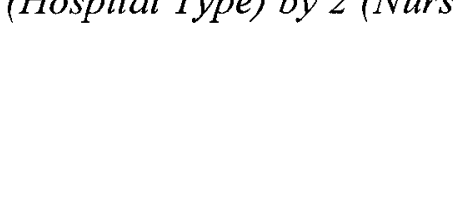 }} & \multicolumn{2}{|c|}{ Hospital Type } & \\
\hline & & $\begin{array}{c}\text { Magnet } \\
\mathrm{n}=30 \text { units }\end{array}$ & $\begin{array}{l}\text { Non-Magnet } \\
\mathrm{n}=74 \text { units }\end{array}$ & \\
\hline Nurse & $\begin{array}{c}\text { Manager } \\
\mathrm{N}=104 \text { units }\end{array}$ & $4.0(0.48)$ & $3.9(0.48)$ & $4.0(0.53)$ \\
\hline \multirow[t]{2}{*}{ Status } & $\begin{array}{c}\text { Staff Nurse } \\
\mathrm{N}=104 \text { units }\end{array}$ & $4.3(0.30)$ & $4.2(0.32)$ & $4.0(0.35)$ \\
\hline & & $4.2(0.31)$ & $4.1(0.30)$ & \\
\hline
\end{tabular}

Table 13. Means and Standard Deviations of the Autonomy Scale-Unit within the 2 (Hospital Type) by 2 (Nurse Status) mixed design ANOVA

\begin{tabular}{cc|c|c|c} 
& \multicolumn{2}{|c|}{$\begin{array}{l}\text { Hospital Type } \\
\text { Magnet }\end{array}$} & $\begin{array}{c}\text { Non-Magnet } \\
\mathrm{n}=74 \text { units }\end{array}$ & \\
\hline \multirow{2}{*}{ Nurse } & $\begin{array}{c}\text { Manager } \\
\mathrm{N}=104 \text { units }\end{array}$ & $3.3(0.60)$ & $3.2(0.64)$ & $3.2(0.61)$ \\
\cline { 2 - 5 } & $\begin{array}{c}\text { Staff Nurse } \\
\mathrm{N}=104 \text { units }\end{array}$ & $3.5(0.61)$ & $3.3(0.52)$ & $3.4(0.69)$ \\
\hline & & $3.4(0.44)$ & $3.2(0.43)$ & \\
& & & &
\end{tabular}


Hypothesis 3: Positive nurse manager leadership traits (NMAS) as self-report versus such traits as reported by staff registered nurses would be less different within Magnet hospitals then within non-Magnet hospitals. This hypothesis was tested using the nursing type by hospital type interaction effect from the ANOVA with the expectancy that there would be a significant interaction. The interaction was not significant $[F(1,102)=0.02, p=.90]$. This hypothesis was not supported. See Table 11 for means and standard deviations.

Hypothesis 4: Nurse clinical autonomy as self-report versus such autonomy as reported by nursing managers would be less different within Magnet hospitals than within non-Magnet hospitals. This hypothesis for the Autonomy Scale for patient was tested using the nursing type by hospital type interaction effect from the ANOVA with the expectancy that there would be a significant interaction. The interaction was not significant $[F(1,102)=0.00, p=.96]$. This hypothesis was not supported. See Table 12 for means and standard deviations. This hypothesis for the Autonomy Scale for unit was also tested using the nursing type by hospital type interaction effect from the ANOVA with the expectancy that there would be a significant interaction. The interaction was not significant $[F(1,102)=0.73, p=.40]$. This hypothesis was not supported. See Table 13 for means and standard deviations.

Hypothesis 5: Positive nurse manager leadership traits and nurse clinical autonomy would be positively correlated. This hypothesis was tested using the Pearson product moment correlation. There were three tests of this hypothesis: using the 
dependent variables from the managers alone, from the staff registered nurses alone, and then across managers to staff registered nurses. See Table 14 for the correlation matrix.

Table 14. Correlation Matrix of Manager and Staff Registered Nurse Ratings of Manager Attributes and Nurse Autonomy [N=104 units]

\begin{tabular}{|l|c|c|c|c|c|}
\hline Variables & $\begin{array}{c}\text { Manager } \\
\mathrm{ASp}\end{array}$ & $\begin{array}{c}\text { Manager } \\
\mathrm{ASu}\end{array}$ & $\begin{array}{c}\text { Nurse } \\
\text { NMAS }\end{array}$ & Nurse ASp & Nurse ASu \\
\hline $\begin{array}{l}\text { Manager } \\
\text { NMAS }\end{array}$ & $.36^{* * *}$ & $.53^{* * *}$ & $.21^{*}$ & .15 & .17 \\
\hline $\begin{array}{l}\text { Manager } \\
\text { Asp }\end{array}$ & & $.42^{* * *}$ & .11 & .14 & .18 \\
\hline $\begin{array}{l}\text { Manager } \\
\text { ASu }\end{array}$ & & & $.20^{*}$ & .08 & .11 \\
\hline $\begin{array}{l}\text { Nurse } \\
\text { NMAS }\end{array}$ & & & & $.31^{* *}$ & $.48^{* * *}$ \\
\hline $\begin{array}{l}\text { Nurse } \\
\text { Asp }\end{array}$ & & & & & $.41^{* * *}$ \\
\hline
\end{tabular}

$*=\mathrm{p}<.05 \quad * *=\mathrm{p}<.01 \quad * * *=\mathrm{p}<.001$

Manager NMAS $=$ Manager rated Nurse Manager Action Scale

Manager ASp $=\quad$ Manager rated nurse Autonomy Scale for patients

Manager $\mathrm{ASu}=\quad$ Manager rated nurse Autonomy Scale for unit operations

Nurse NMAS $=$ Nurse rated Nurse Manager Action Scale

Nurse ASp $=\quad$ Nurse rated nurse Autonomy Scale for patients

Nurse $\mathrm{ASu}=\quad$ Nurse rated nurse Autonomy Scale for unit operations

The first test of this hypothesis, using only managers, yielded significant results for each correlation. Managers' ratings of their own attributes were positively related to their ratings of both clinical nurse autonomy for patients and for unit operations.

The second test of this hypothesis, using only nurses, yielded significant results for each correlation. Staff Registered Nurses' ratings of their manager's attributes were positively related to their ratings of both their own clinical nurse autonomy for patients and for unit operations. The results of this second test of this hypothesis replicate the findings of Mrayyan (2004) showing that if nurses are asked to rate manager attributes and their own clinical autonomy regarding patients and unit operations all three variables are positively related to each other. 
The third test of this hypothesis examining the relationship between ratings by managers and by staff registered nurses for each of the three variables generated mixed results. Of the nine correlations, three are of particular interest. That is, the pairs of manager rated NMAS with nurse rated NMAS, manager rated ASp with nurse rated ASp, and manager rated ASu with nurse rated $\mathrm{ASu}$. Of these only the first, manager rated and nurse rated NMAS was statistically significant $(r=.21, p<.05)$. This supports the interpretation that using both Magnet and non-Magnet hospital units results in a demonstration that there is a positive, although low, relationship between how managers rate leadership attributes and how staff registered nurses rate leadership attributes.

Among the remaining correlations, only that for the relationship between manager rated ASu and nurse rated NMAS was significant $(\mathrm{r}=.20, \mathrm{p}<.05)$. Thus managers' perception of nurse autonomy for unit operations is related to nurses' perception of manager leadership attributes. However, it is important to note that here there is no relationship between the managers' ratings of their own leadership attributes and staff registered nurses' ratings of their own autonomy for patients and for unit operations.

Hypothesis 6: Compared to Magnet hospitals, non-Magnet hospitals positive nurse manager leadership traits and nurse clinical autonomy would have lower correlations. The difference between correlations procedure was used to test this hypothesis. See Table 15 for the correlation matrix within Magnet hospitals and Table 16 for the correlation matrix within non-Magnet hospitals. 
Table 15. Correlation Matrix of Manager and Staff Registered Nurse Ratings of Manager Attributes and Nurse Autonomy Among Magnet Hospitals Only [N=30]

\begin{tabular}{|l|c|c|c|c|c|}
\hline Variables & $\begin{array}{c}\text { Manager } \\
\text { ASp }\end{array}$ & $\begin{array}{c}\text { Manager } \\
\text { ASu }\end{array}$ & $\begin{array}{c}\text { Nurse } \\
\text { NMAS }\end{array}$ & Nurse ASp & Nurse ASu \\
\hline $\begin{array}{l}\text { Manager } \\
\text { NMAS }\end{array}$ & .25 & $.37^{*}$ & .21 & $.44^{*}$ & $.37^{*}$ \\
\hline $\begin{array}{l}\text { Manager } \\
\text { Asp }\end{array}$ & & .16 & .12 & .21 & .10 \\
\hline $\begin{array}{l}\text { Manager } \\
\text { ASu }\end{array}$ & & & $.41^{*}$ & .33 & .28 \\
\hline $\begin{array}{l}\text { Nurse } \\
\text { NMAS }\end{array}$ & & & & .20 & $.44^{*}$ \\
\hline $\begin{array}{l}\text { Nurse } \\
\text { Asp }\end{array}$ & & & & & .32 \\
\hline
\end{tabular}

$*=\mathrm{p}<.05 \quad * *=\mathrm{p}<.01 \quad * * *=\mathrm{p}<.001$

Manager NMAS $=$ Manager rated Nurse Manager Action Scale

Manager $\mathrm{ASp}=\quad$ Manager rated nurse Autonomy Scale for patients

Manager $\mathrm{ASu}=$ Manager rated nurse Autonomy Scale for unit operations

Nurse NMAS $=$ Nurse rated Nurse Manager Action Scale

Nurse ASp $=\quad$ Nurse rated nurse Autonomy Scale for patients

Nurse $\mathrm{ASu}=\quad$ Nurse rated nurse Autonomy Scale for unit operations

Table 16. Correlation Matrix of Manager and Staff Registered Nurse Ratings of Manager Attributes and Nurse Autonomy Among Non-Magnet Hospitals Only [N=74]

\begin{tabular}{|l|c|c|c|c|c|}
\hline Variables & $\begin{array}{c}\text { Manager } \\
\text { ASp }\end{array}$ & $\begin{array}{c}\text { Manager } \\
\text { ASu }\end{array}$ & $\begin{array}{c}\text { Nurse } \\
\text { NMAS }\end{array}$ & Nurse ASp & Nurse ASu \\
\hline $\begin{array}{l}\text { Manager } \\
\text { NMAS }\end{array}$ & $.39^{* * *}$ & $.58^{* * *}$ & .21 & .05 & .07 \\
\hline $\begin{array}{l}\text { Manager } \\
\text { ASp }\end{array}$ & & $.51^{* * *}$ & .10 & .10 & .20 \\
\hline $\begin{array}{l}\text { Manager } \\
\text { ASu }\end{array}$ & & & .09 & -.02 & .03 \\
\hline $\begin{array}{l}\text { Nurse } \\
\text { NMAS }\end{array}$ & & & & $.35^{* *}$ & $.51^{* * *}$ \\
\hline $\begin{array}{l}\text { Nurse } \\
\text { ASp }\end{array}$ & & & & & $.42^{* * *}$ \\
\hline
\end{tabular}

$*=\mathrm{p}<.05 \quad * *=\mathrm{p}<.01 \quad * * *=\mathrm{p}<.001$

Manager NMAS $=$ Manager rated Nurse Manager Action Scale

Manager ASp $=\quad$ Manager rated nurse Autonomy Scale for patients

Manager $\mathrm{ASu}=$ Manager rated nurse Autonomy Scale for unit operations

Nurse NMAS $=\quad$ Nurse rated Nurse Manager Action Scale

Nurse ASp $=\quad$ Nurse rated nurse Autonomy Scale for patients

Nurse $\mathrm{ASu}=\quad$ Nurse rated nurse Autonomy Scale for unit operations 
Looking at Tables 15 and 16, the relationships among the ratings on the three scales done only by the manager, the pattern is similar to that found for the entire sample including both Magnet and non-Magnet hospitals. That is, there is generally a positive relationship between the pairs of variables. Note that for Magnet hospitals, two of the three relationships are not significant. This is probably due to lower power because of having 30 Magnet hospitals compared to 74 non-Magnet hospitals. Although these three relationships are not the ones of primary interest here, it should be noted that the three correlations among manager ratings are higher for non-Magnet than for Magnet hospitals. However, the differences in these correlations did not approach significance.

Similarly, looking at the relationships among the ratings on the three scales done only by the staff registered nurse, the pattern is similar to that found for the entire sample including both Magnet and non-Magnet hospitals. Again, two of the three correlations among nurse ratings within Magnet hospitals are not significant and, again, probably due to power issues. Also, the correlation magnitude differences between Magnet and nonMagnet did not approach significance.

Importantly, as hypothesized, when evaluating the 9 relationships between manager rated leadership attributes and staff registered nurse rated autonomy for both patient and unit operations, clearer and greater differences are found between Magnet and non-Magnet hospitals. First, comparing results in Tables 15 and 16, out of 9 correlations ( 3 manager ratings with the 3 nurse ratings), 8 are higher for Magnet than non-Magnet. Since the relationships between Magnet and non-Magnet hospital correlations are binary regarding whether one is higher than the other, a $\mathrm{z}$ for the binomial test can be used to determine the likelihood of 8 out of 9 correlations being higher for Magnet than non- 
Magnet hospitals. Using an alpha of .05 as the criterion for significance, the $\mathrm{z}$ for the binomial for 8 out of 9 correlations being in the predicted direction is $2.33(\mathrm{p}<.02)$. This is an unlikely z-score. Hence, it can be said that this pattern of 8 out of 9 correlations being higher for Magnet than non-Magnet hospitals is unlikely to have happened by chance alone. Indeed, the likelihood here would be the same for tossing a coin 9 times and obtaining 8 heads.

The two correlations of specific conceptual interest here would be that between the manager rated leadership attributes and the staff registered nurse autonomy on patient and on unit operations. Strikingly, these are the two correlations with the greatest differences between Magnet and non-Magnet hospitals (Tables 15 and 16). For the manager rated leadership attributes and staff registered autonomy regarding patients relationship, $r=.44(p<.05)$ for Magnet hospitals and $r=.05(p=.67)$ for non-Magnet hospitals. For the manager rated leadership attributes and staff registered autonomy regarding unit operations relationship, $\mathrm{r}=.37(\mathrm{p}<.05)$ for Magnet hospitals and $\mathrm{r}=.07$ $(p=.55)$ for non-Magnet hospitals. Hence, for both of these important relationships the correlations are significant within Magnet hospitals, but not significant within nonMagnet hospitals. This is the key finding in the study. It means that within Magnet hospitals, but not within non-Magnet hospitals, the leadership attributes of the manager are related to clinical nurse autonomy for both working with patients and operating the unit.

Although there are clearly differences between Magnet and non-Magnet hospitals in the level of significance for these two correlations of interest, this does not in itself mean that the differences in the correlations between Magnet and non-Magnet hospitals 
are themselves significant. These differences can be formally tested via the differences between correlations procedure. For a pair of correlations, each correlation is transformed to a Fisher $Z$ and the difference between the Fisher $Z$ 's is tested with the work-horse statistics, the z-score.

For the two correlations with the greatest magnitude difference between Magnet $(\mathrm{r}=.44)$ and non-Magnet $(.05)$ hospitals, that of the relationship between manager rated leadership attributes and staff registered nurse rated autonomy regarding patient care, the formally tested difference is significant if a one-tailed test is used. The z-score $=1.87$. For a two-tailed test, the $p=.07$. For a one-tailed test, the $p=.04$. Since the prediction was that Magnet hospitals would have larger correlations, a one-tailed test is appropriate. However, it should be noted that the strongest test of difference would be a two-tailed test.

For the other correlation pair of most interest, that of the relationships between manager rated leadership attributes and staff registered nurse rated autonomy regarding unit operation, the result of a formal test of correlation differences was not significant (zscore $=1.41, p=.16$ for two-tailed test and .08 for one-tailed test).

Hypothesis 7: The mediation model would better fit the data than the common cause model. That is, a model where hospital type causes positive nurse manager leadership traits that, in turn, cause higher nurse clinical autonomy would better fit the data than a model where nurse manager leadership traits and nurse clinical autonomy are related to each other because both are caused by hospital type. This hypothesis was not testable in this data set. As be seen in Table 17, hospital type (Magnet versus nonMagnet) was not significantly related to any of the dependent variables of interest. Since 
hospital type is not related to either manager leadership attributes or nurse autonomy, then by definition leadership attributes can neither mutually cause other forms of nurse autonomy nor mediate a relationship between hospital type and nurse autonomy.

Table 17. Correlations Between Hospital Type (Magnet versus non-Magnet) and the Dependent Variables*

\begin{tabular}{|l|c|c|c|c|c|c|}
\hline Variables & $\begin{array}{c}\text { Manager } \\
\text { NMAS }\end{array}$ & $\begin{array}{c}\text { Manager } \\
\mathrm{ASp}\end{array}$ & $\begin{array}{c}\text { Manager } \\
\mathrm{ASu}\end{array}$ & $\begin{array}{c}\text { Nurse } \\
\text { NMAS }\end{array}$ & $\begin{array}{c}\text { Nurse } \\
\mathrm{ASp}\end{array}$ & $\begin{array}{c}\text { Nurse } \\
\mathrm{ASu}\end{array}$ \\
\hline $\begin{array}{l}\text { Hospital } \\
\text { type }\end{array}$ & .08 & .09 & .05 & -.00 & -.03 & .08 \\
\hline
\end{tabular}

Manager NMAS $=$ Manager rated Nurse Manager Action Scale

Manager $\mathrm{ASp}=\quad$ Manager rated nurse Autonomy Scale for patients

Manager $\mathrm{ASu}=\quad$ Manager rated nurse Autonomy Scale for unit operations

Nurse NMAS $=$ Nurse rated Nurse Manager Action Scale

Nurse ASp $=\quad$ Nurse rated nurse Autonomy Scale for patients

Nurse $\mathrm{ASu}=\quad$ Nurse rated nurse Autonomy Scale for unit operations

* These relationships are the same as mean differences between hospital types tested by the ANOVA main effects of Hospital Type for Hypotheses 1 and 2 reported in Tables 11 , 12 , and 13 . Here, the statistical tests used were correlations between the dichotomous variable of Hospital Type and the continuous 6 dependent variables. 


\section{Chapter 5. Discussion}

Overview and Purpose of the Study

The purpose of this study was to examine the relationships among hospital types (Magnet versus non-Magnet), nurse manager leadership attributes, and staff registered nurse clinical autonomy. These variables are important because they have been shown to be related to nurse recruitment and retention, the quality of the nurses' work experience, the culture of patient safety, and patient mortality (Laschinger, Almost, and Tuer-Hodes, 2003; Aiken, Smith, and Lake, 1994).

The general research model used in this research was the Structural Contingency Theory (SCT) modified for a nurse-specific SCT, the Nursing Systems Outcomes Research (NSOR) model (see Figure 1 Chapter). Within the NSOR, the relationships among Magnet hospital status, leadership attributes, and nurse clinical autonomy are specified. Additionally, Critical Social Theory (CST) provided the conceptual and motivational basis for this research. CST functions as a lens through which to frame and view the question. See Figure 2 Chapter 1 for a schematic representation of CST illustrating the relationships among education, inequality, power imbalance, and human suffering. CST then can aid in the generation of alternative, praxis-based approaches to understanding content and practice areas of nursing and how to address issues of embedded power relationships and resulting human suffering. The practical application of such CST functions specific to the profession of nursing can be found in Georges (2002), McGuire and Georges (2003), Georges and McGuire (2004), and McGuire (2006). 
Hence, the present study was designed, in part, to help empirically identify relationships among specified variables that would allow a focus for generating praxisbased efforts to ameliorate problems in and to generally improve the nurses' work environment. As stated above, this is important not only to nurse recruitment and retention and the daily experience of nurses, but also to patient safety (Armstrong and Laschinger, 2006).

Sample Description and Characteristics

The sample consisted of 416 subjects (104 nurse managers and 312 staff registered nurses) from 104 completed hospital units representing 9 Magnet hospitals matched with 23 non-Magnet hospitals. Tests of differences between the Magnet and non-Magnet hospitals on the 11 general hospital characteristics used for the matching procedure yielded no significant differences. These data support that the matching procedure was appropriate.

Subject demographic differences between Magnet and non-Magnet hospitals were not present for staff registered nurses other than a slightly higher percent of Hispanic individuals present in Magnet hospitals. For nurse managers, there was also a higher percent of Hispanic individuals in the Magnet hospitals. In Magnet versus non-Magnet hospitals, managers were younger and had been registered nurses and in leadership positions for fewer years.

Three General Hypotheses Tested

There were three general hypotheses for this study. First, it was hypothesized that there would be differences between hospital type: Magnet hospitals would have higher 
nurse manager leadership attributes and staff registered nurse clinical autonomy than non-Magnet. This general hypothesis was not supported.

Second, it was hypothesized that there would be positive relationships between nurse manager leadership attributes and nurse clinical autonomy. This hypothesis received partial support. There were such relationships within manager reports and $\underline{\text { within }}$ staff registered nurse reports. Indeed, the presence of these relationships within staff registered nurse reports replicated the findings of Mrayyan (2004) who also demonstrated that within staff registered nurses there were positive relationships among the three dependent variables: leadership attributes, nurse autonomy for patient care, and nurse autonomy for unit operations.

However, manager reported leadership attributes were not related to staff registered nurse reported autonomy for either patient care or unit operations. Therefore, the lack of this important relationship did not support the second general hypothesis. However, these relationships emerged within the Magnet hospital sample as reported below for the third general hypothesis. Also, it is interesting and reinforcing to find that managers' self-ratings on leadership attributes were significantly related to staff registered nurses' ratings of managers' leadership attributes. This relationship $(\mathrm{r}=.21)$ remained when evaluated within Magnet and within non-Magnet hospitals, although these correlations were not significant because of the lower sample sizes and resulting reduction in statistical power.

The third general hypothesis was that the relationships among leadership attributes and nurse clinical autonomy would be different within Magnet versus within non-Magnet hospitals. This hypothesis was supported by the 9 correlations between 
manager reported and staff registered nurse reported leadership attributes and nurse clinical autonomy. First, in terms of absolute values, 8 of the 9 correlations were larger within Magnet compared to non-Magnet hospitals. This pattern was statistically significant and supported this hypothesis.

The two correlations of most conceptual interest, that of the relationship between manager rated leadership attributes and staff registered nurse clinical autonomy for both patient care and unit operations, were significantly positive within Magnet hospitals $(r=$ .44 and .37 , respectively) and were essentially absent within non-Magnet hospitals $(\mathrm{r}=$ .05 and .07 respectively). These results support the third general hypothesis, although only the Magnet versus non-Magnet difference in strength of relationship between manger rated leadership attributes and staff registered nurse autonomy for patient care actually tested as statistically significant via a one-tailed z-score test.

The final proposed set of analyses, those testing Hypothesis 7, evaluating model fit, were not conducted. Hypothesis 7 predicted that the relationships among the 3 dependent variables of interest (leadership attributes, nurse autonomy for patient care, and nurse autonomy for unit operations) would better be modeled by a mediation model rather than a common cause model. These analyses were not run because the first required relationship, that between hospital type and leadership characteristics, was not present.

Consistency of Results and Existing Literature

In this study comparing Magnet and non-Magnet hospitals, there were no significant mean score differences on the 6 dependent variables of interest: 3 manager and 3 staff registered nurse reported variables (leadership attributes, nurse autonomy for 
patient care, and nurse autonomy for unit operations). At first glance this would appear to contradict much of the existing literature, but the comparisons are not straight forward. However, as noted in the literature review above, there few reported direct comparisons of Magnet and non-Magnet hospitals on leadership attributes and nurse autonomy. Some of the literature characterizes what makes for good hospitals and what is descriptive of Magnet hospitals. There are reports of qualitative research and use of interviews that assert that Magnet hospitals as compared to non-Magnet hospitals are characterized by better leadership and higher levels of nurse autonomy as well as by other outcomes such as nurse job satisfaction. The Upenieks study series (Upenieks, 2000; 2002; 2003a; $2003 b$ ) is used as the example here. Fortunately, the Upenieks series of studies triangulates the question by also using quantitative assessments. Upenieks used the Nurse Work Index Revised (NWI-R) and the Conditions of Work Effectiveness Questionnaire (CWEQ-II). These instruments assess components of nurse autonomy and empowerment. Upenieks used 2 Magnet and 2 non-Magnet hospitals with 305 useable questionnaires from respondents. She noted that the Magnet and non-Magnet hospitals were matched on a number of characteristics and reports that the Magnet hospitals registered higher on the assessments of empowerment and that the leadership in Magnet hospitals was more likely to foster autonomy.

The difference in outcomes between this study and the studies of Upenieks may be due to Upenieks using a total of four hospitals while this study used a total of 32 hospitals. Of course, the assessments of empowerment or autonomy were also different between this study and those of Upenieks. Also, the evaluation of the empowering nature of the institution and the leadership was different from that in the current study. While 
Upenieks looked at empowerment structural elements, the current study evaluated specific managerial behaviors of the nurse managers. Additionally, the procedures for sample attainment were different. Upenieks went into the 4 hospitals and distributed questionnaires to medical-surgical registered nurses receiving a $44 \%$ response rate. In the current study, the researcher contacted the Chief Nursing Officer and through that individual contacted nurse managers who, in turn, distributed questionnaires to staff registered nurses on different types of units.

Armstrong and Laschinger (2006) also report a relationship between Magnet hospital characteristics and empowerment. They, like Upenieks, used the CWEQ-II to assess empowerment. However, they did not compare Magnet and non-Magnet hospitals. Their study was done in a single hospital with a sample of $40 \mathrm{RNs}$. They evaluated the relationship between empowerment and a scale assessing Magnet hospital characteristics, Lake's Practice Environment Scale of the Nursing Work Index. They found a relationship between Magnet hospital characteristics and feelings of empowerment. Laschinger, Almost, and Tuer-Hodes (2003) report secondary analyses of 3 studies that yielded the same outcome of a relationship between Magnet hospital characteristics and feelings of empowerment. These studies support the contention that Magnet hospital characteristics are related to empowerment and nurse autonomy, but this is not the same thing as comparing Magnet with non-Magnet staff ratings.

In the current study, some relationships were found between leadership attributes and nurse autonomy. In this case, for all subjects there were significant relationships between these two constructs within the manager responses and within the staff registered nurse responses, but none were present between the manager and staff registered nurse 
responses. Relationships between the manager and staff registered nurse responses emerged only within the Magnet hospital sample. In the general literature, other than Mrayyan's (2004) research, there appear to be to no direct tests of a relationship between leadership attributes and nurse autonomy. Mrayyan's study used only staff registered nurses. Within the staff registered nurse sample, there were significant relationships between leadership attributes and nurse autonomy. These results within staff registered nurses were replicated in the current study. In her published article, Mrayyan called for the nurse managers themselves to be studied as well.

\section{Implications for the Nursing Profession}

The central goal of nursing is the alleviation or amelioration of patient suffering. Patient outcomes are directly affected by the competence and decisions of nurses. This research evaluated the relationships among Magnet hospital status, leadership attributes, and nurse autonomy in managers and staff registered nurses. This area of research is important to nursing because of the strong relationship between nurse autonomy and patient outcomes (Kramer, et al. 2005). Also, the experience of nurses within their work environment can and does impact their job satisfaction and their behavior (Upenieks, 2003a). Hence, both the ultimate patient outcomes and the intermediate outcomes of nurse experience and behavior are addressed in this research area. As such, the understanding of clinical nurse autonomy and its sources is key to the professional practice of nursing. It is this understanding that will enable necessary change via identifying an alternative praxis-based approach leading to less human suffering (see Figure 2). If there is a relationship between empowered nurses who can operate within more nonhierarchical communication and decision making approaches, with all members 
of a unit or healthcare team participating in decisions, and better nurse experiences and better patient outcomes, then this is a condition that must be fostered.

One of the important elements of this study was the differentiation between institutional empowerment structural elements and leadership attributes operationally defined as manager actions. This differentiation both led to a specific finding in this study and may lead to the development of an alternative praxis-based approach. The results of this study are not that there are scale score mean or reported differences in leadership attributes and/or nurse autonomy between Magnet and non-Magnet hospitals. Rather, the centrally important finding was that there was a different relationship between leadership attributes and nurse autonomy within Magnet versus within non-Magnet hospitals. Hence, there are similar levels of both leadership attributes and nurse autonomy across Magnet and non-Magnet hospitals. But, it appears to be something about the Magnet hospital work environment that allows the varying levels of leadership attributes among the nurse managers to impact the nurse perceived levels of autonomy. That is, there are managers within both Magnet and non-Magnet hospitals that have similar levels and ranges of leadership attributes, but it is only within the Magnet hospital that this range of leadership attributes manifests itself in different levels of nurse perceived autonomy. Somehow within Magnet, but not within non-Magnet hospitals, when managers have leadership visibility, engage in specific behaviors that support an autonomous climate for nurses as measured by the NMAS, then nurses have a heightened perception of their autonomy as measured by the Autonomy Scale. Perhaps it is when nurses can decide how to deploy resources and experience a relative freedom to make decisions regarding patient care, they also feel accountable for those decisions. There 
may also be a clue regarding both this process and the goal of identifying an alternative praxis-based approach in this study and within Mrayyan's (2004) research: staff registered nurses report less autonomy for unit operations than for patient care. In the current study, this difference was also reported by managers.

Hence, the finding of different relationships functioning within Magnet hospitals may provide clues for where to begin deconstructing manager and staff registered nurses roles, power relationships within a unit, and the relationship of these roles and the unit to the large hospital arena. This may aid in the development of alternative praxis-based approaches to change within both Magnet hospitals (nurse managers report a range of leadership attributes within such hospitals) and non-Magnet hospitals where, in those hospitals in this study, there is no relationship between manager leadership attributes and nurse autonomy.

\section{Implications for Future Research}

It is important to use models and conceptual frameworks because they help guide the thinking about the research, the constructs of importance to the question, the differentiation among those constructs, the operational definitions, and the ultimate goals. As mentioned earlier, in this research, the SCT/NSOR model helped differentiate between Magnet hospital characteristics and leadership attributes while the CST framework served as a constant reminder of the point of the research endeavor and all of the work that it entails.

Specific recommendations would include more research on nurse managers themselves, a recommendation also made by Mrayyan (2004), and on the relationship between leadership attributes as reported by the administrator and nurse autonomy and 
other characteristics as reported by staff registered nurses. Also, given the central finding in this study, there should be more research on differences in relationships within Magnet versus non-Magnet hospitals. This type of focus would then be using a moderation statistical model. Such a model demonstrates that relationships are not always either simple or mediational, but can be ones where the relationship between two variables is itself affected by other variables.

Additional developmental work on both the NMAS and Autonomy Scale should be undertaken. This would apply particularly to content areas for both managers and nurses that are not currently included. Perhaps a good approach here would be to involve managers and nurses in a qualitative research project to identify possible expansion of content.

Given that there were huge differences on various hospital characteristics between Magnet and non-Magnet hospitals presented in Table 6, some type of matching is important in research comparing these types of hospitals. Some reported research has compared nonmatched Magnet and non-Magnet hospitals (, Aiken, Havens \& Sloane, 2000). If a study compares groups of non-matched Magnet and non-Magnet hospitals, then there is no way to identify the source of any differences that do emerge.

Another approach that may be of value would be to use some type of observational evaluation. This would address issues regarding self-report. Also other methods would include the use of cohort designs and the use of multilevel modeling analysis.

Researchers should consider true experimental studies using interventions to identify nurse manager action effects on nurse perceived autonomy. As mentioned in the 
methods section above and in the limitations paragraphs below, this study used a preexperimental static-group comparison design. In order to make reasonable inferences about causal relationships, the gold standard design is a true experiment.

\section{Limitations of the Current Study}

This study was a pre-experimental static-group comparison design. No reasonable causal inferences can be made from such a design. Another limitation was the use of self-report. In this study, there was no functional control over to which staff registered nurses the unit nurse manager distributed the nurse surveys. The effects of this lack of control are unknown.

This research did not have a qualitative component. Thus, no triangulation was carried out. Also, the sample size in this study provided statistical power sufficient to detect down to between medium and large effects. That means that any smaller effects that were present could not be detected and any inferences about their lack of existence runs the risk of Type II errors. Finally, and of course, this study is limited by the particular populations sampled, the samples that were created, the specific constructs chosen for inclusion, and the operational definitions or measurements of those constructs.

\section{Conclusions}

This study examined the relationships among hospital types (Magnet versus nonMagnet), nurse manager leadership attributes, and staff registered nurse clinical autonomy in mangers and staff registered nurses. These variables and relationships are important because they have been shown to be related to nurse recruitment and retention, the quality of nurses' work experience, the culture of patient safety, and patient mortality. The use of a general research model, the Structural Contingency Theory (SCT) modified 
for a nurse-specific SCT, the Nursing Systems Outcomes Research (NSOR) model, was important because it identified relationships among constructs of interest within larger context. Using a framework such as Critical Social Theory (CST) provided the conceptual and motivational basis for this research.

Simple differences between Magnet and non-Magnet hospitals may not be the most important focus for this type of research. The central finding here was the differences in relationships among variables within Magnet versus within non-Magnet hospitals. These relationships were those between manager reported leadership attributes and staff nurse reported autonomy for both patient care and unit operations. It is this central finding that may provide clues for developing alternative praxis-based approaches to this area. 


\section{References}

Aiken, L. H., Havens, D. S. \& Sloane, D. M. (2000). The magnet nursing services recognition program: A comparison of two groups of magnet hospitals. American Journal of Nursing, 100(3), 26-36.

Aiken. L.H., \& Sloane, D.M. (1997). Effects of organizational innovations in aids care on burnout among urban hospital nurses. Work and Occupations, 24, 453-477

Aiken, L. H., Sloane, D. \& Lake, E. T. (1997). Satisfaction with inpatient aids care: A national comparison of dedicated units and scattered-beds. Medical Care, 35(9), 948-962.

Aiken, L.H., Sloane, D.M., Lake, E.T., Sochalski, J. \& Weber, A.L. (1999). Organization and outcomes of inpatient AIDS care. Medical Care, 37(8), 760-772.

Aiken, L.H. \& Smith, H.L. (1993). Effects of specialization on the status and autonomy of nurses: Results from a natural experiment in hospital aids care. Paper presented at the American Sociological Association, Miami, FL, August.

Aiken, L. H., Smith, H. L. \& Lake, E. T. (1994). Lower Medicare mortality among a set of hospitals known for good nursing care. Medical Care, 32(5), 771787.

Aiken, L.H., Clarke, S.P., Sloane, D., Sochalski, J., and Silber, J.H. (2002). Hospital nurse staffing and patient mortality, nurse burnout, and job dissatisfaction. The Journal of the American Medical Association, 288(16), 1987-1993.

Ambert A.M., Adler P.A., Adler P., Detzner D.F. (1995) Understanding and evaluating qualitative research. Journal of Marriage and the Family, 57, 879-893.

Allen, D. (1985). Nursing research and social control: Alternative Models of 
Science that emphasize understanding and emancipation. Image: The Journal of Nursing Scholarship. Spring, XVll, (2), 58-64.

Allen, D., Benner, P., \& Diekel, N. (1986). Three paradigms for nursing research: Methodological implications. In P. Chinn (Ed.), Nursing research methodology: Issues and implementation in nursing (pp. 23-38). Rockville, MD: Aspen Systems.

American Nurses Association. (1996). Nursing quality indicators: Definitions and implications (No. NP-108). Washington, DC: Author.

Armstrong, K.J. and Laschinger, H., (2006), Structural empowerment, magnet hospital characteristics, and patient safety culture: making the link. Journal of Nursing Care Quality, 21, 124-132.

Ballou, K.A. (1998). A concept analysis of autonomy. Journal of Professional Nursing, 14, 102-110.

Barker, A.M. (1992). Transformational nursing leadership. A vision for the future (No. NLN Publication, 15-2473). New York: National League for Nursing. Beauchamp, T.L. \& Childress, J.F. (2001). Principles of Biomedical Ethics. $5^{\text {th }}$ ed. Oxford, England: Oxford University Press.

Berman, H., Ford-Gilboe, M., \& Campbell, J. C. (1998). Combining stories and numbers: A methodologic approach for a critical nursing science. _Advances in Nursing Science, 21 (1), 1-15.

Blegen M.A., Goode C.J., Johnson M., Maas M., Chen L. \& Moorhead S. (1993) Preferences for decision-making. Journal of Nursing Scholarship 25, 339-344. Blegen, M.A. (2001). Health care challenges beyond 2001: Mapping the journey for 
research and practice. Communicating Nursing Research, 34,3-16.

Boyle D.K., Bott M.J., Hansen H.E., Woods C.Q. \& Taunton R.L. (1999) Managers' leadership and critical care nurses' intent to stay. American Journal of Critical Care, 8, 361-371.

Boutain. D. M. (1999). Critical nursing scholarship: Exploring critical social theory with African American studies. Advances in Nursing Science, 21(4), 37-47.

Braten, J. (1991). Habermas's critical theory of society. Albany: State University of New York Press.

Brown, S.G. (2004). Ethnography Unbound: From Theory Shock to Critical Praxis. Albany: State University of New York Press.

Campbell, D.T. \& Stanley, J.C. (1963). Experimental and quasi-experimental designs for research. Boston: Houghton Mifflin Company.

Cobb A.K., Hagemaster J.N. (1987) Ten criteria for evaluating research proposals. Journal of Nursing Education, 26(4), 138-143.

Cohen, J. (1988). Statistical power analysis for the behavioral sciences $\left(2^{\text {nd }}\right.$ Edition). Hillsdale, NJ: Lawrence Erlbaum Assoc.

Cohen, J. (1992). A power primer. Psychological Bulletin, 112(1), 155-159.

Cook, M.J. (1999). Improving care requires leadership in nursing. Nurse Education Today, 19, 30-6-312.

Davidson, H., Flocarell, P.H., Crawford, S., Dupart, L.J., \& Clifford, J.C. (1997). The effect of healthcare reforms on job satisfaction and voluntary turnover among hospital-based nurses. Medical Care, 35, 634-645.

Dent, H. (1990). Job satisfaction and autonomy in head nurses. Unpublished manuscript, 
George Mason University, Fairfax, VA.

Denzin, N.K., Lincoln, Y.S. eds. (2000). Handbook of Qualitative Research. London: Sage Publications.

Donaldson L. (1999) The normal science of structural contingency theory. In: Clegg S, Hardy C, eds. Studying Organizations: Theory and Method. Thousand Oaks, CA: Sage, 51-70.

Downe-Wamboldt, B. (1992). Content analysis: Method applications and issues. Health Care for Women International, 13, 313-321.

Duffy, K., \& Scott, P. A. (1998). Viewing an old issue through a new lens: A critical theory insight into the education-practice gap. Nurse Education Today, $18,183-189$.

Fox, R.C., Aiken, L.H., \& Messikomer, C. (1990). The culture of care: AIDS and the nursing profession. Milbank Quarterly, 68(suppl 2): 226-256.

Freire, P. (1972). Pedagogy of the Oppressed. Harmondsworth: Penguin.

Freire, P. (1995). Pedagogy of Hope. Reliving Pedagogy of the Oppressed. New York: Continuum.

Georges, J. M., (2002). Suffering: Toward a contextual praxis. Advances in Nursing Science, $25,80-87$.

Georges, J.M. \& McGuire, S., (2004). Deconstructing clinical pathways: mapping the landscape of health care. Advances in Nursing Science, 27, 2-11.

Gleason-Scott, J. S., Sochalski, J., \& Aiken, L. (1999). Review of magnet hospital research: Findings and implications for professional nursing practice. Journal of Nursing Administration, 29(1), 9-19. 
Guba, E. G. (1990). The alternative paradigm dialog. In E. G. Guba (Ed.), The paradigm dialog (pp. 17-30). Newbury Park: Sage.

Hackman, J.R. and Oldham, G.R. (1975) Development of the Job Diagnostic Survey. Journal of Applied Psychology, 60, 159-170.

Hastings C., \& Waltz, C. (1995). Assessing the outcomes of professional practice redesign. Journal of Nursing Administration, 25(3), 34-42.

Havens, D. S., \& Aiken, L. H. (1999). Shaping systems to promote desired outcomes: The magnet hospital model. Journal of Nursing Administration, 29(2), 14-20.

Held, D. (1980). Introduction to critical theory: Horkheimer to Habermas. Berkeley: University California Press.

Henderson, D. J. (1995). Consciousness raising in participatory research: Method and methodology for emancipatory nursing inquiry. Advances in_Nursing Science, 17(3), 58-69.

Hersey, P. \& Blancard, K.H. (1988). Management of Organizational Behavior, $5^{\text {th }}$ ed. Prentice Hall, Englewood Cliffs.

Hintze, J. (1991) The SOLO Statistical System: Power Analysis. BMDP Statistical Software, Los Angeles.

Holter, I. M. (1988). Critical theory: A foundation for the development of nursing theories. Scholarly Inquiry for Nursing Practice: An International Journal, 2 (3), 223-231.

Johnson, J.H. (1988). Differences in the performances of baccalaureate, associate degree, and diploma nurses: A meta-analysis. Research in Nursing and Health, 11, 183- 
197.

Keenan, J. (1999). A concept analysis of autonomy. Journal of Advanced Nursing, 29(3), 556-552.

Kovner, C. T., Hendrickson, G., Knickman, J. R., \& Stevens, A. F. (1994). Nursing care delivery models and nurse satisfaction. Nursing Administration Quarterly, 19(1), 74-85.

Kim, H. \& Holter, I. (1995). Critical theory for the science of nursing practice. In A. Omery, C. E. Kasper, \& G. G. Page (Eds.), In search of nursing research (pp.205-218). Thousand Oaks, CA: Sage Publications.

Kramer, M. (1990). The magnet hospitals excellence revisited. Journal of Nursing Administration, 20(9), 35-44.

Kramer, M. \& Hafner, L.P. (1989) Shared values: impact on staff nurse job satisfaction and perceived productivity. Nursing Research, 38(3), 172-179.

Kramer, M. \& Schmalenberg, C. (1987). Magnet hospitals talk about drgs on nursing care. Nursing Management, 18(10), 33-40.

Kramer, M. \& Schmalenberg, C. \& Hafner, L. (1989). Job satisfaction and productivity. In: Moore, T., Simendinger E, eds. Nurse Recruitment and Retention (69-87). Ann Arbor: Health Administration Press.

Kramer, M., Schmalenberg, C., Lund, C., King, C., Poduska, D., Goode, C., \& Rapp, D. Excellence through evidence: securing collegial/collaborative nurse-physician relationships. In press, Journal of Nursing Administration, Nov-Dec, 2005.

Laschinger, H., Almost, J., and Tuer-Hodes, D. (2003). Workplace empowerment and 
magnet hospital characteristics: making the link. Journal of Nursing Administration, 33, 410-422.

LaMonica, E., Oberst M, Madea A, \& Walf R. (1986). Development of a patient satisfaction scale. Research in Nursing \& Health, 9, 43-50.

Lake, E. (2002). Development of the practice environment scale of the nursing work index. Research in Nursing Health, 25, 176-188.

Larrabee, J.H., Ostrow, C.L., Withrow, M.L., Janney, M.A., Hobbs Jr,G.R., \& Burant, C. Predictors of patient satisfaction with inpatient hospital nursing care. Research in Nursing \& Health, 27, 254-268.

Leedy, P.D., \& Ormrod, J.E. (2005). Practical Research: Planning and Design, $8^{\text {th }}$ Ed. Upper Saddle River, New Jersey: Pearson Prentice Hall.

Lewis, C.K. \& Matthews, J.H. (1998). Magnet program designates exceptional nursing services. American Journal of Nursing, 98(12), 51-52.

Lutz, K., Jones, K., \& Kendall, J. (1997). Expanding the praxis debate: Contributions to clinical inquiry. Advances in Nursing Science, 20 (2), 23-30.

Mark, B.A., Sayler, J., \& Smith, C.S. (1996). A theoretical model for nursing systems outcomes research. Nursing Administration Quarterly, 20(4), 12-27.

Mark, B., Salyer J., \& Wan T.T.H. (2003). Professional nursing practice: Impact on organizational and patient outcomes. Journal of Nursing Administration, 33(4), 224-234.

Martin, P., Corron, J., Reinhart, M.J., Risner, P., Gustin, X., Lupo, T, \& Mals, D. (1991, May). Organizational dimensions in hospital nursing practice: Organizational climate, professional practice climate, work satisfaction, power orientation, and 
professional nursing autonomy. A poster presented at the 1991 Annual Meeting of the American Organization of Nurse Executives, San Diego.

Massey University course offering in Nursing Praxis entitled 168.142 - Introduction to Nursing and Praxis I http://cohss.massey.ac.nz/papers/outlines/168/168142_WEL_I_12.shtml

McClure, M.M., Poulin, M.A, \& Sovie, M.D. Wandelt, M.A. (1983). Magnet hospitals: attraction and retention of professional nurses. Kansas City (MO):American Academy of Nurses.

McGillis, L., \& Donner, G.J. (1997). The changing role of hospital nurse managers: A literature review. Canadian Journal of Nursing Administration, 10, 14-39.

McGuire, S. \& Georges, J. (2003). Undocumentedness and liminality as health variables. Advances in Nursing Science, 26, 185-195.

McGuirk, K.T. \& Miles T. (1987). Establishing a dedicated AIDS unit. Journal of Nursing Administration, 17, 25.

McKay, P. (1983). Interdependent decision-making: redefining professional autonomy. Nursing Administration Quarterly, 4(7), 21-30.

McLain, B. R. (1988). Collaborative practice: A critical theory perspective. Research in Nursing \& Health, 11, 391-398.

Morse J.M. (2001) Toward a praxis theory of suffering. Advances in Nursing Science, 24, 47-59.

Morse J.M. (2003) A review of committee's guide for evaluating qualitative proposals. Qualitative Health Research 13(6), 833-851.

Mrayyan, M.T. (2004). Nurses' autonomy: influence of nurse manager's actions. Nursing 
and Healthcare Management and Policy, 45(3), 326-336.

Munson, P. \& Heda, S. (1976). Service unit management and nurses' satisfaction. Health Services Research, 15, 128-142.

Pankratz, L., \& Pankratz, D., (1974). Nursing autonomy and patient rights: Development of a nursing attitude scale. Journal of Health and Social Behavior, 15, 211-216.

Perry, G.R. (1986). Myth or reality: Autonomy of RNs. Nursing Success Today, 3(9), 23-24.

Pinch, W.J. (1985). Ethical dilemmas in nursing: The role of the nurse and perceptions of autonomy. Journal of Nursing Education, 24, 372-376.

Popkewitz, T. S. (1990). Whose Future? Whose Past? Notes on critical theory and methodology. In E. G. Guba (Ed.), The paradigm dialog (46-66). Newbury Park, CA: Sage Publications.

Ray, M. A. (1992). Critical theory as framework to enhance nursing science. Nursing Science Quarterly, 5(3), Fall 98-100.

Rolfe, G. (1999). Nursing Praxis and the Reflexive Practitioner Collected Papers 1993 1999 http://www.nursingpraxis.com/gary.htm

Sales, A. (2004). Nurse staffing and patient outcomes in VA. http://wwwl.va.gov/pshsrd/page.cfm?pg=154 accessed on March 10, 2005.

Salyer, J. (1995). Environmental turbulence: Impact on nurse performance. Journal of Nursing Administration. 25(4), 12-20.

Salyer, J. (2003). Professional nursing practice: Impact on organizational and patient outcomes. Journal of Nursing Administration, 33(4), 224-234.

Schutzenhofer, K.K. (1987). The measurement of professional autonomy. Journal of 
Professional Nursing, 3, 278-282.

Schutzenhofer, K.K., \& Musser, D. M. (1994). Nurse characteristics and professional autonomy. Image: Journal of Nursing Scholarship, 26(3), 201-205.

Scott, J., Sochalski,J. \& Aiken, L. (1999). Review of magnet hospital research. Journal of Nursing Administration, 29(1), 9-18.

Sheehan, K. B., \& Hoy, M. G. (1999). Using e-mail to survey internet users in the United States: Methodology and assessment. Journal of Computer Mediated Communication, 4 (3). [Online]. Available:

http://www.ascusc.org/jcmc/vol4/issue3/sheehan.html.

Slavitt, D. (1979). Measuring nurses' job satisfaction. Hospital and Health Services Administration, 24, 62-76.

Spence, J.T., \& Helmreich, R.L. (1978). Masculinity and Femininity: Their Psychological Dimensions, Correlates and Antecedents. Austin: University of Texas Press.

Spence, J.T., \& Helmreich, R.L.(1980). Masculine instrumentality and feminine expressiveness: Their relationships with sex role attitudes and behavior. Psychology of Women Quarterly, 5, 147-163.

Spence, J.T., Helmreich, R.L. \& Stapp, L.L. (1974). The personal attribute questionnaire: A measure of sex-role stereotypes and masculinity-femininity. JSAS Catalog of Selected Documents in Psychology, 4, 42, MS\#617.

Stamps, P.L, \& Piedmonte, E.B. (1986). Nurses and Work Satisfaction-An Index for Measurement. Ann Arbor, Mich.: Health Administration Press.

Stevens, P. E. (1989). A Critical social reconceptualization of environment in 
nursing: Implications for methodology. In J. Kenney, Philosophical and theoretical perspectives for advanced nursing practice (159-168). Massachusetts: Sage Publications.

Sweet, S. J. \& Norman, I. J. (1995). The nurse-doctor relationship: A selective literature review. Journal of Advanced Nursing, 22, 165-170.

Taunton, R.L. Krampitz S.D., \& Woods, C.Q. (1989a) Manager impact on retention of hospital staff. Journal of Nursing Administration, 19(5), 14-19.

Taunton, R.L., Krampitz, S.D., Woods, C.Q. (1989b) Absenteeism-retention links. Journal of Nursing Administration, 19(6), 13-21.

Taunton, R.L., Boyle, D.K., Woods, C.Q., Hanson, H.E., \& Bott, M.J. (1997). Manager leadership and retention of hospital staff nurses. Western Journal of Nursing Research, 19, 205-226.

Thomas, J. (1992). Doing Critical Ethnography. Thousand Oaks, CA: Sage.

Thompson, J. L. (1987). Critical scholarship: The critique of domination in nursing. Advances in Nursing Science, 10(1), 27-38.

Thorndike, R.L. (1982). Applied Psychometrics. Houghton Mifflin, Boston.

Thorne, S.E. \& Hayes, V.E (1997). Nursing Praxis: Knowledge and Action. Thousand Oaks, CA: Sage

Upenieks, V.V. (2000). The relationship of nursing practice models and job satisfaction outcomes. Journal of Nursing Administration, 30(6), 330-335.

Upenieks, V.V. (2002), Assessing differences in job satisfaction of nurses in magnet and nonmagnet hospitals. Journal of Nursing Administration, 32(11), $564-576$

Upenieks, V.V. (2003a). The interrelationship of organizational characteristics of magnet 
hospitals, nursing leadership, and nursing job satisfaction. The Health Care Manager, 22(2), 83-98.

Upenieks, V.V. (2003b). What constitutes effective leadership?: Perceptions of magnet and nonmagnet nurse leaders. Journal of Nursing Administration, 33(9), 456-467.

Upenieks, V.V. (2005). Nurse perceptions of job satisfaction and empowerment: is there a difference between nurses employed at magnet versus non-magnet hospitals? Nursing Management, $\underline{34}$, 43-44.

Weaver, S.H., Byrnes, R., Dibella, M., \& Hughes, A.M. (1991). First-line manager skills: Perceptions and performances. Nursing Management, 22, 33-39.

Weisman C.S., Alexander C.S., Chase G.A. (1980). Job satisfaction among hospital nurses: A longitudinal study. Health Services Research, 15(4):341-364.

Weisman, C. \& Nanthanson, C. (1985). Professional satisfaction and patient outcomes: a comparative organizational analysis. Medical Care, 23(10), 948-962.

Wells, D. L. (1995). The importance of critical theory to nursing: A description using research concerning discharge decision-making. Canadian Journal of Nursing Research, 27 (2), 45-55.

Westrope, R.A., Vaugh, L., Bott, M., \& Taunton, R.L. (1995). Shared governance: From vision to reality. Journal of Nursing Administration, 25(12, 45-54.

Wilson, F. (1992). Language, technology, gender, and power. Human Relations, $45(9), 883-901$.

Wood, J.E., Tiedje, L.B., \& Abraham, L.L. (1986). Practicing autonomously: A comparison of nurses. Public Health Nursing, 3, 130-139. 
APPENDIX A

BACKGROUND INFORMATION FOR NURSING MANAGERS 


\section{BACKGROUND INFORMATION FOR NURSING MANAGERS}

Instructions:

Please check or provide the most accurate response in each question.

Please answer every question.

The information that you give will be held in the strictest confidence and your questionnaires will be identified only by a code.

1. What is your sex?

1. Female

2. Male

2. What is your age?

3. What is your marital status?

1. single

2. married

3. separated

4. - divorced

5. - widowed

4. What is your ethnic/racial background?

This has two parts, A \& B. Please answer both.

A.

1. _. Not Hispanic or Latino

2. Hispanic or Latino

B.

1. White

2. Native Hawaiian or Other Pacific Islander

3. Black or African American

4. Asian

5. American Indian or Alaska Native

5. What is the highest educational nursing degree you currently hold?

1. _ diploma

2. - associate degree

3. bachelor

4. masters

5. doctorate

6. _ other If other, please specify

6. How many years have you been a registered nurse?

7. How many years have you been employed as an administrator? 
8. How many years have you been in your current position?

9. How long have you worked under the Chief Nursing Officer?

10. How many hours per week do you work?

11. Are you a member of any nursing organization? (Please check all that apply.)

1. American Nurses Association

2. _ Sigma Theta Tau

3. - Other/s If other, please specify

4. - None

12. What is your approximate current yearly salary?

13. Which type of unit do you manage (if more than one type of unit, please mark each one)?

1. __ medicine

2. - surgery

3. _ ambulatory surgery

4. _ operating room

5. - intensive care

6. - emergency room

7. - spinal cord injury

8. AIDS

9. _ psychiatry

10. drug \& alcohol rehab

11. - medical surgery step down

12. - telemetry

13. _ other -if other, please describe 
APPENDIX B

BACKGROUND INFORMATION FOR STAFF REGISTERED NURSES 


\section{BACKGROUND INFORMATION for STAFF REGISTERED NURSES}

Instructions:

Please check or provide the most accurate response in each question.

Please answer every question.

The information that you give will be held in the strictest confidence and your questionnaires will be identified only by a code.

1. What is your sex?

1. Female

2. Male

2. What is your age?

3. What is your marital status?

1. single

2. _ married

3. - separated

4. - divorced

5. widowed

4. What is your ethnic/racial background?

This has two parts, A \& B. Please answer both.

A.

1. Not Hispanic or Latino

2. Hispanic or Latino

B.

1. White

2. Native Hawaiian or Other Pacific Islander

3. Black or African American

4. Asian

5. American Indian or Alaska Native

5. What is the highest educational nursing degree you currently hold?

1. _ diploma

2. _ associate degree

3. bachelor

4. - masters

5. - doctorate

6. _ other If other, please specify

6. How many years have you been a registered nurse?

7. How many years have you been employed as a registered nurse on your unit? 
8. How long have you worked under your immediate supervisor?

9. What shift do you primarily work?

10. How many hours per week do you work?

11. Are you a member of any nursing organization? (Check all that apply.)

1. American Nurses Association

2. Sigma Theta Tau

3. _ Other/s If other, please specify

4. None

12. What is the method of care delivery on your unit?

1. _ primary nursing

2. _ modified primary nursing

3. team nursing

4. _ Other If other, please specify

13. What is your approximate current yearly salary?

14. Which type of unit do you work on (if more than one type of unit, please mark each one)?

1. medicine

2. — surgery

3. _ ambulatory surgery

4. _ operating room

5. _ intensive care

$6 . \quad$ emergency room

$7 . \quad$ spinal cord injury

8. - AIDS

9. - psychiatry

10. _ drug \& alcohol rehab

11. - medical surgery step down

12. telemetry

13. _ other -if other, please describe 
APPENDIX C

NMAS FOR NURSE MANAGERS 
Leadership Characteristics as Assessed by the Nurse Manager's Actions Scale (NMAS)

\section{NMAS for Nurse Managers}

The following statements describe actions of executive and managing nurses. Please read each one and consider whether you engage in the behavior described.

Then, for each of these statements, please circle the number that best represents your own opinion of how often you do the described behavior.

1. Encourages nurses to communicate openly with all members of the health care team.

$\begin{array}{ccccc}1 & 2 & 3 & 4 & 5 \\ \text { does not do } & \text { seldom } & \text { sometimes } & \text { usually } & \text { always }\end{array}$

2. Supports nurses to resolve conflicts with physicians, patients, and colleagues

$\begin{array}{ccccc}1 & 2 & 3 & 4 & 5 \\ \text { does not do } & \text { seldom } & \text { sometimes } & \text { usually } & \text { always }\end{array}$

3. Encourages leadership among nurses.

$\begin{array}{ccccc}1 & 2 & 3 & 4 & 5 \\ \text { does not do } & \text { seldom } & \text { sometimes } & \text { usually } & \text { always }\end{array}$

4. Supports staff nurses' autonomous decision-making.

$\begin{array}{ccccc}1 & 2 & 3 & 4 & 5 \\ \text { does not do } & \text { seldom } & \text { sometimes } & \text { usually } & \text { always }\end{array}$

5. Consults nurses while establishing standards of care

$\begin{array}{ccccc}1 & 2 & 3 & 4 & 5 \\ \text { does not do } & \text { seldom } & \text { sometimes } & \text { usually } & \text { always }\end{array}$

6. Allows staff nurses to self-schedule 24-hour responsibility about their units decisions

$\begin{array}{ccccc}1 & 2 & 3 & 4 & 5 \\ \text { does not do } & \text { seldom } & \text { sometimes } & \text { usually } & \text { always }\end{array}$


7. Delegates to nurses 24 -hour responsibility about their units decisions

$\begin{array}{ccccc}1 & 2 & 3 & 4 & 5 \\ \text { does not do } & \text { seldom } & \text { sometimes } & \text { usually } & \text { always }\end{array}$

8. Helps nurses to develop plans to meet their educational needs.

$\begin{array}{ccccc}1 & 2 & 3 & 4 & 5 \\ \text { does not do } & \text { seldom } & \text { sometimes } & \text { usually } & \text { always }\end{array}$

9. Stimulates nurses' intellectual discussions about work.

$\begin{array}{ccccc}1 & 2 & 3 & 4 & 5 \\ \text { does not do } & \text { seldom } & \text { sometimes } & \text { usually } & \text { always }\end{array}$

10. Encourages nurses to participate in research projects and use research.

$\begin{array}{ccccc}1 & 2 & 3 & 4 & 5 \\ \text { does not do } & \text { seldom } & \text { sometimes } & \text { usually } & \text { always }\end{array}$

11. Involves staff nurses in planning the capital expenditure.

$\begin{array}{ccccc}1 & 2 & 3 & 4 & 5 \\ \text { does not do } & \text { seldom } & \text { sometimes } & \text { usually } & \text { always }\end{array}$


APPENDIX D

NMAS FOR STAFF REGISTERED NURSES 
Leadership Characteristics as Assessed by the Nurse Manager's Actions Scale (NMAS)

\section{NMAS for Staff Registered Nurses}

The following statements describe actions of executive and managing nurses. Please read each one and consider whether the nurse manager of your unit does the behavior described.

Then, for each of these statements, please circle the number that best represents your own opinion of how often the nurse manager of your unit does the described behavior.

1. Encourages nurses to communicate openly with all members of the health care team.

$\begin{array}{ccccc}1 & 2 & 3 & 4 & 5 \\ \text { not do } & \text { seldom } & \text { sometimes } & \text { usually } & \text { always }\end{array}$

2. Supports nurses to resolve conflicts with physicians, patients, and colleagues

$\begin{array}{ccccc}1 & 2 & 3 & 4 & 5 \\ \text { does not do } & \text { seldom } & \text { sometimes } & \text { usually } & \text { always }\end{array}$

3. Encourages leadership among nurses.

$\begin{array}{ccccc}1 & 2 & 3 & 4 & 5 \\ \text { does not do } & \text { seldom } & \text { sometimes } & \text { usually } & \text { always }\end{array}$

4. Supports staff nurses' autonomous decision-making.

$\begin{array}{ccccc}1 & 2 & 3 & 4 & 5 \\ \text { does not do } & \text { seldom } & \text { sometimes } & \text { usually } & \text { always }\end{array}$

5. Consults nurses while establishing standards of care

$$
\begin{array}{ccccc}
1 & 2 & 3 & 4 & 5 \\
\text { does not do } & \text { seldom } & \text { sometimes } & \text { usually } & \text { always }
\end{array}
$$

6. Allows staff nurses to self-schedule 24-hour responsibility about their units decisions

$\begin{array}{ccccc}1 & 2 & 3 & 4 & 5 \\ \text { does not do } & \text { seldom } & \text { sometimes } & \text { usually } & \text { always }\end{array}$


7. Delegates to nurses 24-hour responsibility about their units decisions

$\begin{array}{ccccc}1 & 2 & 3 & 4 & 5 \\ \text { does not do } & \text { seldom } & \text { sometimes } & \text { usually } & \text { always }\end{array}$

8. Helps nurses to develop plans to meet their educational needs.

$\begin{array}{ccccc}1 & 2 & 3 & 4 & 5 \\ \text { does not do } & \text { seldom } & \text { sometimes } & \text { usually } & \text { always }\end{array}$

9. Stimulates nurses' intellectual discussions about work.

$\begin{array}{ccccc}1 & 2 & 3 & 4 & 5 \\ \text { does not do } & \text { seldom } & \text { sometimes } & \text { usually } & \text { always }\end{array}$

10. Encourages nurses to participate in research projects and use research.

$\begin{array}{ccccc}1 & 2 & 3 & 4 & 5 \\ \text { does not do } & \text { seldom } & \text { sometimes } & \text { usually } & \text { always }\end{array}$

11. Involves staff nurses in planning the capital expenditure.

$\begin{array}{ccccc}1 & 2 & 3 & 4 & 5 \\ \text { does not do } & \text { seldom } & \text { sometimes } & \text { usually } & \text { always }\end{array}$


APPENDIX E

AUTONOMY SCALE FOR NURSE MANAGERS AND STAFF REGISTERED

NURSES 


\section{Autonomy Scale}

\section{Patient Care for both Nurse Managers and Staff Registered Nurses}

The following statements describe decisions that a nurse can make regarding patient care. Please read each one and consider whether nurses in your hospital unit participate or do not participate in such decisions.

Then, for each of these statements, please circle the number in front of the statement that best represents your own opinion of how nurses participate in the described decision.

The numbers represent the following levels of involvement in a patient care decision.

$1=$ nurses have no authority and accountability

$2=$ nurses assume authority and accountability when asked

$3=$ nurses share authority and accountability with others

$4=$ nurses consult with others and participate in group decisions

$5=$ nurses have full independent authority and accountability

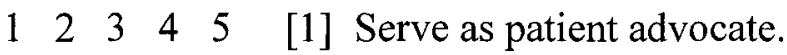

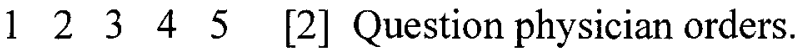

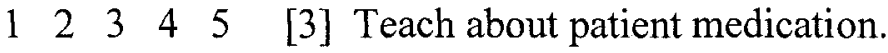

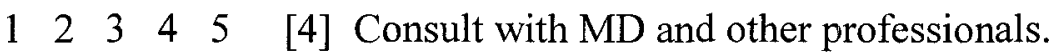

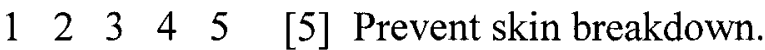

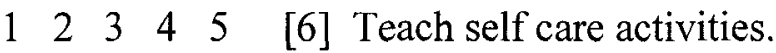

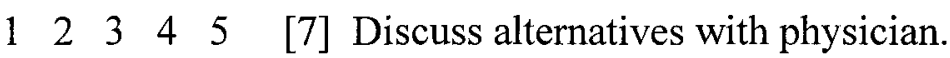

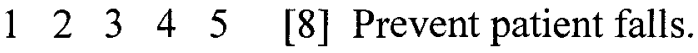

$\begin{array}{llllll}1 & 2 & 3 & 4 & 5 & \text { [9] Teach health care promotion activities }\end{array}$

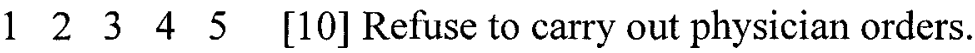

$\begin{array}{llllll}1 & 2 & 3 & 4 & 5 & \text { [11] Decide time to administer care. }\end{array}$

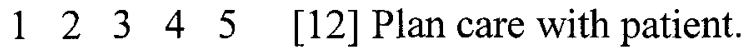

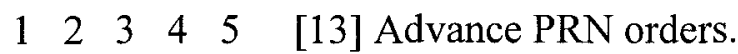


$1=$ nurses have no authority and accountability

$2=$ nurses assume authority and accountability when asked

$3=$ nurses share authority and accountability with others

$4=$ nurses consult with others and participate in group decisions

$5=$ nurses have full independent authority and accountability

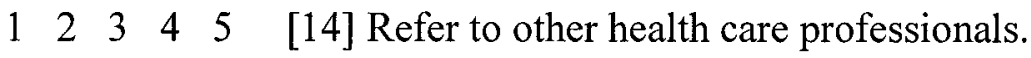

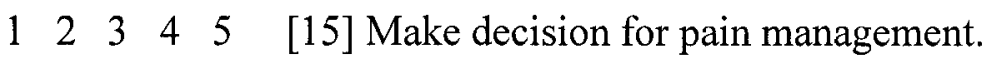

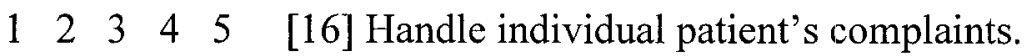

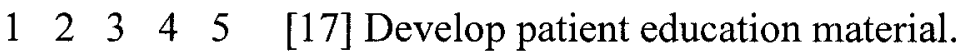

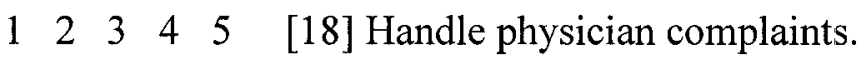

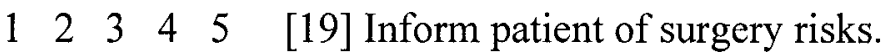

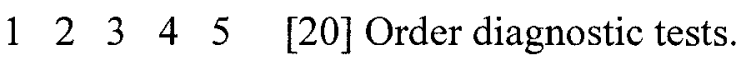

$\begin{array}{llllll}1 & 2 & 3 & 4 & 5 & \text { [21] Determine day of discharge. }\end{array}$ 


\section{Unit Operations for both Nurse Managers and Registered Nurses}

The following statements describe decisions that a nurse can make regarding unit operations. Please read each one and consider whether nurses in your hospital participate or do not participate in such decisions.

Then, for each of these statements, please circle the number in front of the statement that best represents your own opinion of how nurses participate in the described decision.

The numbers represent the following levels of involvement in a patient care decision.

$1=$ nurses have no authority and accountability

$2=$ nurses assume authority and accountability when asked

$3=$ nurses share authority and accountability with others

$4=$ nurses consult with others and participate in group decisions

$5=$ nurses have full independent authority and accountability

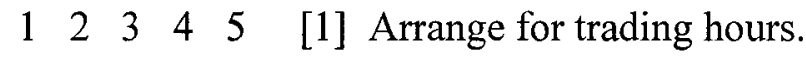

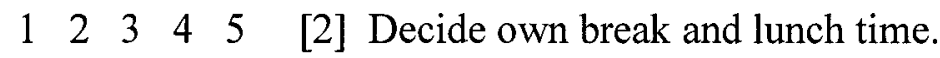

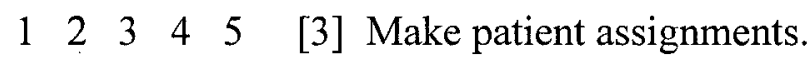

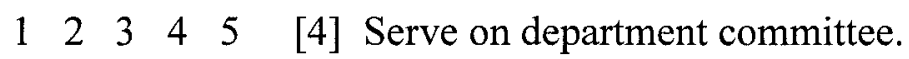

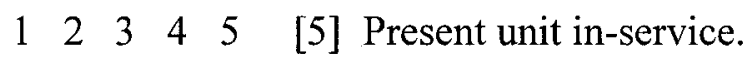

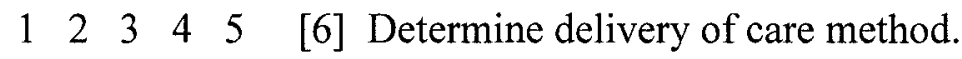

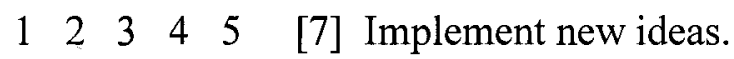

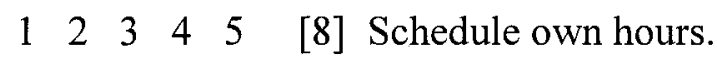

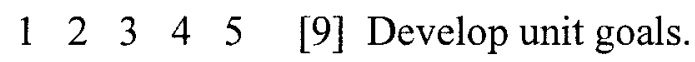

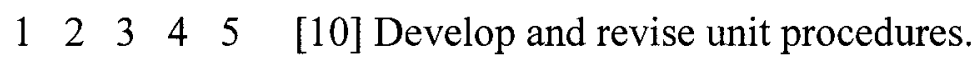

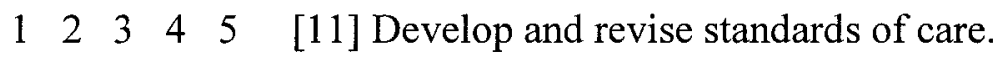

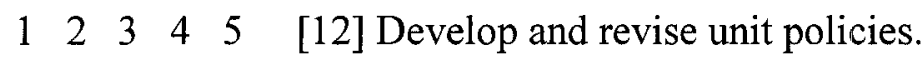

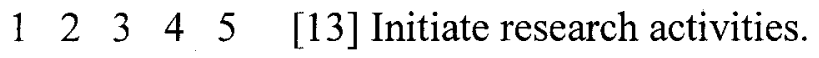


$1=$ nurses have no authority and accountability

$2=$ nurses assume authority and accountability when asked

$3=$ nurses share authority and accountability with others

$4=$ nurses consult with others and participate in group decisions

$5=$ nurses have full independent authority and accountability

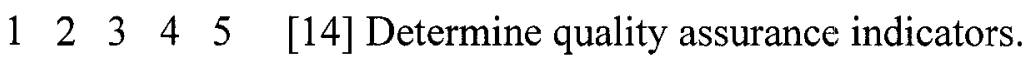

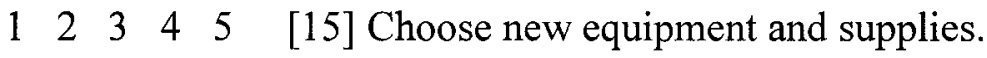

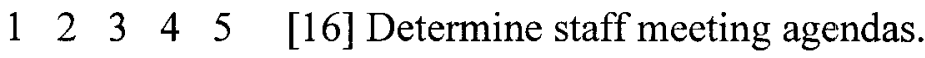

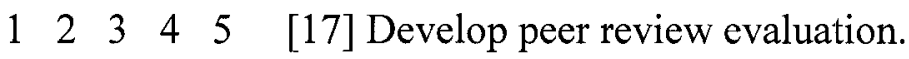

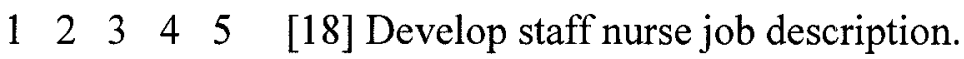

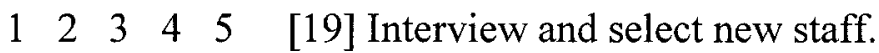

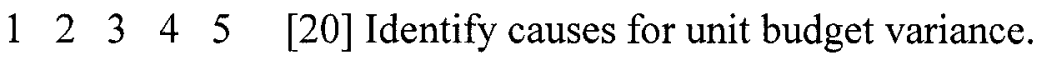

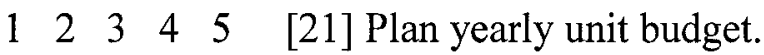




\section{APPENDIX F}

INTRODUCTION LETTER TO NURSE MANAGERS 


\section{Dear Nurse Manager,}

In the ever-changing environment of health care, good leaders are of utmost importance to the effective and efficient functioning of the organization and to patient outcomes. Your success as a leader in the health care arena is the main reason I am asking for your assistance.

I am a graduate student pursuing a doctoral degree in Nursing Administration at the University of San Diego, San Diego, California. My dissertation research focuses on the leadership attributes of nurse managers and staff registered nurses' autonomy in a variety of American hospitals. The purpose of this research study is to provide these data from nurse managers and staff registered nurses from among approximately 388 hospitals.

I am requesting that you take the next 10 minutes of your time to complete these short surveys. Similar surveys will also be completed by staff registered nurses because the study design requires input from both nursing roles. Since I am a nurse executive, I realize that you have many demands on your time and I really appreciate your consideration in completing these important surveys. To show my appreciation of your participation, your name will be entered into a drawing for $\$ 250$.

I am also asking that you distribute the enclosed staff registered nurse envelopes to up to 5 registered nurses on the unit. You should choose the order in which nurses are approached regarding voluntary participation on the basis of the alphabetical order [A through Z] of the last names of the nurses on the unit. If a nurse declines participation, you simply go to the next one on the list. Please note that even if no staff registered nurse volunteers to participate, your signing your own consent from, completing and returning the consent and the surveys in the return envelope still qualifies you for inclusion in the $\$ 250$ drawing.

Included here are a consent form and the surveys where the items are short and have check and circle options or one or two word responses. If you decide to participate, please sign the Informed Consent form. The Informed Consent document states that your participation is voluntary and that you may elect not to answer any question(s) that make you feel uncomfortable. Please be assured that I am committed to confidentiality. Your consent form will be stored in a separate locked file. No names will be attached to survey forms themselves or data in our files.

Summary results will be presented in dissertation format and may be published in the future. No participant or facility names will be disclosed. Summary results of the study are available upon request.

Your participation is vital to the completion of this important study. Thank you in advance for your time and valuable input. If you have any questions, please do not hesitate to contact me at (858) 552-8585 x1223 or e-mail me at cathy.verkaaik@med.va.gov. If you have a question about your rights as a research subject or to report research related problems you may contact the University of San 
Diego Institutional Review Board at (619) 260-4600 or the University of California San Diego Human Research Protections Program at (858) 455-5050.

Sincerely,

Catherine A. Verkaaik

Doctoral Student, University of San Diego 


\section{APPENDIX G}

INTRODUCTION FOR STAFF REGISTERED NURSES 
Dear Staff Registered Nurse,

In the ever-changing environment of health care, good clinical staff registered nurses and good nurse managers are of utmost importance to the effective and efficient functioning of the organization and to patient outcomes. Your role as a staff registered nurse is the main reason I am asking for your assistance.

I am a graduate student pursuing a doctoral degree in Nursing Administration at the University of San Diego, San Diego, California. My dissertation research focuses on the leadership attributes of nurse managers and staff registered nurses' autonomy in a variety of American hospitals. The purpose of this research study is to provide these data from nurse managers and staff registered nurses from among approximately 388 hospitals.

I am requesting that you take the next 10 minutes of your time to complete these short surveys. Similar surveys will also be completed by the nurse manager because the study design requires input from both nursing roles. Since I am a nurse executive, I realize that you have many demands on your time and I really appreciate your consideration in completing this important survey. To show my appreciation of your participation, your name will be entered into a drawing for $\$ 250$.

Included here are a consent form and the surveys where the items are short and have check and circle options or one or two word responses. If you decide to participate, please sign the Informed Consent form. The Informed Consent document states that your participation is voluntary and that you may elect not to answer any question(s) that make you feel uncomfortable. Please be assured that I am committed to confidentiality. Your consent form will be stored in a separate locked file. No names will be attached to survey forms themselves or data in our files.

Summary results will be presented in dissertation format and may be published in the future. No participant or facility names will be disclosed. Summary results of the study are available upon request.

Your participation is vital to the completion of this important study. Thank you in advance for your time and valuable input. If you have any questions, please do not hesitate to contact me at (858) $552-8585 \times 1223$ or e-mail me at cathy.verkaaik@med.va.gov. If you have a question about your rights as a research subject or to report research related problems you may contact the University of San Diego Institutional Review Board at (619) 260-4600 or the University of California San Diego Human Research Protections Program at (858) 455-5050.

Sincerely,

Catherine A. Verkaaik

Doctoral Student, University of San Diego 
APPENDIX H INFORMED CONSENT FORM 


\section{Informed Consent}

The following informed consent applies to the survey documents contained in this packet. The purpose of this research study is to provide data from unit nurse managers and registered staff nurses on leadership attributes and nurse autonomy.

1. If you complete the survey, you are participating in a study of nurse leadership attributes and nurse autonomy in the healthcare setting.

2. The only task is to consent to participate and the completion and return of the surveys.

3. There is a potential minimal risk of loss of confidentiality associated with participation in this survey.

4. Using an identification code for follow-up and analysis will minimize the risk of loss of confidentiality. This signed consent form will be stored in a locked file separate from all questionnaire forms. The identification code will be known only to the Primary Investigator and shredded at the conclusion of the study. The raw data will be secured for five years and then shredded.

5. The benefit of the study is to add to the body of knowledge regarding hospital leadership and nurse autonomy.

6. If you participate, your name will be entered into a random drawing for $\$ 250$.

7. Although results may be made public, only a summary format will be used. No individual or facility specific data will be disclosed.

8. Participation is voluntary. Refusal to participate will not negatively affect the potential participant. The participant may withdraw from the research at any time.

9. Further questions may be directed to Catherine A. Verkaaik at (858) 552-8585 x1223 or cathy.verkaaik@med.va.gov or Dr. Jane Georges at (619) 260-4600. If you have a question about your rights as a research subject or to report research related problems you may contact the University of San Diego Institutional Review Board at (619) 260-4600 or the University of California San Diego Human Research Protections Program at (858) 455-5050.

I have read and understood this form and consent to participate in this research by completing the attached survey. 
Signature

date

Print name

Thank you for your participation!

Catherine A. Verkaaik, Principal Investigator 
APPENDIX I

EXPERIMENTAL SUBJECTS' BILL OF RIGHTS 


\section{EXPERIMENTAL SUBJECT'S BILL OF RIGHTS}

The faculty and staff of the University of California, San Diego wish you to know:

Any person who is requested to consent to participate as a subject in a research study, or who is requested to consent on behalf of another, has the right to:

1. Be informed of the nature and purpose of the research.

2. Be given an explanation of the procedures to be followed during the research process.

3. Be given a description of any attendant discomforts and risks reasonably to be expected from the research activities.

4. Be given an explanation of any benefits to the subject reasonably to be expected from the research, if applicable.

5. Be given an opportunity to ask any questions concerning the research or the procedures involved.

6. Be instructed th at consent to participate in an interview or other research activity may be withdrawn at any time, and the subject may discontinue participation in the research without prejudice.

7. Be given a copy of a signed and dated written consent form when one is required.

8. Be given the opportunity to decide to consent or not to consent to an interview or other research activity without the intervention of any element of force, fraud, deceit, duress, coercion, or undue influence on the subject's decision.

If you have questions regarding a research study, the researcher or his/her assistant will be glad to answer them (858) $552-8585 \times 1223$. You may seek information from the Human Research Protections Program - established for the protection of volunteers in research projects - by calling (858) 455-5050 from 8:00 a.m. to 4:30 p.m., Monday through Friday, or by writing, UCSD Human Research Protections Program, La Jolla Village Professional Center, Suite A208, 8950 Villa La Jolla, La Jolla, California 92037. 
APPENDIX K

UNIVERSITY OF CALIFORNIA, SAN DIEGO IRB APPROVALS 


\section{UNIVERSITY OF CALIFORNIA, SAN DIEGO HUMAN RESEARCH PROTECTIONS PROGRAM}

TO:

Ms. Catherine Verkaaik Mailcode: 118

RE: $\quad$ Project \#050919X

The Relationship Between Nurse Manager Leadership Attributes and Nurse Clinical Autonomy

Dear Ms. Verkaaik:

The above-referenced project was reviewed and approved by one of this institution's Institutional Review Boards in accordance with the requirements of the Code of Federal Regulations on the Protection of Human Subjects (45 CFR 46 and 21 CFR 50 and 56), including its relevant Subparts. This approval, based on the degree of risk, is for 365 days from the date of IRB review and approval unless otherwise stated in this letter. The regulations require that continuing review be conducted on or before the 1-year anniversary date of the IRB approval, even though the research activity may not begin until some time after the IRB has given approval.

This study was reviewed by the IRB through the expedited review procedure as authorized by 45 CFR 46,110 and 21 CFR 56.110 and falls under research category (7): Research on individual or group characteristics or behavior (including, but not limited to, research on perception, cognition, motivation, identity, language, communication, cultural beliefs or practices, and social behavior) or research employing survey, interview, oral history, focus group, program evaluation, human factors evaluation, or quality assurance methodologies.

Date of IRB review and approval: $\underline{8 / 17 / 2006}$

On behalf of the Institutional Review Board,

Michael Caligiuri, Ph.D.

$/ \mathrm{nm}$

Director, Clinical Research Protections Program

(858) $455-5050$

Note: All Human Subject research conducted at the VA facility and/or utilizing VA/VMRF funds MUST BE APPROVED by the VA Research and Development Committee prior to commencing any research. In addition, please ensure that the clinical trial agreement or other funding is appropriately in place prior to conducting any research activities. IRB approval does not constitute funding approval.

cc: VA

Approval release date: $8 / 28 / 2006$ 


\title{
UNIVERSITY OF CALIFORNIA, SAN DIEGO HUMAN RESEARCH PROTECTIONS PROGRAM
}

\author{
TO: $\quad$ Catherine Verkaaik Mailcode: 118 \\ RE: $\quad$ Project \#050919X \\ The Relationship Between Nurse Manager Leadership Attributes and Nurse \\ Clinical Autonomy
}

Dear Ms. Verkaaik:

The above-referenced project was reviewed and approved by one of this institution's Institutional Review Boards in accordance with the requirements of the Code of Federal Regulations on the Protection of Human Subjects (45 CFR 46 and 21 CFR 50 and 56), including its relevant Subparts. This approval, based on the degree of risk, is for 365 days from the date of IRB review and approval unless otherwise stated in this letter. The regulations require that continuing review be conducted on or before the 1-year anniversary date of the IRB approval, even though the research activity may not begin until some time after the IRB has given approval.

This study was reviewed by the IRB through the expedited review procedure as authorized by 45 CFR 46.110 and 21 CFR 56.110 and falls under research category (7): Research on individual or group characteristics or behavior (including, but not limited to, research on perception, cognition, motivation, identity, language, communication, cultural beliefs or practices, and social behavior) or research employing survey, interview, oral history, focus group, program evaluation, human factors evaluation, or quality assurance methodologies.

It is acknowledged you are a student at University of San Diego (USD) and USD IRB Approval for this study has been granted. Documentation regarding this USD Approval has been provided.

Date of IRB review and approval: $\underline{9 / 15 / 2005}$

/af

Mamie Gonzalez, Acting Director

Human Research Protections Program

Mailcode 0052 Phone: 858-455-5050

E-mail: hrpp@ucsd.edu

Note: All Human Subject research conducted at the VA facility and/or utilizing VA/VMRF funds MUST BE APPROVED by the VA Research and Development Committee prior to commencing any research. 


\section{APPENDIX L}

VA SAN DIEGO HEALTHCARE SYSTEM DOCUMENTS 


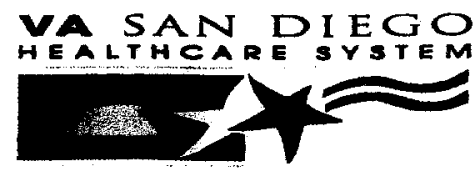

\section{Memorandum}

Date: October 3, 2005

From: Harry Klemfuss, Ph.D.

Research Compliance Officer (RCO)

Mail Code: $11 \mathrm{R}$

Re: Title: The relationship between nurse manager leadership attributes and nurse clinical autonomy

Protocol \#: 050519

To: Dr. Catherine Verkaaik

1. The Independent Review Committee (IRC), chaired by Stephen M. Baird, M.D., reviewed this IRB Protocol for potential or apparent conflict of interest on October 3 , 2005.

2. This Memorandum will serve as documentation for your records that there is no apparent conflict of interest associated with this IRB Protocol.

3. If you have any questions or require assistance please contact me at (858) 642-3817 or hklemfuss@vapop.ucsd.edu.
cc: Ms. Vanessa Finney
Human Subjects Coordinator
Mail Code 151
cc: Dr. Martha Shively $111 \mathrm{~N} 1$
VA Responsible Investigator

To: Dr. Catherine Verkaaik

Mail Code: 118 


\section{REPORT OF SUBCOMMITTEE ON HUMAN STUDIES}

VA DEMARTMENT OF VETERANS AFTARES

Project/Program Title: The Relationship Between Nurse Manager Leadership Attributes and Nurse Clinical Autonomy

Principal Investigator: Ms. Catherine Verkaaik, (118)

VAMC: SANDEGO, CA Review Date: VA: 09/27/2006 UCSD: 08/17/2006

$\begin{array}{lll}\text { PROJECT \#; 05-0919 } & \text { Expedited: } X \quad \text { Tissue Only: Initial/Renewal: } R\end{array}$

\section{COMMITTEE FINDINGS:}

1. The information given in the Informed Consent under the Description of Research by Investigator is complete, accurate, and understandable to a research subject or a

surrogate who possesses standard reading and comprehension skills.

2. The informed consent is obtained by the principal investigator or a trained and supervised designate under suitable circurnstances.

3. Every effort has been made to decrease the risk to the subject(s)?

4. The potential research benefits justify the risk to the subject(s)?

5. If the subject is incompetent and surrogate consent is obtained, have all of the following conditions been met: a) the research can't be done on competent subjects; b) there is no risk to the subject, or if risk exists, the direct benefit to subject is substantially greater;

c) if an incompetent subject resists, he will not have to participate; d) if there exists any question about the subject's competency, the basis for decision on competency has been fully described.

6. If the subject is paid, the payment is reasonable and commensurate with the subject's contribution.

7. Members of minority groups and women have been included in the study population whenever possible and scientifically desirable.

8. Comments/Other Investigators: Dr. Shively is the VARI
RECOMMENDATION:
X APPROVE
DISAPPROVE/REVISE

SIGNATURE OF IRB CHAIR

DATE

Michael Caligiuri, Ph.D., CRESP Director

$09 / 27 / 2006$

Human Research Protections Program 


\section{REPORT OF SUBCOMMITTEE ON HUMAN STUDIES}

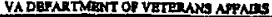

ProjectProgram Title: The Relationship Between Nurse Manager Leadership Attributes and Nurse Clinical Autonorny

Principal Investigator: Ms. Catherine Verkaaik, (118)

VAMC: SANDIEGO,CA Review Date: VA: 09/28/2005 UCSD: 09/15/2005

PROJECT \#: 05-0919 Expedited: X Tissue Only: Initial/Renewal: I

\section{COMMITTEE FINDINGS:}

1. The information given in the Informed Consent under the Description of Research by Investigator is complete, accurate, and understandable to a research subject or a surrogate who possesses standard reading and comprehension skills.

2. The informed consent is obtained by the principal investigator or a trained and $\underline{X} / \mathrm{A}$

2. The informed consent is obtained by the principat
supervised designate under suitable circumstances.

3. Every effort has been made to decrease the risk to the subject(s)?

4. The potential research benefits justify the risk to the subject(s)?

5. If the subject is incompetent and surrogate consent is obtained, have all of the following conditions been met: a) the research can't be done on competent subjects; b) there is no risk to the subject, or if risk exists, the direct benefit to subject is substantially greater;

c) if an incompetent subject resists, he will not have to participate; d) if there exists any question about the subject's competency, the basis for decision on competency has been fully described.

6. If the subject is paid, the payment is reasonable and commensurate with the subject's contribution.

7. Members of minority groups and women have been included in the study population whenever possible and scientifically desirable.

8. Comments/Other Investigators: Dr. Shively will be the VARI

RECOMMENDATION: $\quad \underline{X \text { APPROVE DISAPPROVE/REVISE }}$

\begin{tabular}{|lc|}
\hline SIGNATURE OF IRB CHAIR & DATE: \\
NamieGónzálež, Agłing Director & $09 / 28 / 2005$ \\
Human Research Protections Program & \\
\hline
\end{tabular}

VA FORM 10-1223 (REVISED 10/95) 


\section{APPENDIX M}

EAST CAROLINA UNIVERSITY AND MEDICAL CENTER IRB 


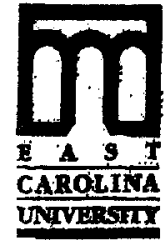

University and Medleal Center Institutional Revien Bourd

East Carolina University

Ed Warren Life Sciences Building - 600 Moye Boulevand - LSB 104 * Greenville, NC 27834

Oftice 252-744-2914 - Fix 252-744-2284 - wwm.ecuedwiorb

Chate and Director of Biomedica] IRB: Charles W. Daesehwer, III, MD

Chair and Director of Behaviorsl and Social Science IRB: Susan L. McCammon, PhD

TO:

Catherine A. Verkaaik, RN, Doctoral Student, Uriversity of San Diego, California

FROM:

UMCIRB

DATE: January 6, 2006

RE: Expedited Category Rescarch Study

IITLE: "The Relationship Between Nurse Manager Leadership Attributes and Nurse Clinical Autonomy"

UMCIRB $\# 05-0660$

This research study has undergone review and approval using expedited review on 12-30-05. This research study is eligible for review under an expediced category because research on individual or group characteristics or behavior (including, but not limited to, research on perception, cognition, motivation, identity, language, communication, cultura) beliefs or practices, and social behavior) or research employing survey, interview, oral history, focus group, program evaluation, human factors evaluation, or quality assurance methodologies. Dr. C. Daeschner deemed this unfunded sponsored study no more than minimal risk requiring a continuing review in 12 months.

The above referenced research study has been given approval for the period of 12-30-05 to 12-29-06. The approval includes the following items:

- Intemal Processing Form dated 12-01-05

- Introduction letter for nurse manager and staff registered nurse

- Informed consent document

- Experimental Subject's Bill of Rjghts

- Demographic forms for nurse menager and staff registered nurse

- Nurse Managers' Action Scale for nurse manager and staff registered nurse

- Autonomy Scale

- PCMH lefter of support

DT. C. Dscschner does not have a potential for conflict of interest on this study.

The UMCIRB complies with 45 CFR 46, 21 CFR 50, 21 CFR 56, ICH Guidelines, UMCIRB operating policies and procedures, institutional policies and other spplicable federal regalations. 
APPENDIX N

PERMISSION TO USE INSTRUMENTS 
From: Wilson Laura [Laura.Wilson@oxon.blackwellpublishing.com]; on behalf of; Journals Rights [Journals.Rights@oxon.blackwellpublishing.com]

To: Verkaaik, Cathy A.

Subject: RE: Request to use 2 scales in dissertation research

Sent: Tue 8/2/2005 12:07 AM

Thank you for your email request. Permission is granted for you to use the material below for your thesis subject to the usual acknowledgements and on the understanding that you will reapply for permission if you wish to distribute or publish your thesis commercially.

Good Luck!

Permissions Dept.

Blackwell Publishing

PO Box 805

9600 Garsington Road

Oxford

OX4 2ZG

United Kingdom

Fax: 00441865471150

Permission requests can now be sent to journalsrights@oxon.blackwellpublishing.com

Blackwell is committed to creating a culture of value and respect for all of our staff. We expect to work in an environment where there are high standards of behaviour and achievement. We maintain a culture which operates within accepted boundaries of professional behaviour and performance.

\footnotetext{
----Original Message-----

From: Verkaaik, Cathy A. [mailto:Cathy.Verkaaik@med.va.gov]

Posted At: 01 August 2005 23:27

Posted To: 1st August

Conversation: Request to use 2 scales in dissertation research

Subject: Request to use 2 scales in dissertation research

Hello,

Melody Jones [melody@stti.iupui.edu] directed me to write to you for permission to use scales in my dissertation work.

I am a member of the Gamma Gamma (073) chapter of the Sigma Theta Tau International Honor Society of Nursing. I am a student in the Nursing program at the University of San Diego and an Associate Chief of Nursing and Patient Care Services at the VA Healthcare System in San Diego. I am conducting a doctoral dissertation wherein I am evaluating the relationships among nurse manager attributes, nurse clinical autonomy, and magnet hospital status.
} 
In my dissertation research, I would like to use two scales.

The first scale is The Autonomy Scale reported in Blegen, Goode, Johnson, Maas, Chen, and Moorhead 1993

Journal of Nursing Scholarship article, "Preferences for decision-making autonomy," Vol 25, Num 4, pp 339-344.

The second scale is the Nurse Managers' Action Scale reported in Mrayyan, M.T. 2004. Nurses' autonomy: influence of nurse manager's actions. Nursing and Healthcare Management and Policy, 45(3), 326-336.

Is there a special form for making such requests or is this email request sufficient?

Thank You

Catherine

Catherine A. Verkaaik Ph.D.(c), RN .

Director Inpatient Services/Associate Chief

VA San Diego Healthcare System

3350 la Jolla Village Drive

San Diego, CA 92161

ph: 858-642-1223

Fax: 858-552-7422

e-mail: cathy.verkaaik@med.va.gov 
Permission to use the Nurse Autonomy Questionnaire:

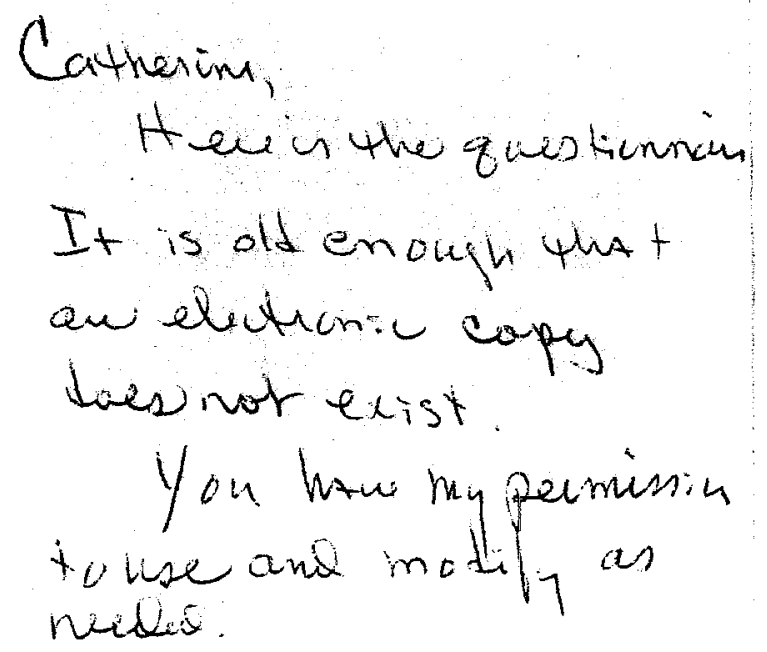

